\title{
LIGAÇÕES COM PINOS METÁLICOS EM \\ ESTRUTURAS DE MADEIRA
}

\author{
Marcos Antonio Melo e Oliveira
}

Dissertação apresentada à Escola de Engenharia de São Carlos da Universidade de São Paulo, como parte dos requisitos para a obtenção do título de Mestre em Engenharia de Estruturas

ORIENTADOR: Prof. Dr. Antonio Alves Dias

São Carlos

2001 


\section{FOLHA DE APROVAÇÃO}

Autor:

Título:

Dissertação defendida e aprovada em 1 pela comissão julgadora:

(Assinatura)

(Nome/Instituição)

(Assinatura)

(Nome/Instituição)

(Assinatura)

(Nome/Instituição)

Coordenador de Área 
À minha esposa

e filhas,

pelo incentivo e compreensão em todos os momentos 
Ao Prof. Dr. Antonio Alves Dias, pela amizade e orientação durante a elaboração deste trabalho.

Ao Prof. Dr. Carlito Calil Júnior, pelo incentivo e apoio em todos os momentos desta jornada.

Aos professores, funcionários e técnicos do Laboratório de Madeiras e Estruturas de Madeira - LaMEM da EESC/USP que muito colaboraram para a efetiva realização deste trabalho.

A professora Valeska Guimarães Rezende da Cunha pelo apoio e disponibilidade nas aulas de inglês.

A todos os colegas, professores e funcionários do Departamento de Engenharia de Estruturas da EESC/USP pela colaboração. 


\section{SUMÁRIO}

LISTA DE FIGURAS

LISTA DE TABELAS

LISTA DE ABREVIATURAS E SIGLAS vii

LISTA DE SÍMBOLOS viii

RESUMO

ABSTRACT

1 - INTRODUÇÃO

1.1 - Objetivo 2

1.2 - Justificativa. 2

2- REVISÃO BIBLIOGRÁFICA 3

2.1 - Modelos teóricos de cálculos 4

2.1.1 - Modelo de JOHANSEN (1949) 8

2.1.2 - Método de MÖLLER (1951), apud ALMEIDA (1987) 13

2.2 - Rigidez das ligações 15

2.3 - Pré furação das ligações $\quad 15$

2.4 - Efeito do número de pinos em uma ligação 18

$\begin{array}{ll}2.5 \text { - Critérios de dimensionamento } & 19\end{array}$

2.5.1 - Critério da NBR 7190/97 20

2.5.2 - Critérios do EUROCODE 5 24

2.6 - Métodos de Ensaio $\quad 27$

$\begin{array}{ll}2.6 .1 \text { - Ligações } & 27\end{array}$

2.6.1.1 - Ligações por pinos metálicos, segundo a NBR 7190/97 27

2.6.1.2 - Ligações com juntas mecânicas, segundo o EN 26891

2.6.2 - Ensaios de Embutimento 35

2.6.2.1 - Método da NBR 7190/97 35 
2.6.3 - Ensaio de compressão paralela às fibras segundo a NBR 7190/97 39

2.6.4 - Teor de umidade - NBR 7190/97 42

2.7- Conclusões sobre a revisão bibliográfica 42

3 - MATERIAIS E MÉTODOS 44

3.1 - Ensaios realizados pela equipe do LaMEM 44

3.1.1 - Materiais utilizados 45

3.1.2 - Métodos utilizados nos ensaios $\quad 46$

3.1.3 - Forma de obtenção da resistência e da rigidez das ligações pela equipe do LaMEM 49

3.1.4 - Forma de obtenção da resistência e da rigidez das ligações por critério $\begin{array}{ll}\text { aproximado ao da norma NBR 7190/97 } & 50\end{array}$

3.2 - Ensaios complementares

3.2.1 - Materiais utilizados $\quad 52$

3.2.2 - Métodos utilizados nos ensaios 53

3.2.3 - Procedimentos gerais dos ensaios de ligações 55

4 - RESULTADOS OBTIDOS NOS ENSAIOS 59

4.1 - Ensaios realizados pela equipe do LaMEM 59

4.1.1 - Caracterização da madeira 59

4.1.2 - Resistência e rigidez das ligações segundo critério da equipe do LaMEM 61

4.1.3 - Resistência e rigidez das ligações segundo o critério da NBR 7190/97 66

4.2 - Resultados obtidos nos ensaios complementares $\quad 71$

4.2.1 - Caracterização da madeira $\quad 72$

4.2.2 - Pinos metálicos: resistência ao escoamento do aço 77

$\begin{array}{ll}\text { 4.2.3 - Resultados obtidos nos ensaios de ligações } & 78\end{array}$

5 - ANALISE DOS RESULTADOS 83

5.1 - Resistência e rigidez das ligações obtidos nos ensaios LaMEM 83

5.2 - Resistência das ligações obtidas nos ensaios complementares 98

5.3 - Comparação dos valores de resistência com as forças de ruptura das

$\begin{array}{ll}\text { ligações } & 107\end{array}$ 
5.4 - Comparação entre a resistência ao embutimento e a resistência à compressão paralela às fibras da madeira

6 - CONCLUSÕES 


\section{LISTA DE FIGURAS}

FIGURA 1 - Ligação com pino rígido e uma seção de corte 9

FIGURA 2 - Ligação com pino flexível e uma seção de corte 9

$\begin{array}{ll}\text { FIGURA } 3 \text { - Ligação com pino rígido e duas seções de corte } & 10\end{array}$

$\begin{array}{ll}\text { FIGURA } 4 \text { - Ligação com pino rígido e duas seções de corte } & 12\end{array}$

FIGURA 5 - Ligação com pino flexível e duas seções de corte 12

$\begin{array}{ll}\text { FIGURA 6 - Pinos em corte simples } & 21\end{array}$

$\begin{array}{ll}\text { FIGURA } 7 \text { - Pinos em corte duplo } & 22\end{array}$

FIGURA 8 - Espaçamentos em ligações com pinos $\quad 24$

FIGURA 9 - Pino em corte simples e pino em corte duplo 26

FIGURA 10 - Esquema para extração da madeira para corpos-de-prova das $\begin{array}{ll}\text { ligações } & 28\end{array}$

FIGURA 11 - Corpos-de-prova para ensaios de ligações mecânicas 29

a) resistência na direção paralela às fibras;

b) resistência na direção normal às fibras

FIGURA 12 - Diagrama de carregamentos e descarregamentos sucessivos para $\begin{array}{ll}\text { determinação da carga limite das ligações } & 30\end{array}$

FIGURA 13 - Diagrama de carregamento 31

FIGURA 14 - Diagrama força deformação específica da ligação de acordo com a NBR 7190/97 32

FIGURA 15 - Método de carregamento segundo a EN 26891

FIGURA 16 - Carga x deformação: curva e calibragem ideal segundo a EN $26891 \quad 34$

FIGURA 17 - Corpo-de-prova para ensaio de embutimento 35

FIGURA 18 - Diagrama tensão x deformação específica de embutimento 36

FIGURA 19 - Diagrama de carregamento para ensaio de embutimento 37 
FIGURA 20 - Diagrama de carregamento para ensaios de embutimento de acordo com a EN 383

FIGURA 21 - Arranjo de ensaio para compressão paralela às fibras, com instrumentação baseada em reló gios comparadores

FIGURA 22 - Arranjo dos corpos-de-prova para ensaios das ligações

a) direção paralela às fibras;

b) direção normal às fibras

FIGURA 23 - Diagrama para determinação da resistência da ligação pelo critério adotado pela equipe do LaMEM

FIGURA 24 - Determinação da resistência da ligação com critério aproximado ao da NBR 7190/97 - ensaios LaMEM

FIGURA 25 - Determinação da resistência da madeira ao embutimento

FIGURA 26 - Dispositivo de montagem e pré furação no corpo-de-prova

FIGURA 27 - Cravação dos pinos no corpo-de-prova de ligação

FIGURA 28 - Ensaio de ligação na direção paralela às fibras da madeira-

FIGURA 29 - Determinação da resistência da ligação - pontos registrados

FIGURA 30 - Determinação das resistências das ligações pelo critério da equipe LaMEM e pelo critério NBR

FIGURA 31 - Determinação da resistência da ligação - parafuso - Cupiúba

FIGURA 32 - Determinação da resistência da ligação - prego - Cupiúba

FIGURA 33 - Determinação da resistência da ligação - parafuso - Jatobá

FIGURA 34 - Determinação da resistência da ligação - prego - Jatobá

FIGURA 35 - Comparação entre os resultados experimentais e teóricos das resistências das ligações na direção paralela sob o critério LaMEM - parafusos FIGURA 36 - Comparação entre os resultados experimentais e teóricos das resistências das ligações na direção paralela sob o critério LaMEM - pregos FIGURA 37 - Comparação entre os resultados experimentais e teóricos das resistências das ligações na direção paralela sob o critério NBR - parafusos FIGURA 38 - Comparação entre os resultados experimentais e teóricos das resistências das ligações na direção paralela sob o critério NBR- pregos FIGURA 39 - Comparação entre os resultados experimentais e teóricos das 
resistências das ligações na direção paralela - ensaios complementares parafusos

FIGURA 40 - Comparação entre os resultados experimentais e teóricos das resistências das ligações na direção paralela - ensaios complementares - pregos FIGURA 41 - Comparação entre os resultados experimentais e teóricos das resistências das ligações, utilizando o $\mathrm{f}_{\mathrm{c} 0}$ - ensaios complementares - parafusos FIGURA 42 - Comparação entre os resultados experimentais e teóricos das resistências das ligações, utilizando o $\mathrm{f}_{\mathrm{c} 0}$ - ensaios complementares - pregos 


\section{LISTA DE TABELAS}

TABELA 1 - Agrupamento de classes de resistência 46

TABELA 2 - Valores do comprimento da base de medida (Lo) 50

$\begin{array}{ll}\text { TABELA } 3 \text { - Características das vigas } & 60\end{array}$

TABELA 4 - Ensaios em ligações com parafusos e pregos - Pinus Elliottii 61

TABELA 5 - Ensaios em ligações com parafusos e pregos - Cupiúba 62

TABELA 6 - Ensaios em ligações com parafusos e pregos - Garapa 63

TABELA 7 - Ensaios em ligações com parafusos e pregos - Eucalipto Citriodora $\quad 64$

TABELA 8 - Ensaios em ligações com parafusos e pregos - Jatobá 65

TABELA 9 - Resultados das ligações pelo critério NBR 7190/97 - Pinus Elliottii

TABELA 10 - Resultados das ligações pelo critério NBR 7190/97 - Cupiúba 67

TABELA 11 - Resultados das ligações pelo critério NBR 7190/97 - Garapa 68

TABELA 12 - Resultados das ligações pelo critério NBR 7190/97 - Eucalipto $\begin{array}{ll}\text { Citriodora } & 69\end{array}$

TABELA 13 - Resultados das ligações pelo critério NBR 7190/97 - Jatobá $\quad 70$

TABELA 14 - Resistência ao embutimento paralelo às fibras - primeira série de ensaios

TABELA 15 - Resistência ao embutimento paralelo às fibras - segunda série de ensaios

TABELA 16 - Resistência à compressão paralela às fibras - primeira série de ensaios

TABELA 17 - Resistência à compressão paralela às fibras - segunda série de ensaios

TABELA 18 - Teor de umidade das vigas - primeira série de ensaios 76

TABELA 19 - Teor de umidade das vigas - segunda série de ensaios 76 
TABELA 20 - Resistência ao escoamento do aço dos pinos utilizados na primeira e segunda séries de ensaios

TABELA 21 - Resistência e força de ruptura na direção paralela - Pinus

Elliottii- Primeira série de ensaios

TABELA 22 - Resistência e força de ruptura na direção paralela - Cupiúba -

Primeira série de ensaios

TABELA 23 - Resistência e força de ruptura na direção paralela - Cupiúba -

Segunda série de ensaios

TABELA 24 - Resistência e força de ruptura na direção paralela - Jatobá Segunda série de ensaios

TABELA 25 - Comparação entre os resultados experimentais e teóricos das resistências das ligações $\left(\mathrm{R}_{1 \mathrm{v}}\right)$ - Pinus Elliottii

TABELA 26 - Comparação entre os resultados experimentais e teóricos das resistências das ligações $\left(\mathrm{R}_{1 \mathrm{v}}\right)$ - Cupiúba

TABELA 27 - Comparação entre os resultados experimentais e teóricos das resistências das ligações $\left(\mathrm{R}_{1 \mathrm{v}}\right)$ - Garapa

TABELA 28 - Comparação entre os resultados experimentais e teóricos das resistências das ligações $\left(\mathrm{R}_{1 \mathrm{v}}\right)$ - Eucalipto Citriodora

TABELA 29 - Comparação entre os resultados experimentais e teóricos das resistências das ligações $\left(\mathrm{R}_{1 \mathrm{v}}\right)$ - Jatobá

TABELA 30 - Comparação entre os valores da rigidez das ligações - Pinus Elliottii

TABELA 31 - Comparação entre os valores da rigidez das ligações - Cupiúba

TABELA 32 - Comparação entre os valores da rigidez das ligações - Garapa

TABELA 33 - Comparação entre os valores da rigidez das ligações - Eucalipto Citriodora

TABELA 34 - Comparação entre os valores da rigidez das ligações - Jatobá

TABELA 35 - Resistência de embutimento médio e valor médio do $\beta_{\lim }-$ Primeira série de ensaios - Pinus Elliottii

TABELA 36 - Resistência de embutimento médio e valor médio do $\beta_{\mathrm{lim}}$ Primeira série de ensaios - Cupiúba 
TABELA 37 - Resistência de embutimento médio e valor médio do $\beta_{\text {lim }}$ Segunda série de ensaios - Cupiúba

TABELA 38 - Resistência de embutimento médio e valor médio do $\beta_{\text {lim }}-$ Segunda série de ensaios - Jatobá

TABELA 39 - Comparação entre os resultados experimentais e teóricos Primeira série de ensaios - Pinus Elliotti

TABELA 40 - Comparação entre os resultados experimentais e teóricos Primeira série de ensaios - Cupiuba

TABELA 41 - Comparação entre os resultados experimentais e teóricos Segunda série de ensaios - Cupiúba

TABELA 42 - Comparação entre os resultados experimentais e teóricos Segunda série de ensaios - Jatobá

TABELA 43 - Relação entre os valores médios da força de ruptura e da resistência da ligação - critério equipe LaMEM

TABELA 44 - Relação entre os valores médios da força de ruptura e da resistência da ligação - critério aproximado NBR 7190/97

TABELA 45 - Relação entre os valores médios da carga de ruptura e da resistência da ligação nos ensaios complementares - média por pino

TABELA 46 - Comparação entre a resistência à compressão $\left(f_{c 0}\right)$ e a resistência ao embutimento $\left(\mathrm{f}_{\mathrm{e} 0}\right)$ da madeira - ensaios complementares 


\title{
LISTA DE ABREVIATURAS E SIGLAS
}

\author{
ABNT - Associação Brasileira de Normas Técnicas \\ ASTM - American Society for Testing and Materials \\ BSI - British Standard Institute \\ CEN - Comitê Europeu de Normalização \\ DIN - Deutsches Institut für Normung \\ LaMEM - Laboratório de Madeiras e Estruturas de Madeira
}




\section{LISTA DE SÍMBOLOS}

Letras romanas maiúsculas

$$
\begin{aligned}
& \text { A - área } \\
& \text { E - módulo de elasticidade } \\
& \mathrm{F} \text { - força aplicada } \\
& \mathrm{F}_{\mathrm{u}} \text { - carga última } \\
& \mathrm{F}_{\text {rup }} \text { - força de ruptura } \\
& \mathrm{L} \text { - comprimento } \\
& \mathrm{L}_{0} \text { - comprimento da base de medida } \\
& \mathrm{M} \text { - momento fletor } \\
& \mathrm{M}_{\mathrm{np}} \text { - momento de plastificação do prego } \\
& \mathrm{R} \text { - resistência } \\
& \mathrm{U} \text { - umidade } \\
& \mathrm{V} \text { - força cortante }
\end{aligned}
$$

Letras romanas minúsculas

$$
\begin{aligned}
& \text { a - distância } \\
& \text { b - largura } \\
& \text { d - diâmetro } \\
& \mathrm{f} \text { - resistência de um material } \\
& \mathrm{f}_{\mathrm{c}} \text { - resistência à compressão } \\
& \mathrm{f}_{\mathrm{e}}-\text { resistência ao embutimento } \\
& \mathrm{f}_{\mathrm{e}, 0}-\text { resistência ao embutimento paralelo às fibras da madeira } \\
& \mathrm{f}_{\mathrm{e}, 90} \text { - resistência ao embutimento normal às fibras da madeira } \\
& \mathrm{f}_{\mathrm{y}}-\text { tensão de escoamento do aço } \\
& \mathrm{h}_{1}=\text { espessura da peça central }
\end{aligned}
$$


$\mathrm{k}$ - coeficiente em geral

$\ell$ - vão, comprimento

m - número de planos de corte

$\mathrm{n}$ - número de elementos

q- carga distribuída

$\mathrm{q}_{\mathrm{u}}$ - carga última por unidade de comprimento

$\mathrm{r}$ - raio do pino

$\mathrm{t}$ - espessura

$\mathrm{t}_{1}$ - espessura de cobrejunta

$\mathrm{t}_{2}$ - espessura de peça central

$\mathrm{x}$ - coordenada

$\mathrm{y}$ - coordenada

Letras gregas

$\alpha$ - ângulo, coeficiente

$\beta$ - coeficiente

$\delta$ - coeficiente de variação

$\varepsilon$ - deformação específica

$\theta$ - rotação, ângulo

$\pi-$ constante $=3,14159$

$\rho$ - massa específica (densidade)

$\sigma-$ tensão normal

$\tau$ - tensão tangencial

Índices

$\mathrm{e}$ - embutimento

c - compressão

d - valor de cálculo 


$$
\begin{aligned}
& \text { ef - valor efetivo } \\
& \mathrm{k} \text { - característico } \\
& \mathrm{m} \text { - média } \\
& \mathrm{p} \text { - pino, prego ou parafuso } \\
& \mathrm{s} \text { - aço } \\
& \mathrm{t} \text { - tração } \\
& \mathrm{u} \text { - última } \\
& \mathrm{v} \text { - cisalhamento } \\
& \mathrm{w} \text { - madeira } \\
& \text { y - escoamento do aço } \\
& \text { est - estimado } \\
& \text { lim - limite } \\
& \text { máx. - máximo } \\
& \text { mín. - mínimo }
\end{aligned}
$$




\section{RESUMO}

A construção de estruturas de madeira usualmente requer ligações entre as peças que as compõem. Estas uniões devem ser compatíveis com as solicitações mecânicas avaliadas, garantindo durabilidade e segurança à estrutura. Atualmente, a normalização brasileira referente ao uso estrutural da madeira, NBR 7190/97 Projeto de estruturas de madeira, aborda os critérios de dimensionamento para as ligações por meio de pinos metálicos, ligações coladas, cavilhas ou conectores. O critério da NBR 7190/97 para o dimensionamento das ligações por pinos metálicos conduz ao aumento do número de elementos nas ligações, em relação ao observado na norma anterior. Dentro deste contexto, o objetivo deste trabalho é avaliar o critério de dimensionamento da NBR 7190/97 por meio da análise de resultados experimentais.

Palavras chave: pinos metálicos, estruturas de madeira, ligações. 


\section{ABSTRACT}

The construction of timber structures usually requires connections between the parts that compose them. These connections must be compatible with the evaluated mechanical requests, guaranteeing durability and reliability to the structure. Nowadays, the referring Brasilian standardization to the structural use of the wood, NBR 7190/97 - "Design of Timber Structures", applies the design methods for the connections by means of steel dowels, glued joints, bolts or connectors. The NBR 7190/97 criterion for the design of connections for steel dowels leads to the increase of elements number in the connections in relation to the observed one in the previous norm. In this argument, the objective of this work are to evaluate the design method results of the NBR 7190/97 by means of experimental results analysis.

Keywords: dowels steel, wood structures, connections. 


\section{1 - INTRODUÇÃO}

Nos anos mais recentes, a madeira está sendo redescoberta como elemento estrutural pelos profissionais do meio produtivo e, conseqüentemente, tem requerido a investigação científica para o seu uso. A evolução de recursos, como os tratamentos preservativos, a industrialização de madeiras de baixa densidade, os processos construtivos, dentre outros fatores, tem transformado a madeira num produto para atender às mais diversas necessidades.

A execução de grandes estruturas de madeira requer peças maciças com dimensões que dificilmente são encontradas. Para viabilização dessas estruturas, é necessário efetuar uniões compatíveis com as solicitações mecânicas, oferecendo resistência, durabilidade e segurança. Atualmente, a normatização brasileira referente à madeira aborda as ligações por meio de pinos metálicos, ligações coladas, cavilhas ou conectores. Os pinos metálicos são constituídos pelos pregos e parafusos, enquanto os conectores podem ser anéis metálicos ou chapas metálicas com dentes estampados. As ligações constituem-se no ponto crítico das estruturas de madeira e, por isso, demandam estudos experimentais que avaliem o seu real comportamento.

Há 5 anos, foi formada uma comissão de professores pesquisadores da Escola Politécnica e da Escola de Engenharia de São Carlos (EESC), da Universidade de São Paulo (USP), com a finalidade de revisarem a norma brasileira NBR 7190 Cálculo e Execução de Estruturas de Madeira da Associação Brasileira de Normas Técnicas (ABNT).

Uma série de pesquisas e ensaios foi realizada com essa finalidade, tendo sido também investigadas as ligações com pinos metálicos. Esses ensaios de ligações foram utilizados para calibrar o critério de dimensionamento do novo documento 
normativo, NBR 7190/97 - Projeto de Estruturas de Madeira -, baseado em estados limites.

Neste trabalho, será feita a reavaliação dos resultados de experimentos realizados pelo Laboratório de Madeiras e Estruturas de Madeira - LaMEM - Departamento de Estruturas da Escola de Engenharia de São Carlos, da Universidade de São Paulo, quando do processo de revisão da norma. Tais ensaios englobam o estudo para solicitações na direção normal e paralela às fibras. Também são apresentados ensaios complementares, realizados para a verificação dos critérios de dimensionamento atuais da norma. Nesses ensaios complementares, é abordado o estudo da resistência da ligação na direção paralela às fibras da madeira.

\section{1 - Objetivo}

O objetivo deste trabalho é verificar o critério de dimensionamento para ligações com pinos metálicos em estruturas de madeira da norma brasileira NBR7190/97 por meio da análise de resultados experimentais.

\section{2 - Justificativa}

Observa-se que o critério da NBR 7190/97 para o dimensionamento das ligações por pinos metálicos em estruturas de madeira conduz ao aumento do número de elementos nas ligações em relação ao observado na norma anterior, "NBR 7190/82 Cálculo e Execução de Estruturas de Madeira". Esta situação tem levado ao dimensionamento de estruturas de madeira com custos mais elevados do que o observado anteriormente e requer estudos que possam contribuir na verificação das reais condições das ligações, comparando-as ao modelo teórico de dimensionamento da NBR 7190/97. 


\section{2- REVISÃO BIBLIOGRÁFICA}

ALMEIDA (1987) divide o emprego de pregos em ligações estruturais em duas gerações. A primeira geração é aquela na qual a função do pino é manter as peças de madeira em posição ou, em alguns casos, solidarizar as uniões obtidas por entalhe, em que o prego é solicitado ao arrancamento e não ao corte. Para a realização das ligações por entalhe, era necessário o uso de peças muito compridas e de grande seção transversal, cujo trabalho de entalhe requeria grande precisão. Tais fatores levavam à necessidade de mão de obra especial e dificultavam a execução de sistema treliçado.

Segundo Stoy e Fonrobert, apud ALMEIDA (1987), a partir de meados do século XVII, surgiu a segunda geração de ligações, utilizando peças de madeira de pequenas dimensões, ligadas por elementos metálicos ou qualquer outro tipo de elemento cuja função fosse a de transmitir os esforços entre duas peças estruturais de madeira.

Estudando as ligações pregadas e parafusadas em estruturas de madeira, ALMEIDA (1990) conclui que, normalmente, os pontos críticos das peças são as regiões dessas ligações, onde a concentração de esforços deve ser controlada. A melhoria da eficiência das ligações foi o que possibilitou a aplicação racional da madeira em estruturas de grande porte. Essa evolução está ligada, principalmente, ao desenvolvimento das ligações pregadas e parafusadas.

Em sua dissertação de mestrado, ALMEIDA (1987) abordou os problemas relativos ao comportamento das ligações pregadas, analisando os métodos de ensaios existentes e propondo novos métodos experimentais que pudessem levar a resultados 
que representassem os estados limites. Tais estudos conduziram a um modelo matemático representativo dos esforços que levam essas ligações ao estado limite.

ALMEIDA (1987) concluiu que os métodos de determinação da força admissível das ligações pregadas utilizam equações empíricas obtidas de ensaios de uniões pregadas, sem uma análise mais detalhada do comportamento destas.

Segundo JOHANSEN (1949), a ligação por parafuso depende do efeito de pino e do atrito entre as superfícies, causado pelo tracionamento do parafuso. No entanto os resultados de seus ensaios mostraram que apenas o efeito de pino deve ser considerado, pois o tracionamento é desprezível.

A resistência das ligações por pinos depende da resistência da madeira ao embutimento do parafuso $\left(f_{e}\right)$ e da resistência ao escoamento do aço do pino, e, sendo estas de natureza plástica, a capacidade de força de um pino metálico pode ser formulada baseada nesse comportamento.

O critério de dimensionamento de ligações por pinos da NBR 7190/97 baseia-se nesse conceito. A relação entre a espessura da peça de madeira, o diâmetro do pino, a resistência ao embutimento e a tensão de escoamento do pino metálico determinam o comportamento da ligação, que pode deformar-se pelo embutimento na madeira ou pela flexão do pino.

\section{1 - Modelos teóricos de cálculos}

ALMEIDA (1987), de acordo com os preceitos da NBR 8681/84 - Ações e Segurança nas Estruturas - , entende que a ruína da emenda pregada será considerada como uma ruptura, quando ocorrer o aparecimento de deslizamentos, com plastificações exageradas. Para ligações pregadas de madeira, detectou três modos de ruptura da emenda: 
1 - Por plastificação dos pregos: a ligação apresenta grandes deformações por flexão do pino, com eventual esmagamento parcial da parede do furo. A resistência da ligação é estabelecida pela força correspondente à plastificação do prego;

2 - Por embutimento do prego na madeira: ocorre quando a ligação pregada é feita com madeira de baixa resistência ou quando, na emenda, existem peças de espessuras muito pequenas. Outro parâmetro importante, neste modo de ruptura, é a relação entre a resistência de embutimento da madeira $\left(f_{\mathrm{e}}\right)$ e o diâmetro do prego. Ao aumentar o diâmetro do prego, também se aumentou a sua resistência à flexão e, portanto, pode aumentar a força transmitida à madeira. $\mathrm{O}$ aumento do diâmetro do prego também diminuiu a resistência de embutimento, em virtude da redução da pressão específica na parede do furo. Entretanto, para madeiras de baixa resistência à compressão $\left(\mathrm{f}_{\mathrm{c}}\right.$ ), a relação $\mathrm{k}=\mathrm{f}_{\mathrm{e}} / \mathrm{f}_{\mathrm{c}}$ tende a um valor abaixo da unidade, tornando a sua verificação importante para o dimensionamento das ligações;

3 - Por fendilhamento da madeira: ocorre pela ruptura por tração normal às fibras da madeira ao longo de planos paralelos à direção da força transmitida pelo prego à madeira. Duas situações levam à ocorrência deste modo de ruptura: o ato da cravação dos pregos ou quando a ligação é solicitada por carregamento externo. A primeira situação surge durante a fabricação da ligação com pré furação insuficiente. A relação ideal entre os diâmetros do prego e da broca deve ser determinada experimentalmente, pois, se não for devidamente controlada, ocorrerá um fendilhamento imediato, ou um fendilhamento prematuro sob ação das forças externas. A ruptura por fendilhamento da madeira devida ao carregamento depende de vários fatores, sendo o mais importante o espaçamento entre os pregos e a distância destes às bordas das peças da ligação.

Este último modo de ruptura não pode ser controlado por limitações dos valores das tensões, mas sim por regras construtivas que limitem os espaçamentos mínimos para cada situação de uso dos pregos nas ligações. 
A norma DIN 1052 (1988) admite, para espessuras menores que o mínimo calculado ( $\min a$ ), que deve ser feita uma redução na força admissível a uma razão de a/ $6 \mathrm{~d}_{\mathrm{n}}$, em que estão relacionados a espessura da madeira (a) e o diâmetro do pino $\left(\mathrm{d}_{\mathrm{n}}\right)$, para se considerar o efeito do fendilhamento.

O EUROCODE (1999) admite espaçamentos menores que os especificados, desde que se considere um valor $\mathrm{K}_{\mathrm{a}}$ de diminuição da resistência ao embutimento.

Mack (1960), apud ALMEIDA (1987), observa que não só o diâmetro do prego influencia na rigidez e resistência última da ligação, mas também as espessuras das peças de madeira que compõem o corpo-de-prova.

Segundo Mack, a relação entre a resistência de esmagamento local da madeira, que ocorre pela pressão da haste do prego sobre a parede do furo, e a resistência à compressão paralela às fibras da madeira é um parâmetro importante para o estudo de ligações pregadas. Utilizando corpos-de-prova compostos de três peças, uma central com 6,3 mm de espessura e duas laterais com 15,8 mm de espessura cada uma, Mack realizou os ensaios de forma que a ruptura se desse por esmagamento da peça central. A resistência de esmagamento, também designada por resistência ao embutimento, foi obtida por Mack em função da força última $\left(\mathrm{q}_{\mathrm{u}}\right)$ por unidade de comprimento da haste do prego. $\mathrm{O}$ valor de qu é fornecido pela relação entre a força última obtida no ensaio $\left(\mathrm{F}_{\mathrm{u}}\right)$ e o produto do número de pregos (n) pela espessura da peça central $\left(h_{1}\right)$, conforme a equação:

$$
\mathrm{q}_{\mathrm{u}}=\frac{\mathrm{F}_{\mathrm{u}}}{\mathrm{n} \times \mathrm{h}}
$$

Finalmente, dividindo-se o valor de $\mathrm{q}_{\mathrm{u}}$ pelo diâmetro do prego (d), encontra-se o valor convencional da resistência ao embutimento $\mathrm{f}_{\mathrm{e}}$, ou seja:

$$
\mathrm{f}_{\mathrm{e}}=\frac{\mathrm{q}_{\mathrm{u}}}{\mathrm{d}}
$$


A resistência das ligações por pinos, segundo JOHANSEN (1949), depende da resistência da madeira ao embutimento do parafuso $\left(\mathrm{f}_{\mathrm{e}}\right)$ e da resistência do pino a flexão. Como o comportamento de ambas é plástico, a capacidade de força de um pino metálico pode ser formulada por meio desse comportamento. Assim, várias normas atuais, como o EUROCODE 5, DIN 1052 e a NBR 7190/97, utilizam esse conceito.

HILSON (1995), comentando as recomendações do EUROCODE 5 , assegura que \$ equações de Johansen são geralmente aplicáveis para qualquer combinação de materiais derivados da madeira, desde que as propriedades do material sejam conhecidas. Ainda segundo HILSON, devido a essa fácil aplicação a novos materiais é que a formulação de Johansen foi adotada para o dimensionamento de ligações no EUROCODE 5.

De acordo com a NBR 7190/97, a resistência de um pino, correspondente a uma dada seção de corte entre duas peças de madeira, é determinada em função das resistências de embutimento $€$ das duas madeiras interligadas, da resistência de escoamento $f_{\mathrm{y}}$ do pino metálico, do diâmetro d do pino e das espessuras das peças.

ALMEIDA (1987) afirma que a pressão de contato aplicada pelo pino à parede do furo causa um estado múltiplo de tensões na região do entorno do furo que tende a embutir o pino na madeira. Explica, ainda, que as tensões de embutimento podem ocorrer pela própria cravação do pino ou de uma ação externa induzida pelo comportamento solidário das peças de madeira.

Mediante ensaios realizados, ALMEIDA (1987) detectou dois estados limites relevantes para a segurança das ligações pregadas. $\mathrm{O}$ primeiro limite corresponde ao fim do regime elástico, e o segundo ao fim do deslizamento controlado, equivalendo aos estados limites de utilização e último, respectivamente. Expõe que a ligação apenas pode suportar as forças do segundo limite à custa de grandes deformações por estas representarem modificações significativas na geometria do sistema, proporcionando deslocamentos que não podem ser admitidos nas estruturas. 


\subsection{1 - Modelo de JOHANSEN (1949)}

Em seu desenvolvimento teórico, JOHANSEN (1949) afirma que, para um grande deslocamento, em uma ligação com apenas uma seção de corte e um pino de rigidez suficiente para que seja desprezada a deformação por flexão, ocorrerá uma pressão £, praticamente, sobre todo o pino, e uma distribuição das forças $\mathrm{q}$, forças cortantes $\mathrm{V}$ e momentos fletores $\mathrm{M}$, conforme mostra a figura 1. Para as ligações em que o pino tem rigidez suficiente, Johansen apresenta o seguinte equacionamento:

$\mathrm{R}=\mathrm{f}_{\mathrm{e}} \cdot \mathrm{d} \cdot \mathrm{z}$

O valor do momento máximo é fornecido pelas expressões:

$\mathrm{M}_{\max }=\mathrm{f}_{\mathrm{e}} \cdot \mathrm{d} \cdot \mathrm{x}^{2}=1 / 2 \cdot \mathrm{f}_{\mathrm{e}} \cdot \mathrm{d} \cdot \mathrm{z}^{2}$, com base nesta igualdade, obtém-se o valor de $\mathrm{x}$ :

$\mathrm{x}=\mathrm{z} \sqrt{1 / 2}$

A espessura $t_{1}$ da cobrejunta pode ser expressa por:

$\mathrm{t}_{1}=\mathrm{z}+2 \mathrm{x}=\mathrm{z}(1+\sqrt{2})$.

Das expressões acima, obtém-se o valor de z:

$\mathrm{z}=\mathrm{t}_{1}(\sqrt{2}-1)=0,414 \mathrm{t}_{1}$.

Substituindo-se o valor de z nas expressões da resistência R e de x, obtém-se:

$\mathrm{x}=0,293 \cdot \mathrm{t}_{1}$

$\mathrm{R}=0,414 \cdot \mathrm{f}_{\mathrm{e}} \cdot \mathrm{t}_{1} \cdot \mathrm{d}$ 
Se o pino não for suficientemente rígido, como mostrado na figura 2 , ele será fletido, e, no limite de escoamento do pino na flexão, o momento é $(\pi / 32) \cdot f_{y} \cdot d^{3}$, e a força transversal (cortante) é zero. Entre as curvaturas, o embutimento é tão grande que a pressão é praticamente $\mathrm{f}_{\mathrm{e}} \mathrm{d}$.

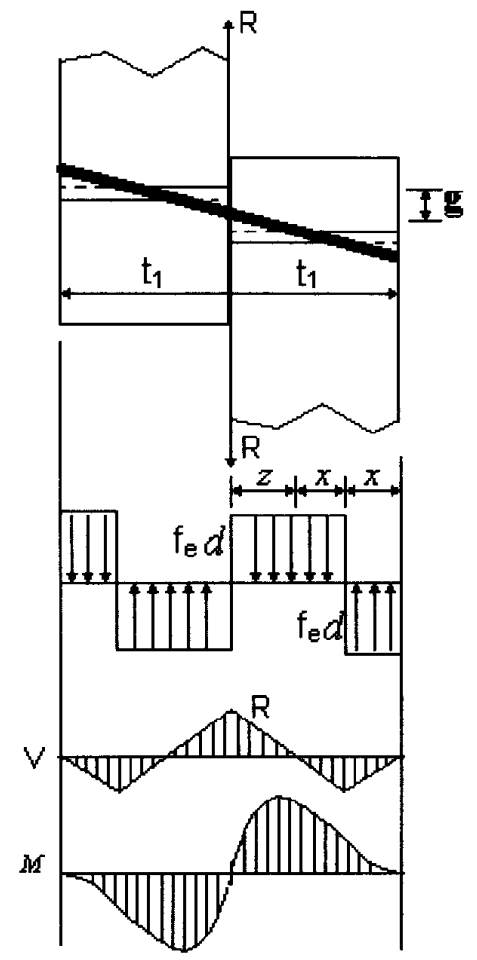

FIGURA 1 - Ligação com pino rígido e uma seção de corte fonte: JOHANSEN (1949)
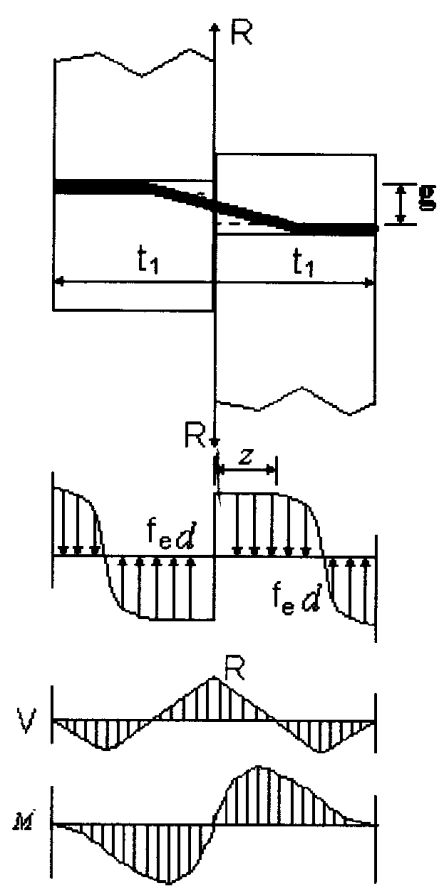

FIGURA 2 - Ligação com pino flexível e uma seção de corte fonte: JOHANSEN (1949)

Considerando a seção do pino onde $M=M_{\max }$ e $V=0$, obtém-se a resistência:

$R=f_{e} \cdot d \cdot z$, da qual se obtém o valor de $z=R /\left(f_{e} \cdot d\right)$.

O momento fletor máximo é fornecido por:

$\mathrm{M}_{\max }=1 / 2 \cdot \mathrm{R} \cdot \mathrm{z}$. 
Entrando com o valor de $\mathrm{z}$ na expressão de $\mathrm{M}_{\max }$ e com a consideração para o limite do escoamento do pino na flexão, chega-se às expressões:

$M_{\max }=\frac{1}{2} \frac{R^{2}}{f_{e} \cdot d}=f_{y} \frac{\partial}{32} d^{3}$

Obtendo-se desta igualdade o valor de z e introduzindo na expressão de R, obtém-se:

$R=0,442 \cdot d^{2} \cdot \sqrt{f_{y} \cdot f_{e}}$

Em uma conexão com dois planos de corte e um pino rígido, conforme figura 3, as fórmulas resultantes são:

$\mathrm{R}=2 \mathrm{f}_{\mathrm{e}} \cdot \mathrm{d} \cdot \mathrm{t}_{1}$ quando $\mathrm{t}_{2}>2 \mathrm{t}_{1}$;

$\mathrm{R}=\mathrm{f}_{\mathrm{e}} \cdot \mathrm{d} \cdot \mathrm{t}_{2}$, quando $\mathrm{t}_{2} \leq 2 \mathrm{t}_{1}$.
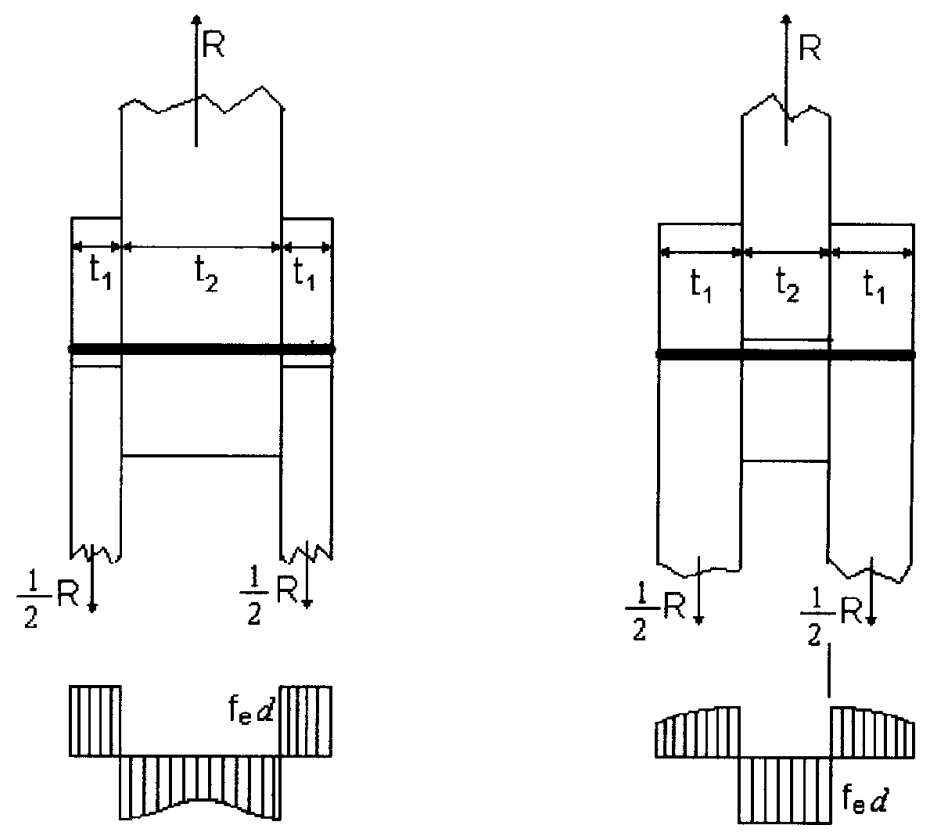

FIGURA 3 - Ligação com pino rígido e duas seções de corte - fonte:

JOHANSEN, (1949)

O pino com baixa rigidez deve fletir na peça de madeira do centro. Isto, geralmente, ocorre em dois pontos, e a madeira deve encontrar-se em estado plástico de 
deformação, assim, o estado limite último se caracteriza pela flexão do pino. Johansen considera o pino rígido quando o estado limite último se caracteriza pelo embutimento do pino na madeira.

$\mathrm{Na}$ união, a distribuição das pressões corresponde a da figura $1 \mathrm{e}$, em cada metade da madeira, uma distribuição que corresponde à da figura 2. Sendo a cortante $V=0$, os momentos máximo $\left(\mathrm{M}_{\max }\right)$ e mínimo $\left(\mathrm{M}_{\min }\right)$ devem ocorrer à mesma distância $\mathrm{z}$ da junção, e, em ambos os casos, $f_{e} d z$ deve ser igual a 1/2 R. Na ligação, o ponto onde V=0 localiza-se a uma distância duas vezes maior do aquela onde a pressão muda de sinal, figura 1 , que vale $\mathrm{t}=\mathrm{z}+2 \mathrm{x}$. Na seção em que o momento é máximo $(\mathrm{M}=$ $\left.\mathrm{M}_{\max }\right)$ e a cortante é zero $(\mathrm{V}=0)$, conforme mostra a figura 4 , a equação do momento será:

$1 / 2 R=f_{e} d z \quad$ e $\quad x=1 / 2\left(t_{1}-z\right)$

$M_{\text {máx }}=\frac{\partial}{32} f_{e} d z=\frac{1}{2} R z-f_{e} d x^{2}=f_{e} d z^{2}-\frac{1}{4} f_{e} d\left(t_{1}-z\right)^{2}$

$\mathrm{z}=\frac{\mathrm{t}_{1}}{3}\left(\sqrt{4+\frac{3 \partial}{8} \frac{\mathrm{f}_{\mathrm{y}} \mathrm{d}^{2}}{\mathrm{f}_{\mathrm{e}} \mathrm{t}_{1}^{2}}}-1\right)$

$\mathrm{R}=\frac{2}{3} \mathrm{f}_{\mathrm{e}} \mathrm{dt}_{1}\left(\sqrt{4+\frac{3 ð}{8} \frac{\mathrm{f}_{\mathrm{y}} \mathrm{d}^{2}}{\mathrm{f}_{\mathrm{e}} \mathrm{t}_{1}^{2}}}-1\right)$

Podendo esta expressão ser aproximada para

$$
R=\left(\frac{1}{4} f_{e} t_{1}^{2}+\frac{3}{5} f_{y} d^{2}\right) \sqrt{\frac{f_{e}}{f_{y}}}
$$



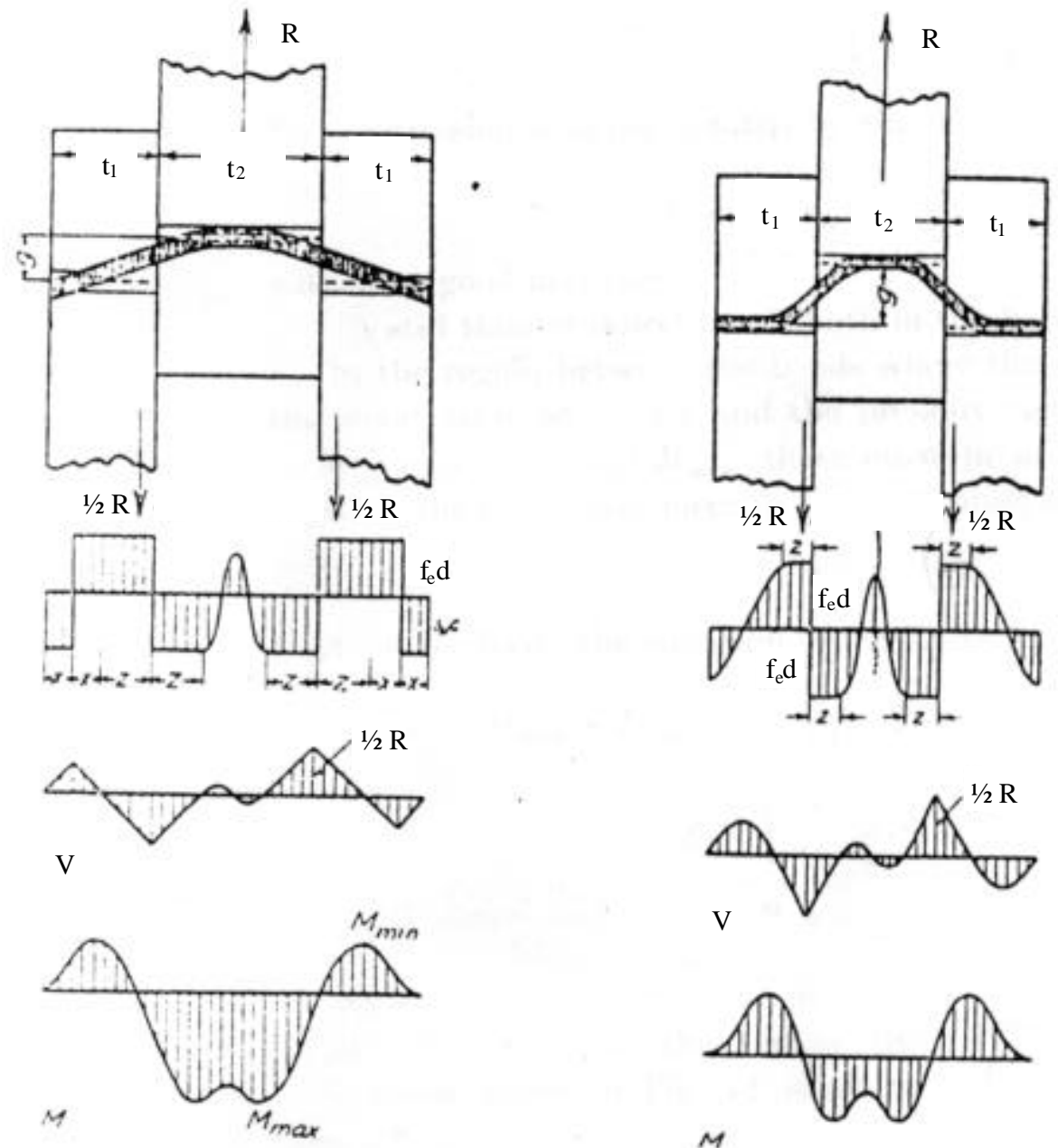

\section{FIGURA 4 - Ligação com pino}

FIGURA 5 - Ligação com pino rígido e duas seções de corte fonte: JOHANSEN (1949) flexível e duas seções de corte fonte: JOHANSEN (1949)

$\mathrm{Na}$ região entre as curvaturas onde o pino foi fletido, conforme mostra a figura 5, a madeira deverá estar no estado plástico, e a pressão do pino será, novamente, $\mathrm{f}_{\mathrm{e}}$. 
$\mathrm{O}$ ponto em que $\mathrm{V}=0$ e $\mathrm{M}$ é $\mathrm{M}_{\max }$ ou $\mathrm{M}_{\text {nim }}$, deve ocorrer à mesma distância $\mathrm{z}$ da junção, onde a força transversal na junção é:

$1 / 2 \mathrm{R}=\mathrm{f}_{\mathrm{e}} \cdot \mathrm{d} \cdot \mathrm{z}$

Tem-se, ainda, a equação de momento para o pino entre as curvaturas:

$$
\begin{aligned}
& M_{\text {max }}+M_{\text {min }}=2 \frac{\partial}{32} f_{y} d^{3}=\frac{1}{2} R z=f_{e} d^{2} \\
& z=\sqrt{\frac{\partial}{16} \frac{f_{y}}{f_{e}}} \cdot d=0,442 \sqrt{\frac{f_{y}}{f_{e}}} \cdot d \\
& R=0,885 d^{2} \sqrt{f_{y} f_{e}}
\end{aligned}
$$

A teoria de Johansen é baseada na teoria da plasticidade, e considera o comportamento dos materiais como sendo elasto-plástico perfeito.

\subsection{2 - Método de MÖLLER (1951), apud ALMEIDA (1987)}

Dentre os estudos sobre o comportamento teórico das ligações em peças de madeira por pinos metálicos, destaca-se o método desenvolvido por Möller (1951) para a determinação da força última $(\mathrm{R})$ da ligação pregada, pois determina a resistência da ligação, considerando a resistência de embutimento da madeira e a plastificação do prego.

Möller (1951), apud ALMEIDA (1987), considera o prego como sendo uma viga apoiada sobre a parede do furo e propõe uma expressão para determinar a resistência das ligações pregadas, admitindo que o valor do carregamento por unidade de comprimento do prego seja igual à resistência ao embutimento multiplicada pelo diâmetro do prego. Admitiu também que, no ponto de momento máximo, ocorreria a 
formação de uma rótula plástica, além de levar em consideração a espessura das peças de madeira, o momento fletor de plastificação do prego $\left(\mathbf{M}_{\mathrm{np}}\right)$ e a força distribuída última $\left(\mathrm{q}_{1}\right)$ necessária para provocar o embutimento da madeira pela haste do prego.

O método de Möller considera que o estado limite último do corpo-de-prova é determinado pela plastificação do prego por flexão ou pelo embutimento da madeira e que qualquer acréscimo de resistência, além deste estado último, é devido ao efeito de segunda ordem que ocorre no corpo-de-prova

$\mathrm{O}$ valor da força última $\mathrm{R}$ da ligação, em corte simples, foi deduzido por Möller em função do momento de plastificação do prego $\left(\mathrm{M}_{\mathrm{np}}\right)$ e do carregamento último $\left(\mathrm{q}_{\mathrm{u}}\right)$, que provoca o embutimento da madeira pela haste do prego, sendo dado por:

$$
\mathrm{R}=\sqrt{2 \mathrm{M}_{\mathrm{np}} \cdot \mathrm{q}_{\mathrm{u}}}
$$

Substituindo o valor de $\mathrm{q}_{\mathrm{u}}=\mathrm{f}_{\mathrm{e}} \cdot \mathrm{d}$ na expressão acima, obtém-se:

$$
\mathrm{R}=\sqrt{2 \mathrm{M}_{\mathrm{np}} \cdot \mathrm{f}_{\mathrm{e}} \cdot \mathrm{d}}
$$

De acordo com a teoria da plasticidade, o momento de plastificação de uma seção circular é dado por $M_{y}=f_{y} \cdot d^{3} / 6$. Substituindo esse valor, em que $M_{y}=M_{n p}$, na equação acima, obtém-se:

$$
R=0,6 d^{2} \sqrt{f_{y} \cdot f_{e}}
$$

em que $f_{y}$ é a resistência de escoamento do prego, que deve ser determinada diretamente com base no ensaio de tração ou indiretamente, por meio do ensaio de flexão do prego, tendo em vista as características das ligações de madeira om pinos de aço. 


\section{2 - Rigidez das ligações}

A NBR 7190/97 não admite ligações com um único pino, e ligações com 2 ou 3 pinos são consideradas deformáveis, sendo seu uso permitido apenas para estruturas isostáticas. O dimensionamento da ligação é feito como se ela fosse rígida, dando-se uma contra-flecha compensatória à estrutura em questão.

Observa-se que, de acordo com o texto normativo, fica praticamente impedido o uso de 2 ou 3 pinos em ligações de estruturas hiperestáticas, por influenciar a distribuição de esforços de maneira não conhecida.

Ligações com 4 ou mais pinos são consideradas rígidas, quando forem respeitadas as condições de pré-furação adotadas para pregos e parafusos.

As condições propostas pela NBR7190/97, quanto à rigidez da ligação, devem ser criteriosamente analisadas e questionadas para cada caso e para cada estrutura. Tais afirmações podem ser contrariadas em diversas situações nas quais o comportamento da ligação pode indicar uma rigidez e uma estabilidade perfeitamente compatíveis com as condições de exposição e de utilização de uma determinada estrutura. Da mesma forma, o uso de quatro pinos não pode garantir que a ligação seja considerada rígida.

\section{3 - Pré-furação das ligações}

A penetração dos pregos na madeira provoca efeitos que exigem dos pesquisadores especial atenção quanto ao comportamento e à resistência de uma ligação pregada de madeira. Tais efeitos constituem-se na plastificação da madeira na região do entorno do prego, gerando, com isso, tensões na ligação, antes mesmo que esta seja carregada. 
ALMEIDA (1987) observou que a diferença entre o diâmetro da pré-furação e o diâmetro do prego deve ser suficientemente pequena para que as tensões resultantes não levem a madeira ao fendilhamento. $\mathrm{O}$ fendilhamento, por sua vez, pode não ser observado macroscopicamente durante a pregação e, mesmo microscopicamente, provoca o afrouxamento entre prego e madeira perdendo, nessa ligação, parte do efeito benéfico do ajuste provocado pela penetração do prego na madeira. Ensaiando ligações pregadas em madeira de elevada densidade, verificou que a ligação é mais rígida quando é feita uma pré-furação em torno de $90 \%$ do diâmetro do prego do que quando a pré-furação é feita com diâmetros menores.

Segundo Wilkinson \& Rowlands (1981), apud STAMATO (1998), pequenas mudanças entre o diâmetro do pino e a pré-furação podem provocar um efeito bastante significativo nas tensões no entorno do furo. Provavelmente, este é o fator que provoca a maior variabilidade em resultados observados em ensaios de ligações parafusadas, ou seja, se a relação entre o diâmetro do pino e o diâmetro do furo é diminuída, a tensão entorno do furo é aumentada.

Mack (1961), apud ALMEIDA (1987), ensaiando madeira, com resistência à compressão paralela às fibras $\mathrm{f}_{\mathrm{c}}=41,5 \mathrm{MPa}$, observou que, ao utilizar brocas com diâmetro de $80 \%$ do diâmetro do prego, em corpos-de-prova de madeira seca, ocorria um acréscimo de $9 \%$ na força máxima de ensaio e de $27 \%$ na força relativa a um deslocamento relativo de $0,38 \mathrm{~mm}$. Para madeira verde, detectou um acréscimo de $13 \%$ na força correspondente ao deslocamento de $0,38 \mathrm{~mm}$. Todos os resultados se comparando-se a corpos-de-prova sem pré furação.

Antes da sua revisão em 1997, a norma brasileira não se preocupava em especificar o diâmetro das brocas e nem o efeito da pré-furação no valor da força admissível da ligação. A norma não admitia para estruturas importantes, salvo comprovações de resultados experimentais, o uso de ligações sem a utilização de ferramentas de furar, ranhurar e frezar, para não ocorrer a destruição das fibras da madeira.

A norma britânica BSI (The British Standard Code of Pratice CP 112 : Part 2 : 1971) permite o uso de brocas de diâmetros de até $80 \%$ do diâmetro do prego, mas não 
especifica se o valor da força admissível de projeto é alterada quando a pré-furação é utilizada.

A norma DIN 1052 estabelece, para ligações sem pré-furação, que a mínima espessura da madeira, mín a, em mm (a qual não deve ser menor que $24 \mathrm{~mm}$ ) deve ser calculada por:

mín $a=\mathrm{d}_{\mathrm{n}}\left(3+0,8 \mathrm{~d}_{\mathrm{n}}\right)$, em que $\mathrm{d}$ é o diâmetro do prego, em mm.

Pela norma DIN 1052 (1988), quando os pregos são cravados com pré-furação, a espessura mínima da madeira é permitida para pinos de 4,2 mm e maiores, podendo, nesses casos, a espessura da madeira ser reduzida a seis vezes o diâmetro do prego. Para espessuras menores, a força admissível deve ser reduzida de um valor correspondente a razão $\mathrm{a} / 6 \mathrm{~d}_{\mathrm{n}}$, conforme já observado no item 2.1 deste trabalho.

A norma DIN também permite que, se os pregos forem cravados com pré-furação aproximada de $0,9 \mathrm{~d}_{\mathrm{n}}$ de diâmetro e com comprimento igual ao comprimento do prego, que a força do prego pode ser assumida como 1,25 vezes a calculada pela equação:

$N_{1, a d m}=\frac{500 x d_{n}^{2}}{10+d_{n}}$

Segundo ALMEIDA (1987), foram realizados vários ensaios no Laboratório de Estruturas do Departamento de Engenharia de Estruturas e Fundações da Escola Politécnica da Universidade de São Paulo, utilizando várias amostras de madeira. Observou-se que as espécies com resistência à compressão superior a $60 \mathrm{MPa}$ apresentavam fendilhamento longitudinal às fibras, quando a pré-furação era feita segundo a norma alemã DIN ou a britânica BSI. Para as espécies de madeira com resistência à compressão em torno de $90 \mathrm{MPa}$ e umidade de $15 \%$, foi necessário usar brocas com diâmetro de 0,98d, enquanto que, para espécies de resistência 50 e 60 $\mathrm{MPa}$, com a mesma umidade, foi necessário $0,85 \mathrm{~d}$ para evitar o fendilhamento. 
Embasado nas suas investigações, ALMEIDA (1987) concluiu que "em toda ligação pregada de madeira, deve-se sempre fazer uma pré-furação, principalmente quando a ligação pertencer a estruturas perenes."

Para ligações pregadas, a NBR 7190/97 estabelece que a pré-furação da madeira deve ter diâmetro $\mathrm{d}_{0}$ não maior que o diâmetro $\mathrm{d}_{\mathrm{ef}}$ do prego, com os valores usuais:

coníferas: $\quad \mathrm{d}_{0}=0,85 \mathrm{~d}_{\mathrm{ef}}$

dicotiledôneas: $\quad \mathrm{d}=0,98 \mathrm{~d}_{\mathrm{ef}}$

A realização da pré-furação, em ligações pregadas, utilizando os diâmetros apresentados pela NBR 7190, são dificultadas em função dos diâmetros de brocas e pregos não serem encontrados com esse nível de precisão na maioria dos casos.

A norma brasileira somente admite o uso de ligações sem pré-furação em estruturas provisórias, empregando-se madeiras de baixa densidade $\left(\rho_{\text {ap }} \leq 600 \mathrm{~kg} / \mathrm{m}^{3}\right)$ e que permitem a penetração de pregos sem o risco do fendilhamento, pregos com diâmetro d não maior que $1 / 6$ da espessura da madeira mais delgada e com espaçamento mínimo de $10 \mathrm{~d}$.

Segundo a NBR 7190/97, para as ligações parafusadas serem consideradas rígidas, a pré-furação deve ser feita com diâmetro đ não maior que o diâmetro d do parafuso acrescido de $0,5 \mathrm{~mm}$. Em caso de $\mathrm{d}_{0}$ maiores, a ligação deve ser considerada deformável.

\section{4 - Efeito do número de pinos em uma ligação}

A NBR 7190/97, nas ligações com mais de 8 pinos, estabelece que os pinos suplementares devem ser considerados com apenas $2 / 3$ de sua resistência individual. Até 8 pinos, a resistência da ligação é dada pela soma das resistências de cada um dos pinos. 
Granholm, em 1949, apud ALMEIDA (1987), demonstrou teoricamente que, em ligações alongadas, os pregos de extremidade absorvem uma maior proporção da força aplicada.

Investigando o efeito do número de pregos em uma ligação, Mack, apud ALMEIDA (1987), recomenda, para ligações com madeira de elevada densidade, composta de dez a doze pregos, que o valor da força admissível da ligação deve ser reduzido de 20\%. Nesse trabalho, Mack concluiu que, nas ligações compostas de até seis pregos por interface, isto é, com seis seções de corte, a força foi proporcional ao número de pregos. O mesmo não ocorreu para ligações com doze pregos por interface, nas quais as forças obtidas foram até $16 \%$ menores que as forças determinadas proporcionalmente ao número de pregos.

A norma DIN-1052 (1988) especifica, para ligações pregadas com mais de dez pregos, reduzir a força admissível em $10 \%$ e, quando contiver vinte pregos, reduzir em $20 \%$.

\section{5 - Critérios de dimensionamento}

A seguir são apresentados alguns critérios de dimensionamento para as ligações em estruturas de madeira utilizando pinos metálicos. Observa-se que as formulações são dadas em função da ocorrência de embutimento do pino na madeira e da ocorrência de flexão do pino.

A norma brasileira NBR 7190/97 apresenta a mesma formulação para ligação em corte simples ou em corte duplo, enquanto que o EUROCODE 5 apresenta formulações para o corte simples e para o corte duplo. 


\subsection{1 - Critério da NBR 7190/97}

A NBR 7190 determina que o valor de cálculo da resistência de um pino metálico correspondente a uma única seção de corte seja determinado em função do valor do parâmetro $\beta$, cujo valor é dado pela expressão:

$\beta=\frac{\mathrm{t}}{\mathrm{d}}$

em que t é a espessura convencional da madeira (figura 6) e d o diâmetro do pino, estabelecendo-se como valor limite e indicador do modo de ruptura da ligação

$\beta_{\text {lim }}=1,25 \sqrt{\frac{f_{y d}}{f_{e d}}}$

sendo $f_{y d}$ a resistência de cálculo ao escoamento do pino metálico, determinada a partir de $f_{\mathrm{yk}}$ com $\gamma_{\mathrm{s}}=1,1$, e $\mathrm{f}_{\mathrm{ed}}$ é o valor de cálculo da resistência ao embutimento da madeira.

$\mathrm{O}$ valor de cálculo $\mathrm{R}_{\mathrm{vd}, 1}$ da resistência de um pino, correspondente a uma única seção de corte, será dado em função da forma de ruptura esperada:

I - forma de ruptura: embutimento na madeira

Esta forma de ruptura ocorrerá quando $\beta \leq \beta_{\lim }$

$\mathrm{O}$ valor de cálculo $\mathrm{R}_{\mathrm{Vd}, 1}$ da resistência de um pino, correspondente a uma única seção de corte, será dado por:

$$
\mathrm{R}_{\mathrm{vd}, 1}=0,40 \frac{\mathrm{t}^{2}}{\hat{\mathrm{a}}} \mathrm{f}_{\mathrm{ed}}=0,40 \mathrm{t} \cdot \mathrm{d} \cdot \mathrm{f}_{\mathrm{ed}}
$$


II - forma de ruptura: flexão do pino

Esta forma de ruptura ocorrerá quando $\beta>\beta_{\lim }$

$\mathrm{O}$ valor de cálculo $\mathrm{R}_{\mathrm{vd}, 1}$ da resistência de um pino, correspondente a uma única seção de corte, será dado por:

$\mathrm{R}_{\mathrm{vd}, 1}=0,625 \frac{\mathrm{d}^{2}}{\beta_{\mathrm{lim}}} \mathrm{f}_{\mathrm{yd}}=0,5 \cdot \mathrm{d}^{2} \cdot \sqrt{\mathrm{f}_{\mathrm{yd}} \cdot \mathrm{f}_{\mathrm{ed}}} \quad\left(\operatorname{com} \hat{\mathrm{a}}=\hat{\mathrm{a}}_{\mathrm{lim}}\right)$.

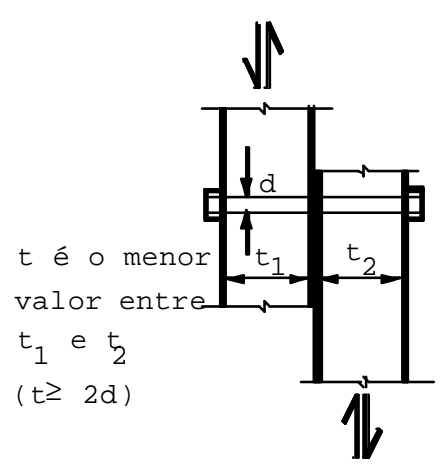

(PARAFUSOS)

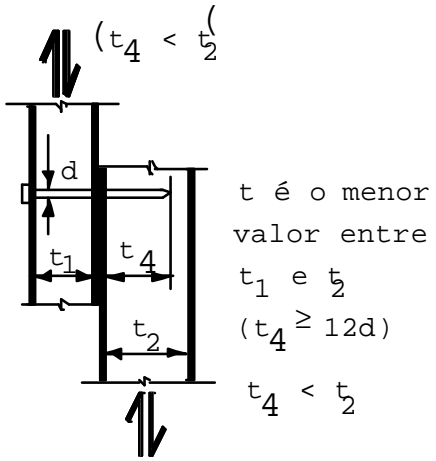

(PREGOS)

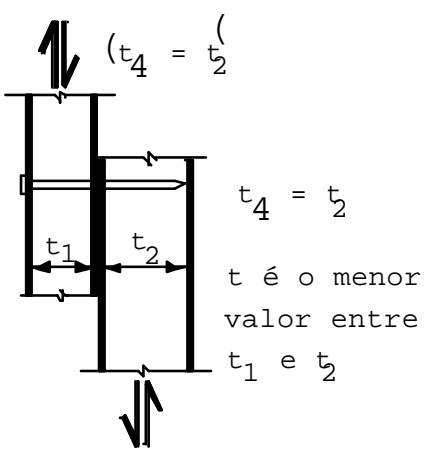

FIGURA 6 - Pinos em corte simples - fonte NBR 7190/97

No caso de pinos em corte duplo, como mostrado na figura 7, a NBR 7190/97 determina que sejam aplicados os mesmos critérios anteriores para a determinação da resistência correspondente a cada uma das seções de corte, considerando-se t como o menor dos valores entre $t_{1}$ e $t_{2} / 2$ em uma das seções, e entre $t_{2} / 2$ e $t_{3}$ na outra. 


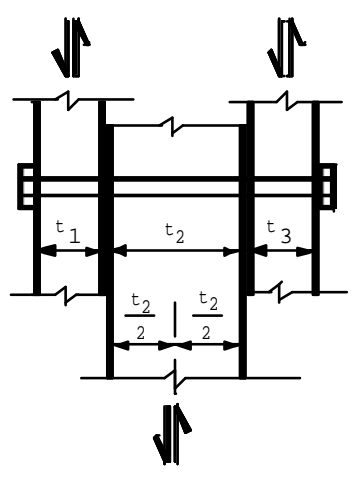

(PARAFUSOS)

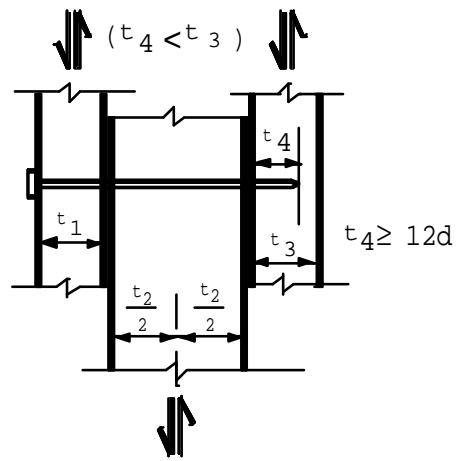

(PREGOS)

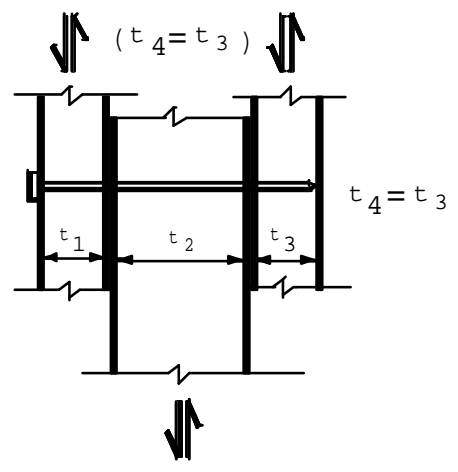

FIGURA 7 - Pinos em corte duplo - fonte NBR 7190/97

Os valores de cálculo da resistência de embutimento nas direções paralela e normal às fibras, $\mathrm{f}_{\mathrm{e} 0}$ e $\mathrm{f}_{\mathrm{e} 90}$, segundo a norma brasileira, são determinadas com base no diagrama tensão $\mathrm{x}$ deformação específica de embutimento mostrado na figura 18. Essas resistências são dadas pelas expressões:

$$
\begin{gathered}
\mathrm{f}_{\mathrm{e} 0}=\frac{\mathrm{F}_{\mathrm{e} 0}}{\mathrm{td}} \\
\mathrm{f}_{\mathrm{e} 90}=\frac{\mathrm{F}_{\mathrm{e} 90}}{\mathrm{td}}
\end{gathered}
$$

em que:

$\mathrm{F}_{\mathrm{e} 0}$ e $\mathrm{F}_{\mathrm{e} 90}$ são as forças aplicadas respectivamente nas direções paralela e normal às fibras, correspondentes às deformações residuais de $\varepsilon=2 \%$;

t é a espessura do corpo-de-prova;

d é o diâmetro do pino.

Os valores de cálculo da resistência ao embutimento da madeira são obtidos com base nos seus valores característicos, levando-se em consideração os coeficientes de ponderação das resistências das madeiras e os coeficientes de modificação estabelecidos em função da classe de carregamento e o tipo de material empregado 
$\left(k_{\text {mod,1 }}\right)$, da classe de umidade e o tipo de material empregado $\left(k_{\text {mod,2 }}\right)$ e se a madeira é de primeira ou segunda categoria $\left(\mathrm{k}_{\mathrm{mod}, 3}\right)$, sendo fornecidos pelas expressões:

$$
\begin{aligned}
& \mathrm{f}_{\mathrm{e} 0 \mathrm{~d}}=\mathrm{k}_{\bmod } \frac{\mathrm{f}_{\mathrm{e} 0, \mathrm{k}}}{\tilde{\mathrm{a}}_{\mathrm{w}}} \\
& \mathrm{f}_{\mathrm{e} 90, \mathrm{~d}}=\mathrm{k}_{\bmod } \frac{\mathrm{f}_{\mathrm{e} 90 \mathrm{k}}}{\tilde{\mathrm{a}}_{\mathrm{w}}}
\end{aligned}
$$

A NBR 7190/97 recomenda (figura 8) como espaçamentos mínimos, para ligações com pinos (pregos com pré furação, parafusos e cavilhas), o seguinte:

a) entre o centro de dois pinos situados em uma mesma linha paralela à direção das fibras: pregos, cavilhas e parafusos ajustados $6 \mathrm{~d}$; parafusos $4 \mathrm{~d}$;

b) do centro do último pino à extremidade de peças tracionadas: 7d;

c) do centro do último pino à extremidade de peças comprimidas: 4d;

d) entre os centros de dois pinos situados em duas linhas paralelas à direção das fibras, medido perpendicularmente às fibras: $3 \mathrm{~d}$;

e) do centro de qualquer pino à borda lateral da peça, medido perpendicularmente às fibras, quando o esforço transmitido for paralelo às fibras: 1,5d;

f) do centro de qualquer pino à borda lateral da peça, medido perpendicularmente às fibras, quando o esforço transmitido for normal às fibras, do lado onde atuam tensões de tração normal 1,5d;

g) do centro de qualquer pino à borda lateral da peça, medido perpendicularmente às fibras, quando o esforço transmitido for normal às fibras, do lado onde atuam tensões de compressão normal: $4 \mathrm{~d}$. 

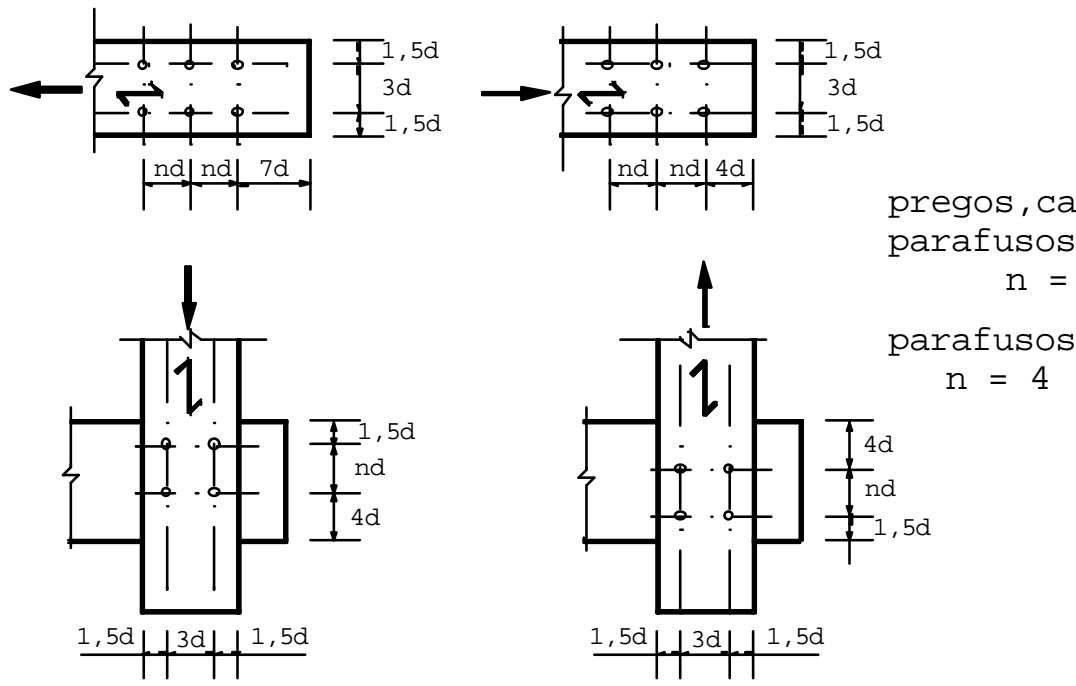

FIGURA 8 - Espaçamentos em ligações com pinos: fonte NBR 7190/97

\subsection{2 - Critérios do EUROCODE 5}

Segundo o EUROCODE (1999), o valor característico $\mathrm{R}_{\mathrm{k}}$ da resistência de um pino, correspondente a uma única seção de corte (figura 9), deve ser tomado como o menor valor encontrado entre as fórmulas seguintes:

$$
\begin{aligned}
& \left(\begin{array}{l}
\mathrm{f}_{\mathrm{h}, 1 \mathrm{k}} \cdot \mathrm{t}_{1} \cdot \mathrm{d} \\
\mathrm{f}_{\mathrm{h}, 2 \mathrm{k}} \cdot \mathrm{t}_{2} \cdot \mathrm{d}
\end{array}\right. \\
& \frac{\mathrm{f}_{\mathrm{h}, 1 \mathrm{k}} \cdot \mathrm{t}_{1} \cdot \mathrm{d}}{1+\hat{\mathrm{a}}}\left[\sqrt{\hat{\mathrm{a}}+2 \hat{a}^{2}\left[1+\frac{\mathrm{t}_{2}}{\mathrm{t}_{1}}+\left(\frac{\mathrm{t}_{2}}{\mathrm{t}_{1}}\right)^{2}\right]+\hat{a}^{3}\left(\frac{\mathrm{t}_{2}}{\mathrm{t}_{1}}\right)^{2}}-\hat{\mathrm{a}}\left(1+\frac{\mathrm{t}_{2}}{\mathrm{t}_{1}}\right)\right]
\end{aligned}
$$

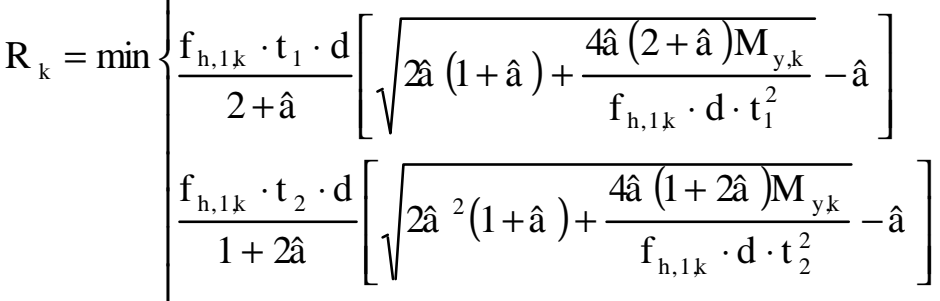

$$
\begin{aligned}
& \sqrt{\frac{2 \hat{a}}{1+\hat{a}}} \cdot \sqrt{2 \mathrm{M}_{\mathrm{y}, \mathrm{k}} \cdot \mathrm{f}_{\mathrm{h}, 1 \mathrm{k}} \cdot \mathrm{d}}
\end{aligned}
$$


Para a situação de corte duplo (figura 9), deve ser tomado como o menor valor encontrado entre as seguintes expressões:

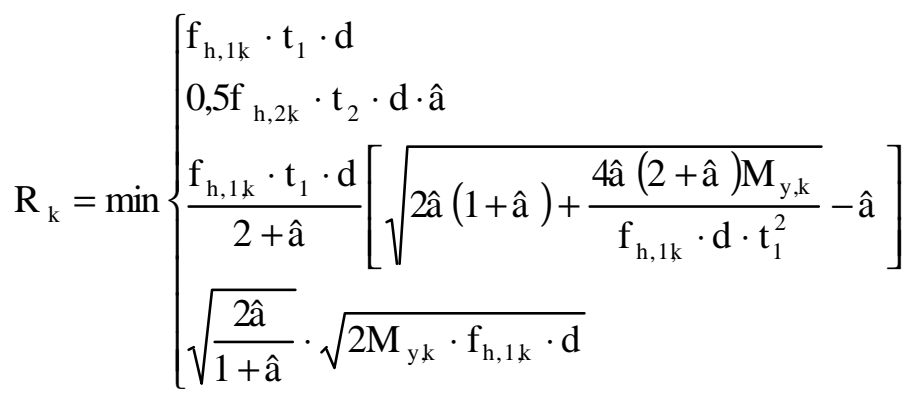

Os parâmetros utilizados nas fórmulas são definidos como sendo:

$t_{1}$ e $t_{2} \quad$ espessura da madeira ou a penetração do pino nesta, conforme figura 3;

$\mathrm{f}_{\mathrm{h}, 1, \mathrm{k}}\left(\mathrm{f}_{\mathrm{h}, 2, \mathrm{k}}\right) \quad$ valor característico da resistência ao embutimento para espessura $\mathrm{t}_{1}\left(\mathrm{t}_{2}\right)$

$\beta \quad \mathrm{f}_{\mathrm{h}, 2, \mathrm{k}} / \mathrm{f}_{\mathrm{h}, 1, \mathrm{k}}$

d diâmetro do pino;

$\mathrm{M}_{\mathrm{y}, \mathrm{k}} \quad$ valor característico do momento de escoamento do pino;

Os valores da resistência ao embutimento e do momento de escoamento do pino são obtidos mediante ensaios realizados, respectivamente, de acordo com a prEN 383, descritos no item 2.6.2.2, e prEN 409 mais o anexo A do EUROCODE 5. 

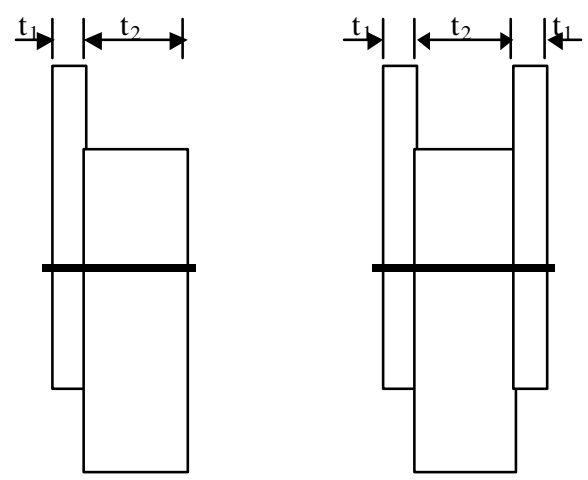

FIGURA 9 - Pino em corte simples e pino em corte duplo - fonte EUROCODE 5 (1999)

O EUROCODE 5 (1999), para ligações pregadas de peças de madeira maciça com madeira maciça, usando pregos de até $8 \mathrm{~mm}$ de diâmetro, e considerando para todos os ângulos em relação à direção das fibras, estabelece os valores para a resistência característica ao embutimento dessas ligações como sendo:

- $\quad$ sem pré-furação: $f_{h, k}=0,082 \cdot \rho_{\mathrm{k}} \cdot \mathrm{d}^{0,3} \mathrm{~N} / \mathrm{mm}^{2}$

- com pré-furação: $f_{\mathrm{h}, \mathrm{k}}=0,082 \cdot(1-0,01 \mathrm{~d}) \cdot \rho_{\mathrm{k}} \quad \mathrm{N} / \mathrm{mm}^{2}$, sendo $\rho_{\mathrm{k}}$ dado em $\mathrm{kg} / \mathrm{m}^{3}$ e d dado em $\mathrm{mm}$.

Para ligações parafusadas em madeira maciça, utilizando parafusos de até $30 \mathrm{~mm}$ de diâmetro, os valores da resistência característica ao embutimento, para forças aplicadas na direção que forma um angulo $\alpha$ em relação à direção das fibras da madeira, são dados por:

$$
\mathrm{f}_{\mathrm{h}, \alpha, \mathrm{k}}=\frac{\mathrm{f}_{\mathrm{h}, 0 \mathrm{k}}}{\mathrm{k}_{90} \operatorname{sen}^{2} \alpha+\cos ^{2} \alpha}
$$

em que:

$\mathrm{f}_{\mathrm{h}, 0, \mathrm{k}}=0,082 \cdot(1-0,01 \mathrm{~d}) \cdot \rho_{\mathrm{k}} \quad \mathrm{N} / \mathrm{mm}^{2}$;

$\mathrm{k}_{90}=1,35+0,015 \mathrm{~d}$ para madeiras macias

$\mathrm{k}_{90}=0,90+0,015 \mathrm{~d}$ para madeiras duras

com $\rho_{\mathrm{k}}$ dado em $\mathrm{kg} / \mathrm{m} 3$ e d em mm. 
O EUROCODE 5 (1999) admite para o valor característico do momento de escoamento do aço $\mathbf{M}_{\mathrm{y}, \mathrm{k}}$, quando usado parafuso de aço circular, a seguinte expressão:

$\mathrm{M}_{\mathrm{y}, \mathrm{k}}=0,8 \frac{\mathrm{f}_{\mathrm{u}, \mathrm{k}} \cdot \mathrm{d}^{3}}{6}$

em que $\mathrm{f}_{\mathrm{u}, \mathrm{k}}$ é a resistência característica à tração

\section{6 - Métodos de Ensaio}

Segundo a NBR 7190/97, a resistência é determinada convencionalmente pela máxima tensão, que pode ser aplicada a corpos-de-prova isentos de defeitos do material considerado, até o aparecimento de fenômenos particulares de comportamento, além dos quais há restrição de emprego do material em elementos estruturais. Define ainda que a rigidez dos materiais é medida pelo valor médio do módulo de elasticidade, determinado na fase de comportamento elástico-linear.

\subsection{1 - Ligações}

\subsubsection{1 - Ligações por pinos metálicos, segundo a NBR 7190/97}

Os corpos-de-prova de ligações devem ser fabricados com peças de madeira isentas de defeitos, de preferência com umidade entre $10 \%$ e $20 \%$, extraídos de regiões afastadas das extremidades de uma mesma peça do lote, conforme mostrado na figura 10 . 


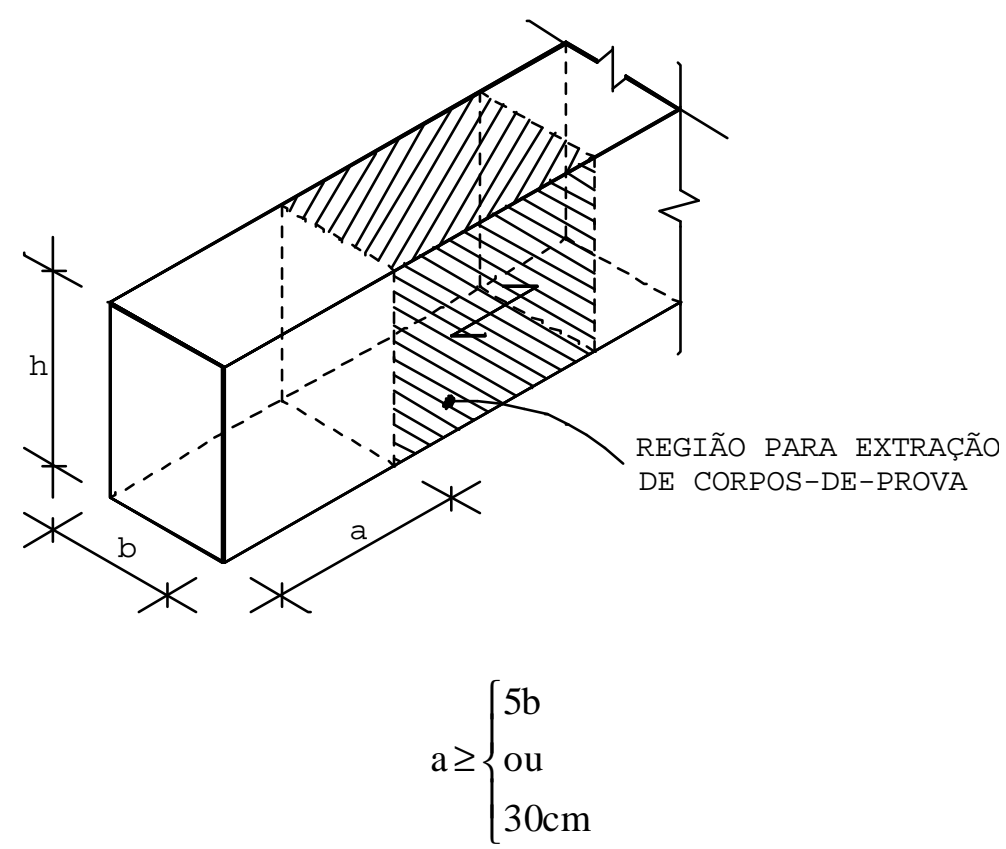

FIGURA 10 - Esquema para extração da madeira para corpos-de-prova das ligações - fonte: NBR 7190/97

Segundo a norma brasileira, os parafusos devem atender às especificações da norma para estruturas metálicas NBR8800 - Projeto e Execução de Estruturas de Aço de Edifícios - Métodos dos Estados Limites - e de preferência com diâmetros de $10 \mathrm{~mm}, 12,5 \mathrm{~mm}$ ou $16 \mathrm{~mm}$, enquanto os pregos devem ser de aço 1011-B e as dimensões devem atender à NBR 6627 - Pregos Comuns e Arestas de Aço para Madeiras.

Na montagem do corpo-de-prova, a metade dos pinos deve ser instalada em uma de suas faces do corpo-de-prova e a outra metade na face oposta. O espaçamento mínimo entre os pinos deve seguir o disposto na norma, descrita neste trabalho no item 2.5.1.

Os pregos devem ser cravados na madeira com pré-furação feita por broca com diâmetro mínimo de acordo com as especificações da norma, assim como os parafusos, ambos descritos no item 2.3 deste trabalho. 
Os comprimentos da base de medida mostrados na figura 11 são os seguintes:

- direção paralela às fibras: $\mathrm{L}_{0}=2(7 \mathrm{~d})+\mathrm{n}(\mathrm{a})$;

- direção normal às fibras: $\mathrm{L}_{0}=(7 \mathrm{~d})+(4 d)+n(a)$.

em que,

$\mathrm{L}_{0}=$ comprimento da base de medida, em milímetros (mm);

$\mathrm{d}=$ diâmetro do pino, em milímetros (mm);

$\mathrm{n}$ = número de espaçamentos entre os pinos segundo a direção paralela ao esforço e

a = espaçamento entre pinos, medido de eixo a eixo na direção paralela ao esforço, em milímetros (mm).
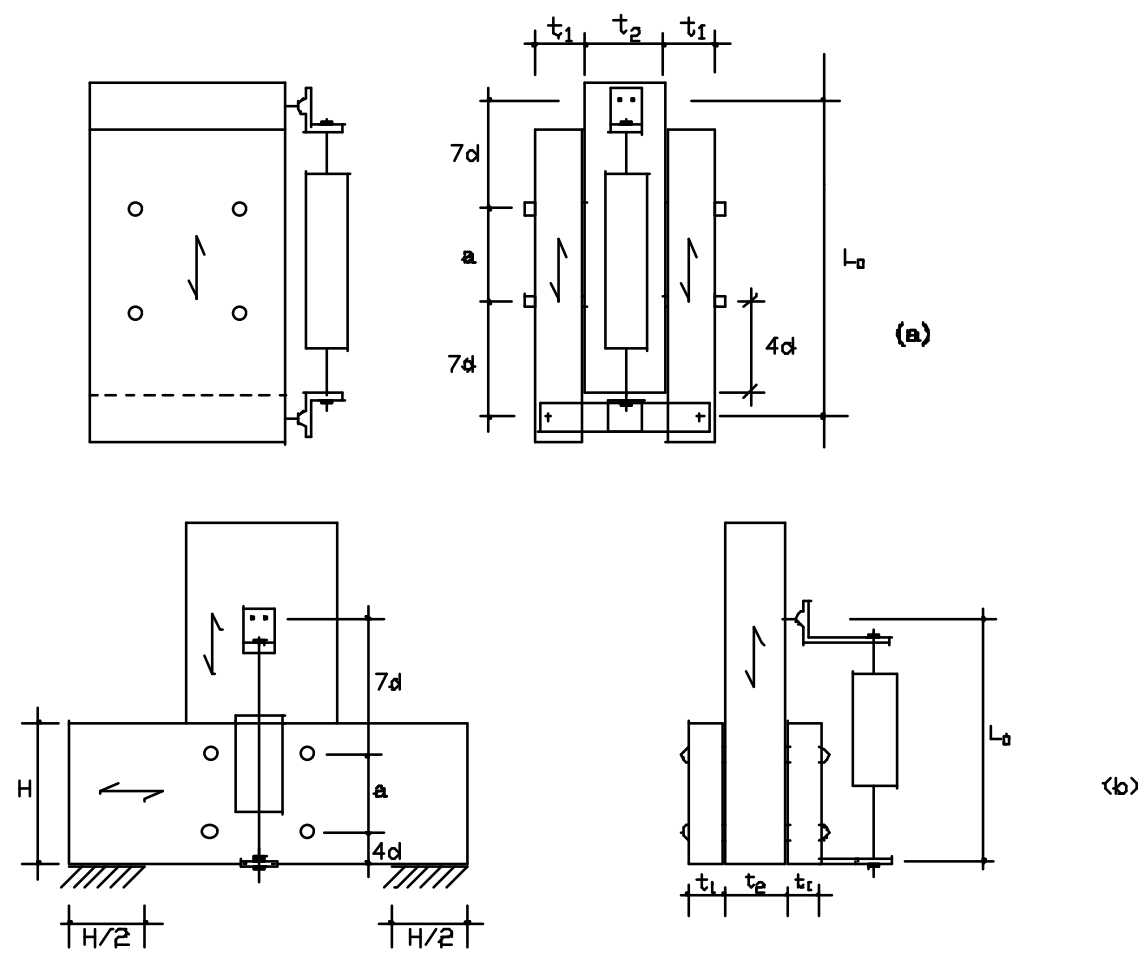

FIGURA 11 - Corpos-de-prova para ensaios de ligações mecânicas

a) resistência na direção paralela às fibras;

b) resistência na direção normal às fibras. 
Para a determinação da resistência das ligações, o carregamento deve ser aplicado de acordo com o diagrama da figura 13. Para isso, deve-se, inicialmente, determinar a força limite da ligação pelo ensaio de um corpo-de-prova.

A determinação dessa força limite deve ser feita por carregamentos e descarregamentos sucessivos do corpo-de-prova, até que seja alcançada uma deformação específica residual total de 5\%o. Em cada ciclo, o carregamento deve ser aumentado de forma a se obter um incremento de deslizamento de $0,1 \mathrm{~mm}$ e, em seguida, reduzido a $0,5 \mathrm{kN}$. O tempo de carregamento e descarregamento é de 30 segundos para cada ciclo, conforme mostrado na figura 12.

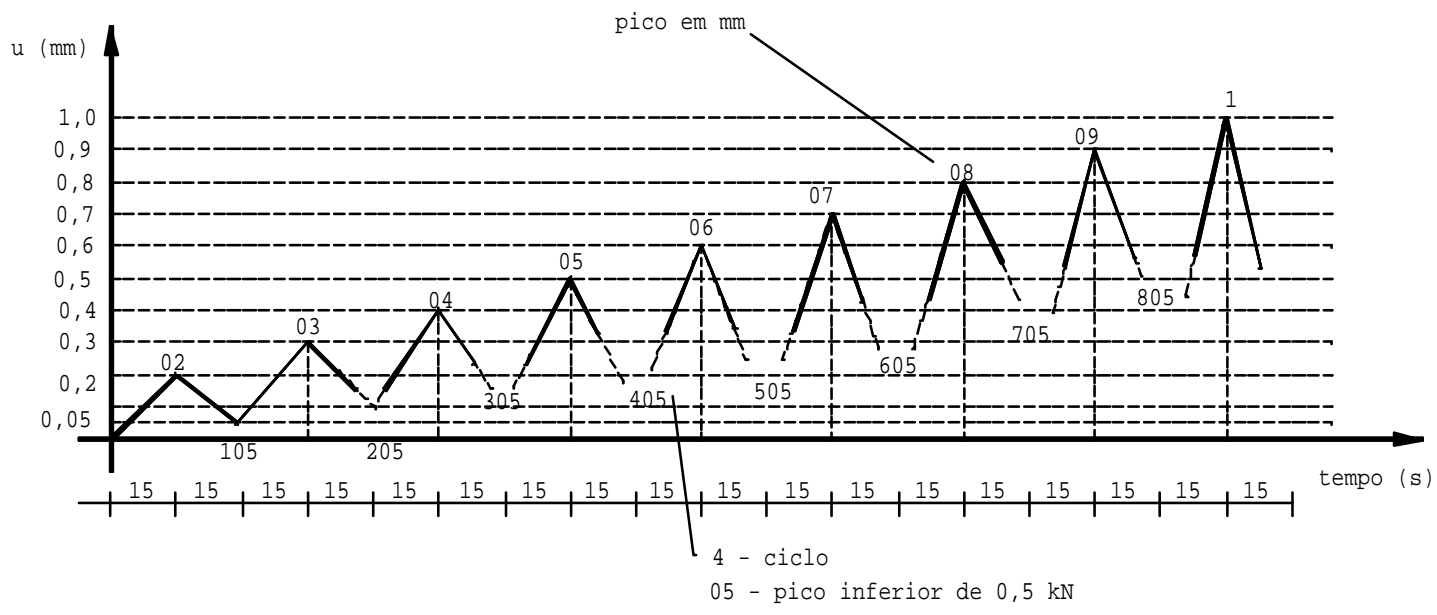

FIGURA 12 - Diagrama de carregamentos e descarregamentos sucessivos para determinação da força limite das ligações

Todos os demais corpos-de-prova da amostra devem ser ensaiados de acordo com o carregamento estabelecido no diagrama da figura 13. Se, para mais de dois corposde-prova, houver uma diferença de mais de $20 \%$ em relação à força limite determinada no primeiro ensaio da amostra, a força limite deve ser reajustada em novo ensaio. 


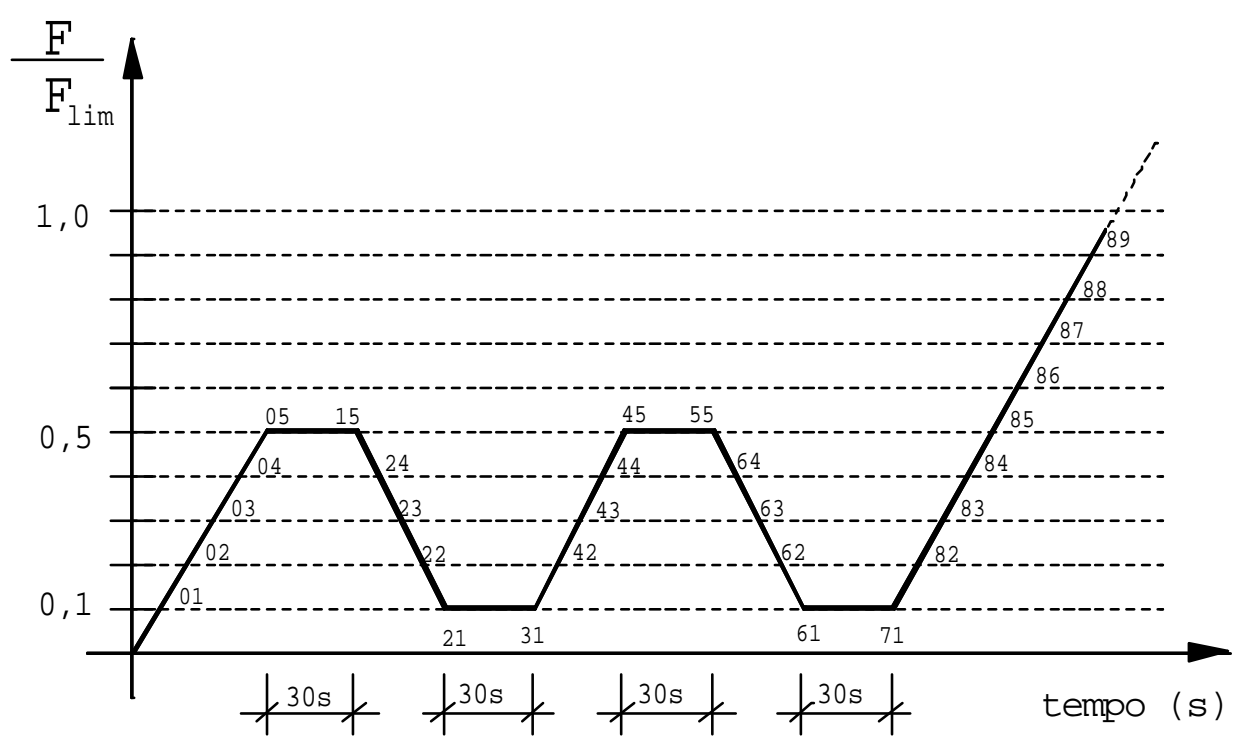

FIGURA 13 - Diagrama de carregamento - fonte: NBR 7190/97

Segundo a norma brasileira NBR 7190/97, a resistência R de uma ligação é determinada convencionalmente pela força aplicada a um corpo-de-prova padronizado, que provoca, na ligação, uma deformação específica residual de $2 \%$, como mostrado na figura 14 .

Para essa finalidade, a deformação específica residual da ligação é medida a partir da interseção com o eixo das deformações da reta secante, definida pelos valores $\left(\mathrm{F}_{71} ; \boldsymbol{\varepsilon}_{71}\right)$ e $\left(\mathrm{F}_{85} ; \boldsymbol{\varepsilon}_{85}\right)$ do diagrama força deformação específica, mostrados na figura 14 e determinados pelos pontos 71 e 85 do diagrama de carregamento da figura 13. A partir dessa interseção constróise a paralela afastada de $2 \%$ até sua interseção com o diagrama força $\times$ deformação específica da ligação. A força correspondente assim determinada é definida como a resistência $\mathrm{R}$ da ligação, conforme mostrado na mesma figura 14. 


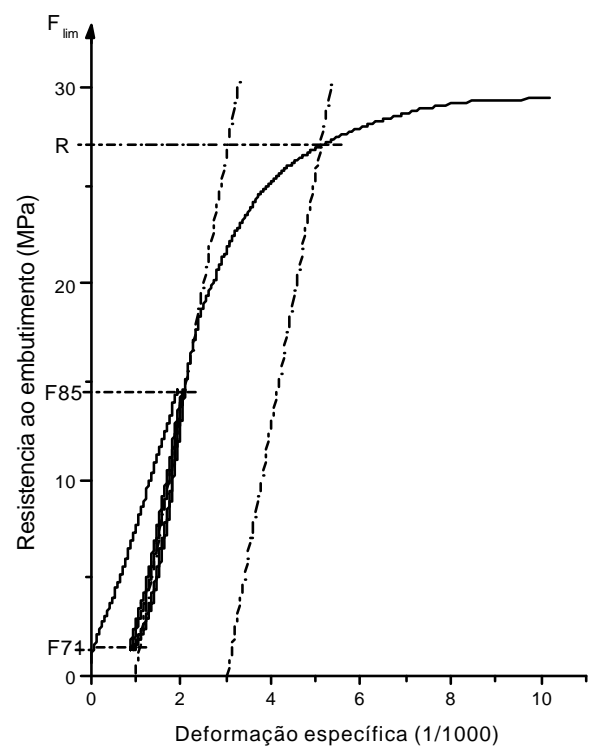

\section{FIGURA 14 - Diagrama força deformação específica da ligação de acordo com a} NBR 7190/97

A deformação específica da ligação $\varepsilon$ é definida pela razão entre o deslocamento relativo $\Delta \mathrm{u}$ e o comprimento da base de medida padronizada $\left(\mathrm{L}_{0}\right)$ mostrada na figura 11, sendo dada por:

$$
\varepsilon=\frac{\Delta u}{L_{0}}
$$

\subsubsection{2 - Ligações com juntas mecânicas, segundo o EN 26891}

Segundo o EN 26891 (1991), ao executar ensaios com ligações mecânicas em estruturas de madeira carregadas estaticamente, deve-se dar atenção ao condicionamento da madeira, antes de fabricar os corpos-de-prova, e às condições da ligação em toda a sua totalidade, antes dos testes. As condições de ensaio devem corresponder de maneira realística às condições da ligação nas estruturas assim como 
a influência do teor de umidade nas propriedades de resistência da madeira, a ocorrência de rachaduras etc., devido à retração.

Para realização dos ensaios, é recomendado o uso de equipamentos que permitam leituras de força com precisão de $1 \%$ da força estimada $\left(\mathrm{F}_{\mathrm{est}}\right)$ ou mais. A leitura do deslizamento deve ser feita com precisão de $1 \%$ ou mais e, para um deslizamento menor que $2 \mathrm{~mm}$, a precisão deve ser de $\pm 0,02 \mathrm{~mm}$. O Equipamento deve garantir que excentricidade, torção etc., não influenciem os resultados.

Para determinar a força estimada $\left(\mathrm{F}_{\text {est }}\right)$, esta deve ser obtida por experimentação preliminar. Sempre que ocorrer um desvio de $20 \%$ da $\mathrm{F}_{\text {est }}$ ela deve ser reavaliada nos testes subsequentes. Neste caso, o valor do deslizamento inicial $\left(\mathrm{v}_{\mathrm{i}}=\mathrm{v}_{04}\right)$ e do módulo de deslizamento $\left(\mathrm{k}_{\mathrm{s}}=0,4 \mathrm{~F}_{\mathrm{es}} \mathrm{/} / \mathrm{v}_{\mathrm{i}}\right)$ deve ser ajustado ao novo valor de $\mathrm{F}_{\text {est. }}$

Conforme mostra a figura 15, o carregamento deve ser aplicado até atingir o ponto de 0,4 $\mathrm{F}_{\text {est }}$ mantendo-a por 30 segundos. A seguir, deverá ser reduzido até atingir o valor correspondente a $0,1 \mathrm{~F}_{\text {est }}$, mantendo-a assim por mais 30 segundos. Logo após, a força deverá ser elevada até a força última ou até que um deslizamento de $15 \mathrm{~mm}$ seja atingido.

A velocidade de aplicação da força ou deslizamento até o ponto de $0,7 \mathrm{~F}_{\text {est }}$ deve ser de $0,2 \mathrm{~F}_{\text {est }}$ por minuto $( \pm 25 \%$ ). Após 0,7 Fest, a uma taxa constante de deslizamento, o carregamento deverá ser ajustado para que a força última, ou deslizamento de 15 $\mathrm{mm}$, ocorra dentro de um tempo adicional de 3 a 5 minutos (o tempo total do ensaio deve ser de 10 a 15 minutos). O ensaio poderá ser interrompido quando a força última for atingida ou quando o deslizamento chegar aos $15 \mathrm{~mm}$.

As medidas de deslizamento $v_{01}, v_{04}, v_{14}, v_{11}, v_{21}, v_{24}, v_{26}$ e $v_{28}$, mostradas na figura 16, devem ser registradas para cada corpo-de-prova. O deslizamento à força máxima, $\mathrm{F}_{\max }$, também deve ser registrado.

Quando o diagrama força $\mathrm{x}$ deslizamento não estiver disponível, as medidas de deslizamento devem ser tomadas a cada $0,1 \mathrm{~F}_{\text {est }}$ de incremento da força. 
O menor valor entre a força última e a força que provoca o deslizamento de $15 \mathrm{~mm}$

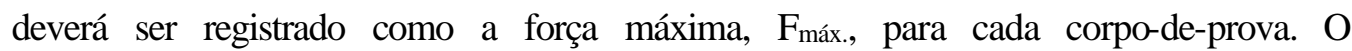
método de ensaios D1761 - Standard Methods of Testing Mechanical Fasteners in Wood, da American Society for Testing and Materials - ASTM (1971) - também estabelece, nos seus procedimentos, que seja tomado o menor entre esses dois valores apresentados no EUROCODE.

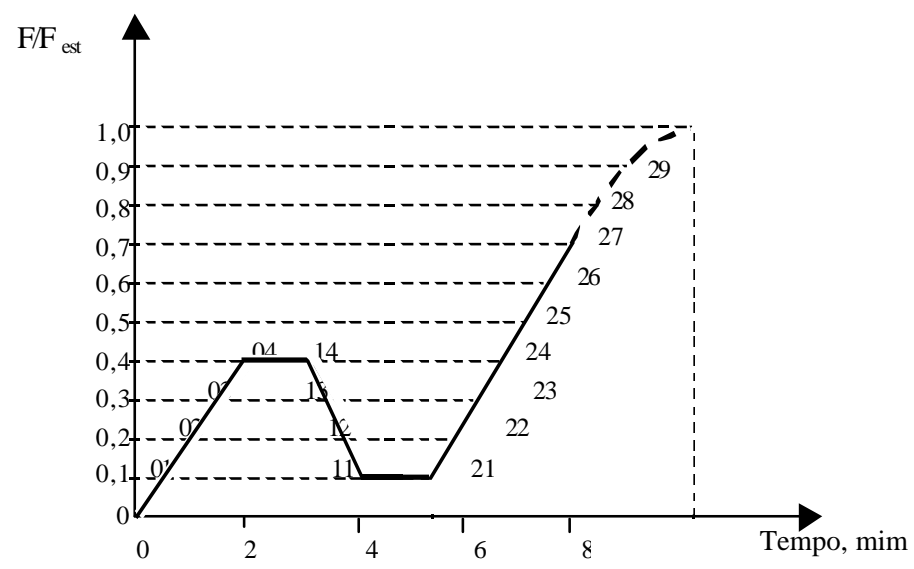

FIGURA 15 - Método de carregamento segundo o EN 26891 - fonte: EN 26891 (1991)

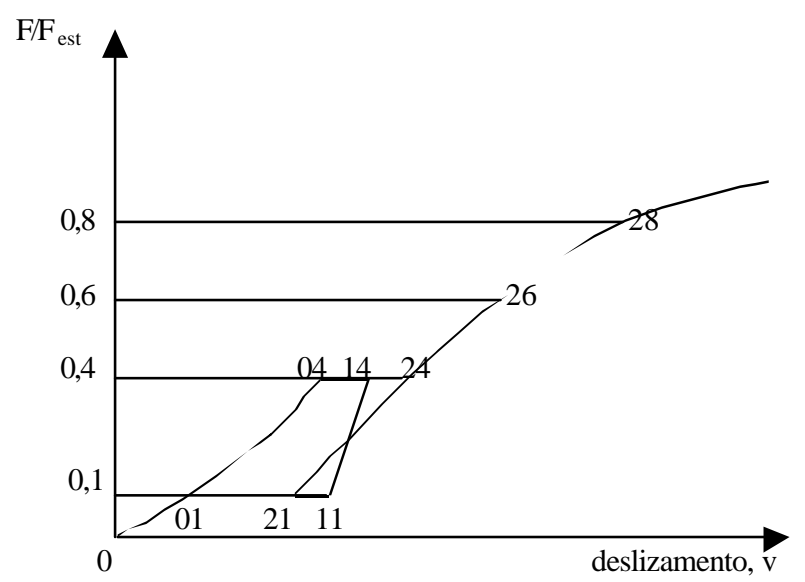

FIGURA 16 - Força x deformação : curva e calibração ideal segundo a EN 26891 - fonte:EN 26891 (1991) 


\subsection{2 - Ensaios de Embutimento}

\subsubsection{1 - Método da NBR 7190/97}

No anexo B da NBR 7190, a resistência de embutimento $\left(f_{w e}\right.$ ou $f_{e}$ ) é definida pela razão entre a força $\mathrm{F}_{\mathrm{e}}$ que causa a deformação específica residual de $2 \%$, e a área de embutimento do pino $A_{e}=t d$, determinada no ensaio do corpo-de-prova mostrado na figura 17.

Assim, as resistências de embutimento nas direções paralela e normal às fibras, $\mathrm{f}_{0} \mathrm{e}$ $\mathrm{f}_{\mathrm{e} 900}$, são determinadas no diagrama tensão $\times$ deformação específica de embutimento mostrado na figura 18, sendo essas resistências dadas pelas expressões apresentadas no item 2.5.1.
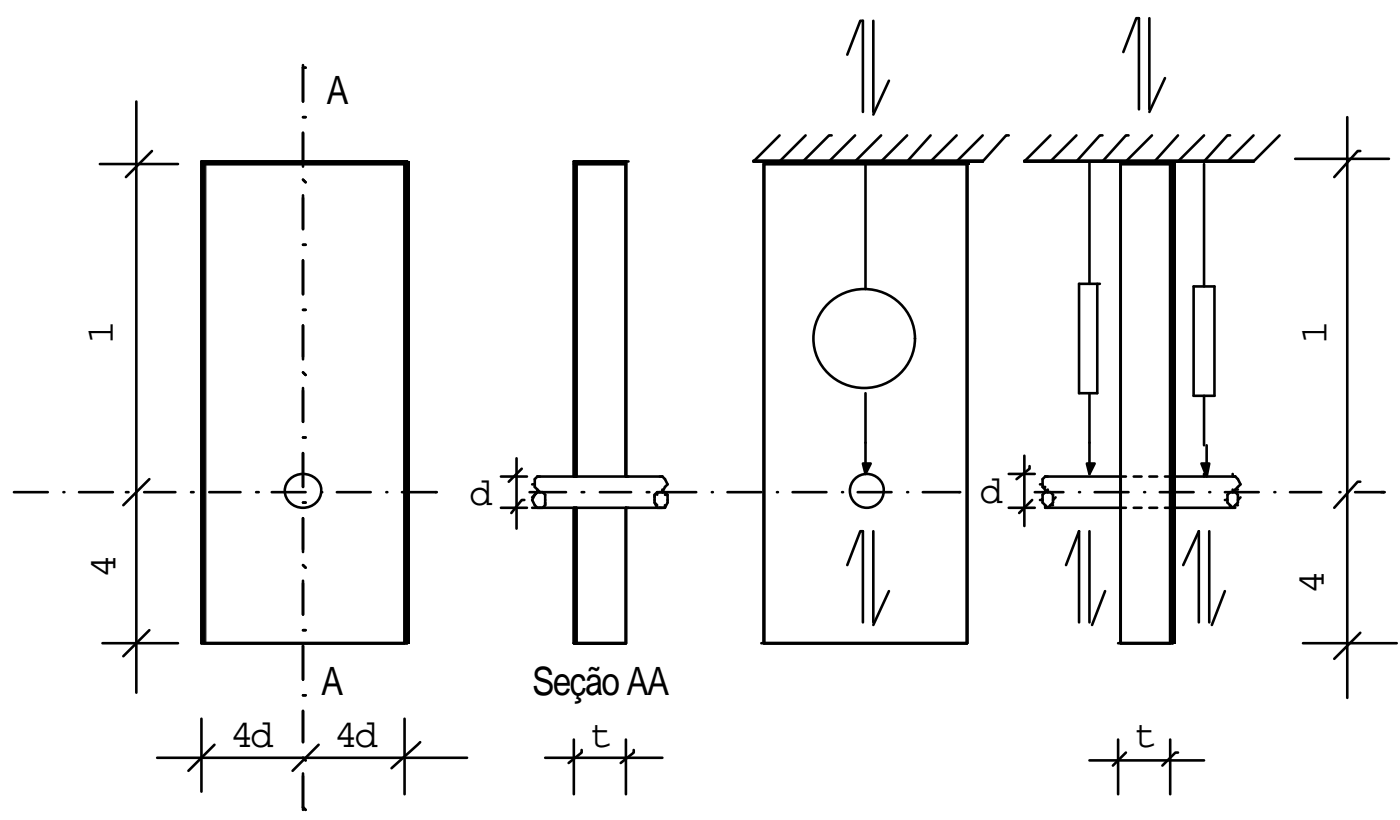

FIGURA 17 - Corpo-de-prova para ensaio de embutimento - fonte NBR 7190/97 
O corpo-de-prova, para caracterizar a resistência de embutimento na direção paralela às fibras, deve ter forma prismática, de seção retangular de $8 \mathrm{~d}$ de largura e $2 \mathrm{~d}$ de espessura correspondentes a $\beta=\mathrm{t} / \mathrm{d}=2$, com comprimento ao longo das fibras de $18 \mathrm{~d}$. Para a resistência de embutimento na direção normal às fibras, o corpo-de-prova deve ter as mesmas dimensões anteriores, tomando-se o eixo maior na direção normal às fibras da madeira.

Nos procedimentos adotados pela NBR 7190/97 para os ensaios de embutimento, as medidas do deslocamento relativo devem ser feitas com um comprimento da base de medida de $14 \mathrm{~d}$ e deve ser estimada a resistência $\left(\mathrm{f}_{\mathrm{e} \theta \text {,est }}\right.$ ) por meio do ensaio destrutivo de um corpo-de-prova gêmeo, selecionado da mesma amostra a ser investigada.

Conhecida a resistência de embutimento estimada, $\mathrm{f}_{\text {et,est }}$, o carregamento deve ser aplicado de acordo com o procedimento constante no diagrama da figura 19. A taxa de carregamento deve ser de $10 \mathrm{MPa}$ por minuto.

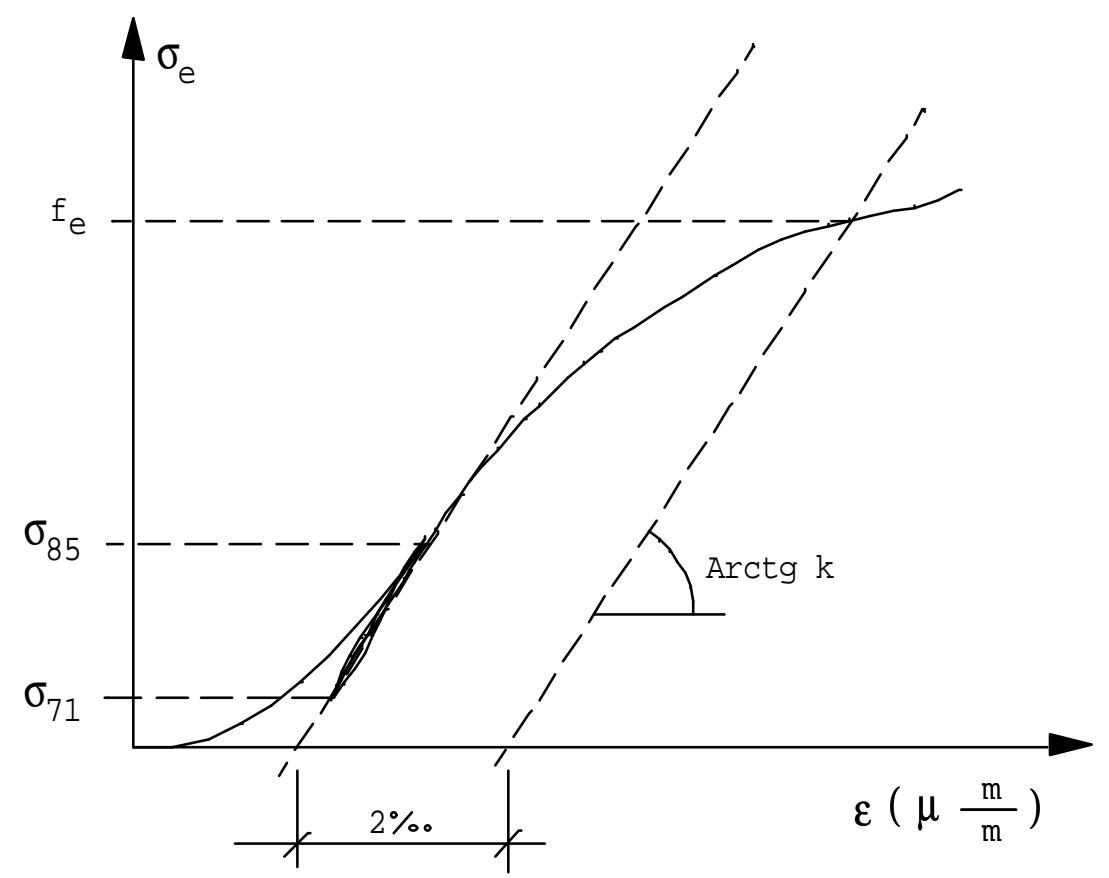

FIGURA 18 - Diagrama tensão X deformação específica de embutimento 
Os registros das forças e das deformações devem ser feitos para cada ponto do diagrama de carregamento mostrado na figura 19, e os ensaios devem ser feitos nas direções paralela e normal às fibras $\left(\theta=0^{\circ}\right.$ e $\left.90^{\circ}\right)$.

Segundo a NBR 7190/97, os resultados das resistências de embutimento nas direções paralela e normal às fibras devem ser apresentados com valores característicos, acompanhados dos respectivos teores de umidade. Estes valores devem ser apresentados em relatórios técnicos especificados na seção 4 dessa norma.

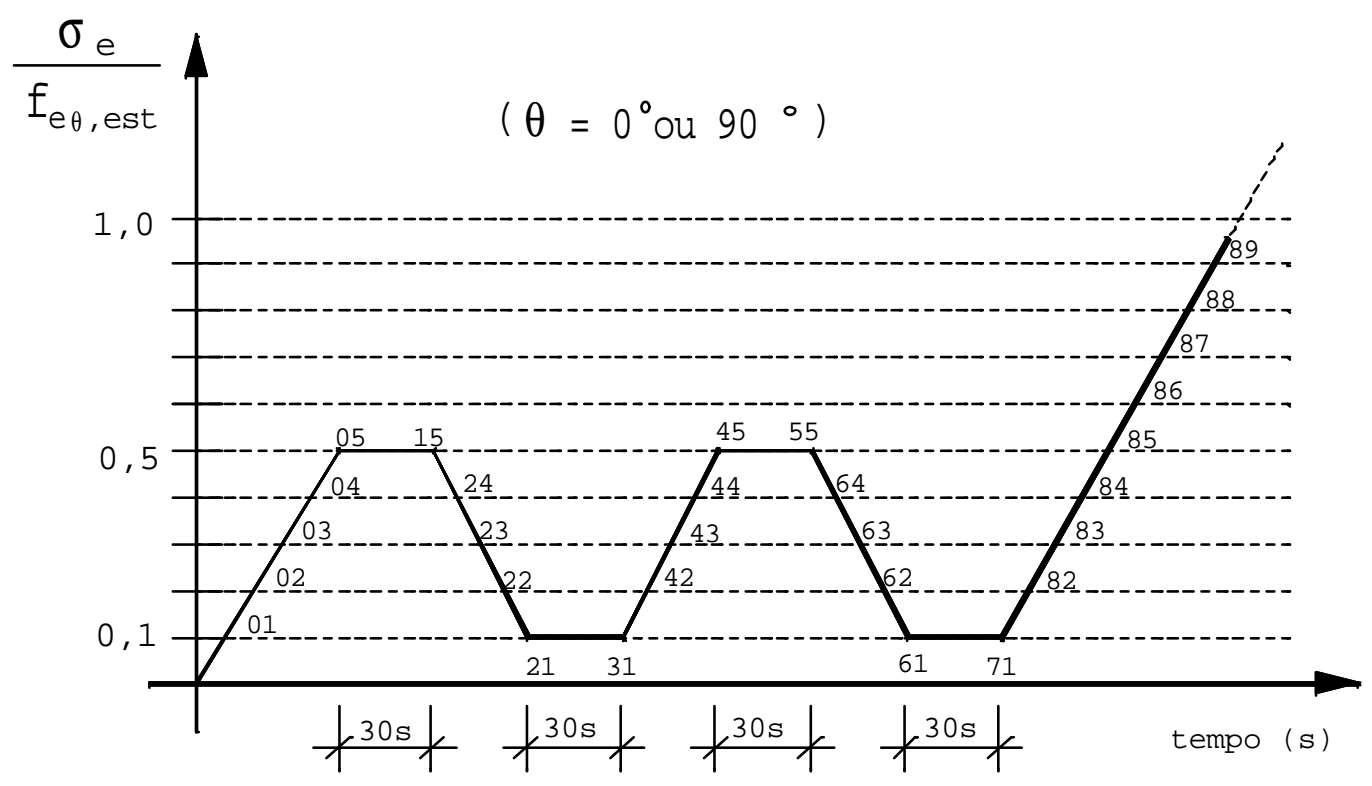

FIGURA 19- Diagrama de carregamento para ensaio de embutimento - fonte NBR 7190/97

\subsubsection{2 - Método do Eurocode}

Segundo a prEN 383 (1993), a determinação experimental da resistência ao embutimento para ligações com um único pino é definida pela relação entre a força máxima resistida pelo corpo-de-prova $\left(\mathrm{F}_{\max }\right)$ ou a força que provoca o deslocamento relativo entre o parafuso e a madeira de $5 \mathrm{~mm}$ ( o menor dos dois valores) e o 
produto do diâmetro d do prego ou parafuso pela espessura da peça de madeira (t), ou seja,

$$
\mathrm{f}_{\mathrm{e}}=\frac{\mathrm{F}_{\max }}{\mathrm{d} \cdot \mathrm{t}} \quad \text { ou } \quad \mathrm{f}_{\mathrm{e}}=\frac{\mathrm{F}_{5 \mathrm{~mm}}}{\mathrm{~d} \cdot \mathrm{t}}
$$

O coeficiente de rigidez de embutimento $\left(\mathrm{K}_{\text {ser }}\right)$, segundo o prEN 383, é definido com base na inclinação da reta secante à curva força $\mathrm{x}$ deslocamento para os pontos de força zero e $40 \%$ da força de embutimento estimada para a ligação $\left(0,4 \mathrm{~F}_{\mathrm{e}, \text { est }}\right)$ e é calculado pela equação

$$
\mathrm{k}_{\mathrm{ser}}=\frac{0,4 \mathrm{~F}_{\mathrm{e}, \mathrm{est}}}{\mathrm{u}_{\mathrm{i}, \mathrm{mod}}}
$$

em que $u_{i, \text { mod }}$ é o deslizamento corrigido pela inclinação da secante dos pontos 01 e 04 do diagrama da figura 20, sendo este dado pela expressão

$$
\mathrm{u}_{\mathrm{i}, \bmod }=\frac{4}{3}\left(\mathrm{u}_{04}-\mathrm{u}_{01}\right)
$$

em que $u_{04}$ e $u_{01}$ são os deslocamentos referentes aos pontos 04 e 01 respectivamente da mesma figura.

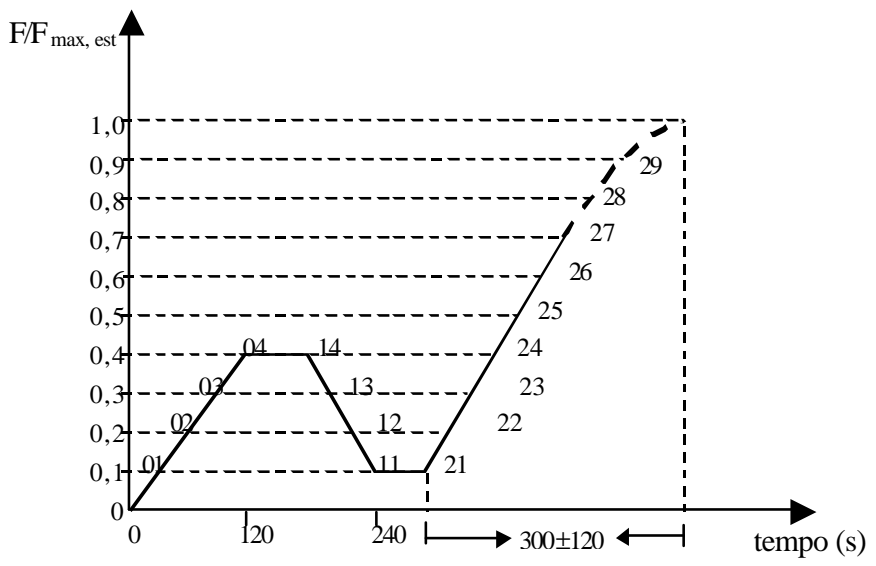

FIGURA 20 - Diagrama de carregamento para ensaios de embutimento de acordo com a EN 383 - fonte prEN 383 (1993) 
Os corpos-de-prova devem ser condicionados até atingir massa constante em ambiente com a umidade relativa do ar de $65 \% \pm 5 \%$ e a temperatura de $20^{\circ} \mathrm{C} \pm 2^{\circ} \mathrm{C}$. $\mathrm{Na}$ montagem, os dispositivos utilizados não devem provocar atrito entre si e o corpo-de-prova, assegurando não haver influência nos resultados.

O prEN 383 especifica que, na aplicação da força, esta deve ser elevada até $0,4 \mathrm{~F}_{\text {máx,est }}$ e mantida por 30 segundos. Então, deve ser reduzida a $0,1 \mathrm{~F}_{\text {máx,est }}$ e mantida por 30 segundos. Na sequiência, a força deve ser aumentada até que o valor máximo dessa força seja atingido, ou até quando a deformação atingir $5 \mathrm{~mm}$ a mais do que a deformação inicial do corpo-de-prova. A força deve ser aumentada ou diminuída na mesma razão carregamento $\mathrm{x}$ tempo de forma que a força máxima deva ser atingida com $300 \pm 120$ segundos, conforme figura 20.

\subsection{3 - Ensaio de compressão paralela às fibras segundo a NBR 7190/97}

Este ensaio tem por finalidade determinar a resistência e a rigidez à compressão paralela às fibras da madeira, utilizando corpos-de-prova montados conforme mostra a figura 21 .

A resistência à compressão paralela às fibras $\left(\mathrm{f}_{\mathrm{wc}, 0}\right.$ ou $\left.\mathrm{f}_{\mathrm{c}, 0}\right)$ é dada pela máxima tensão de compressão, que pode atuar em um corpo-de-prova com seção transversal quadrada de 5,0 cm de lado e $15,0 \mathrm{~cm}$ de comprimento, sendo dada por:

$$
\mathrm{f}_{\mathrm{c} 0}=\frac{\mathrm{F}_{\mathrm{c} 0, \max }}{\mathrm{A}}
$$

em que $\mathrm{F}_{\mathrm{c} 0 \text {,max }}$ é a máxima força de compressão aplicada ao corpo-de-prova durante o ensaio. 
A rigidez da madeira na direção paralela às fibras deve ser determinada por seu módulo de elasticidade, obtido do trecho linear do diagrama tensão deformação específica, como indicado na figura B.4, na pagina 51 do anexo B da NBR 7190/97.

Para essa finalidade, o módulo de elasticidade deve ser determinado pela inclinação da reta secante à curva tensão deformação, definida pelos pontos $\left(\sigma_{10 \%} ; \varepsilon_{10 \%}\right)$ e $\left(\sigma_{50 \%}\right.$; $\varepsilon_{50 \%)}$, correspondentes respectivamente a $10 \%$ e $50 \%$ da resistência a compressão paralela às fibras medida no ensaio, sendo dado por:

$$
E_{c 0}=\frac{\sigma_{50 \%}-\sigma_{10 \%}}{\varepsilon_{50 \%}-\varepsilon_{10 \%}}
$$

em que, $\sigma_{10 \%}$ e $\sigma_{50 \%}$ são as tensões de compressão correspondentes a $10 \%$ e $50 \%$ da resistência $\mathrm{f}_{\mathrm{c} 0}$, representadas pelos pontos 71 e 85 do diagrama de carregamento, conforme figura B.7, na página 53 do anexo da NBR 7190/97. $\varepsilon_{10 \%}$ e $\varepsilon_{50 \%}$ são as deformações específicas medidas no corpo-de-prova, correspondentes às tensões de $\sigma_{10 \%}$ e $\sigma_{50 \%}$.

Os corpos-de-prova devem ser isentos de defeitos e retirados de regiões afastadas das extremidades das peças em, pelo menos, cinco vezes a menor dimensão da seção transversal da peça considerada, mas nunca inferior a $30 \mathrm{~cm}$, conforme estabelece a norma.

Para a determinação das propriedades de resistência e de rigidez, as medidas dos lados do corpo-de-prova devem ser feitas com precisão de $0,1 \mathrm{~mm}$, o ajuste deste na máquina de ensaio deve ser feito utilizando-se uma rótula entre o atuador e o corpode-prova.

A resistência deve ser determinada com carregamento monotônico crescente com uma taxa em torno de 10MPa por minuto. 
Para a determinação do módulo de elasticidade, devem ser feitas medidas de deformações em pelo menos duas faces opostas do corpo-de-prova, podendo ser utilizados relógios comparadores, com precisão de 0,001mm, fixados por meio de duas cantoneiras metálicas pregadas no corpo-de-prova. As medidas das deformações específicas devem ser feitas com extensômetros com precisão mínima de $50 \mu \mathrm{m} / \mathrm{m}$ (micrômetro por metro);

Para determinação da rigidez, a resistência da madeira deve ser estimada $\left(\mathrm{f}_{\mathrm{c} 0 \text {,est }}\right)$ pelo ensaio destrutivo de um corpo-de-prova selecionado da mesma amostra a ser

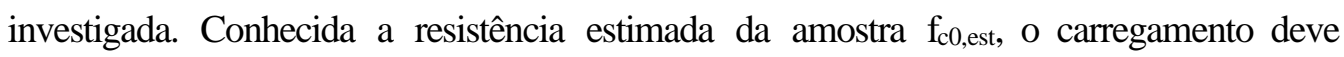
ser aplicado com dois ciclos de força e descarga, de acordo com o procedimento especificado no diagrama de carregamento da figura B.7 da norma brasileira. A taxa de carregamento deve ser de $10 \mathrm{MPa}$ por minuto. Os registros das forças e das deformações devem ser feitos para cada ponto do diagrama de carregamento mostrado na mesma figura B.7.
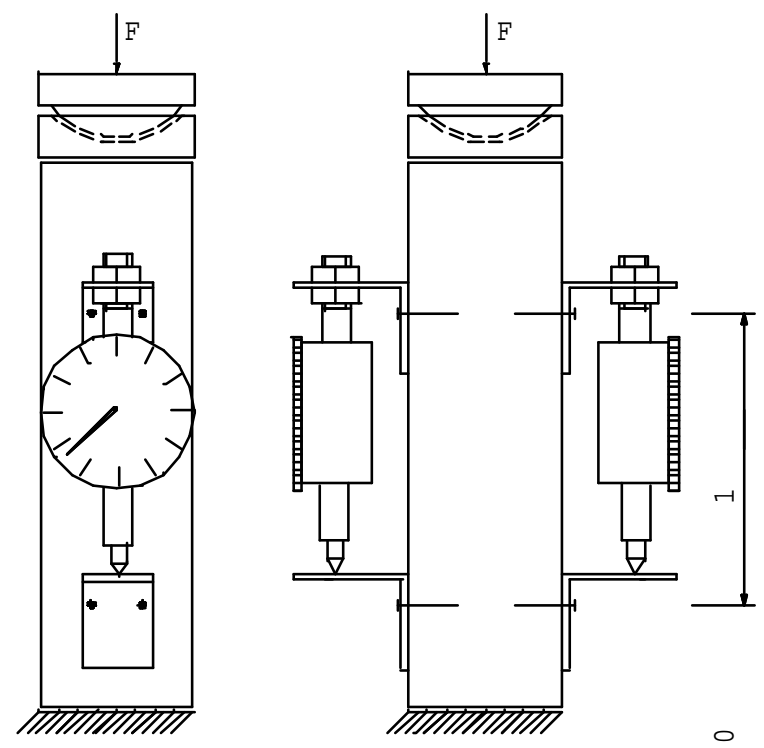

FIGURA 21 - Arranjo de ensaio para compressão paralela às fibras, com instrumentação baseada em relógios comparadores- fonte NBR 7190/97 


\subsection{4 - Teor de umidade - NBR 7190/97}

O teor de umidade da madeira corresponde à relação entre a massa da água nela contida e a massa da madeira seca, dado por

$$
U(\%)=\frac{m_{i}-m_{s}}{m_{s}} \times 100
$$

em que m é a massa inicial da madeira, em g e m é a massa da madeira seca, em g.

O tamanho da amostra e os critérios de extração dos corpos-de-prova devem ser os mesmos estabelecidos em 2.6.3, devendo ter seção transversal retangular, com dimensões nominais de $2,0 \mathrm{~cm} \times 3,0 \mathrm{~cm}$ e comprimento, ao longo das fibras, de 5,0 $\mathrm{cm}$.

$\mathrm{Na}$ fabricação dos corpos-de-prova, devem ser utilizadas ferramentas afiadas para ser evitada a chamada "queima" de suas faces, que pode provocar uma perda de água imediata, prejudicial à determinação da real umidade da amostra.

\section{7- Conclusões sobre a revisão bibliográfica}

Observa-se que muitos itens são levartados e, dentre as fontes consultadas, fica clara a importância em se estudar o real comportamento das ligações utilizando recursos experimentais que possam representar as reais situações das estruturas. A seguir, são apresentados alguns pontos encontrados na bibliografia estudada que merecem ser destacados pela importância que apresentam em relação às questões da resistência das ligações de madeira com pinos metálicos:

- Atualmente, normas, como a DIN 1052, o EUROCODE 5 e a NBR 7190/97, utilizam o conceito do comportamento plástico para a formulação da resistência das ligações por pinos, que depende da resistência ao embutimento da madeira e da resistência do pino à flexão. Estudos mais recentes mostram que deve ser 
considerada a fratura da madeira para obter resultados mais confiáveis no dimensionamento dessas ligações.

- A ruptura da ligação pode ocorrer pela flexão do pino, pelo embutimento do pino na madeira, pelo fendilhamento da madeira ou pela combinação de embutimento e fendilhamento.

- Os modelos e critérios na bibliografia diferem dos da NBR 7190/97 em que é apresentada uma única formulação para expressar a resistência da ligação para um e para dois planos de corte. Também diferem os valores convencionados para a resistência da ligação e o embutimento da madeira obtidos experimentalmente.

- Apesar de baseados na mesma formulação, os critérios da NBR e EUROCODE diferem significativamente no caso da ocorrência do embutimento, sendo a resistência da ligação pelo critério do EUROCODE muito maior que o valor estabelecido no critério da NBR. 


\section{3 - MATERIAIS E MÉTODOS}

Para a realização deste trabalho, duas etapas são consideradas. A primeira remete à utilização dos resultados de experimentos realizados no Laboratório de Madeiras e Estruturas de Madeira, Departamento de Engenharia de Estruturas, da Escola de Engenharia de São Carlos, da Universidade de São Paulo (LaMEM - SET - EESC USP), referente ao processo de revisão da atual norma brasileira. Inicialmente, é apresentada a análise dos resultados feita na época da realização dos ensaios, que é anterior à publicação do texto da norma NBR 7190/97. Na sequiência, os dados desses ensaios são utilizados para uma reavaliação da resistência e rigidez das ligações e para a análise comparativa aos valores obtidos pelo critério de dimensionamento teórico da NBR 7190/97.

$\mathrm{Na}$ segunda etapa do presente trabalho, com a realização de ensaios complementares, serão identificados e analisados os resultados de ensaios de ligações, e obtidos os dados para a caracterização da espécie de madeira Pinus Elliottii (Pinus elliottii var. elliottii), Cupiúba (Goupia glabra) e Jatobá (Hymenaea spp), incluindo-se a resistência ao embutimento. Os resultados obtidos serão comparados com os valores obtidos pelo critério de dimensionamento da NBR 7190/97.

\section{1 - Ensaios realizados pela equipe do LaMEM}

A elaboração da NBR 7190/97 partiu de estudo temático e projeto elaborado por um corpo de docentes da USP composto pelos professores doutores Péricles Brasiliense Fusco (Politécnica), Carlito Calil Júnior (São Carlos) e Pedro Afonso de Oliveira Almeida (Politécnica). As experimentações em ligações de madeira com pinos 
metálicos e os ensaios de caracterização das espécies de madeira foram coordenados pelo professor Dr. Carlito Calil Júnior com contribuição direta dos engenheiros civis Lívio Túlio Baraldi e Marta Cristina de Jesus Albuquerque Nogueira.

A descrição dos ensaios baseia-se nas informações coletadas junto aos realizadores do trabalho e nas suas publicações disponibilizadas por BARALDI (1996) e FUSCO (1995). Os ensaios foram realizados em 1995 para subsidiar a calibração da NBR $7190 / 97$.

\subsection{1 - Materiais utilizados}

Foram utilizadas 5 (cinco) espécies diferentes de madeira, sendo 3 (três) nativas e 2 (duas) de reflorestamento, estando elas contidas em 4 (quatro) classes de resistência apresentadas por FUSCO (1995) no Projeto da nova norma brasileira - NBR 7190.

As madeiras utilizadas para os ensaios foram das seguintes espécies: Cupiúba (Goupia glabra), Garapa (Apuleia leiocarpa), Jatobá (Hymenaea spp), Pinus Elliottii (Pinus elliottii var. elliottii) e Eucalipto Citriodora (Eucalyptus citriodora).

As peças de madeira foram inspecionadas para garantir a ausência de defeitos e caracterizadas para obtenção das seguintes propriedades: densidade; resistência ao cisalhamento; resistência à tração normal às fibras; resistência à tração paralela às fibras; resistência à compressão normal às fibras; resistência à compressão paralela às fibras; módulo de elasticidade paralelo às fibras e módulo de elasticidade normal às fibras.

Segundo BARALDI (1996), foi utilizada madeira no estado verde (umidade acima do ponto de saturação das fibras), por apresentar menor variabilidade nos valores de suas propriedades de resistência e elasticidade e também menores valores de resistência para ligações,. 
Para a escolha das espécies ensaiadas, foi considerada a sua classe de resistência, conforme tabela 1:

TABELA 1 - Agrupamento de classes de resistência - Fonte BARALDI (1996)

\begin{tabular}{|c|c|c|cc|c|c|}
\hline \multicolumn{7}{|c|}{ Características das espécies de madeira } \\
Espécie & Classe & $\begin{array}{c}\mathrm{f}_{\mathrm{c} 0 \mathrm{k}} \\
(\mathrm{MPa})\end{array}$ & $\begin{array}{c}\mathrm{f}_{\mathrm{vk}} \\
(\mathrm{MPa})\end{array}$ & $\begin{array}{c}\mathrm{E}_{\mathrm{c} 0 \mathrm{~m}} \\
(\mathrm{MPa})\end{array}$ & $\begin{array}{c}\rho_{\text {bas,m }} \\
\left(\mathrm{kg} / \mathrm{m}^{3}\right)\end{array}$ & $\begin{array}{c}\rho_{\text {aparente }} \\
\left(\mathrm{kg} / \mathrm{m}^{3}\right)\end{array}$ \\
\hline Pinus Elliottii & C 20 & 20 & 4 & 9500 & 500 & 650 \\
Cupiúba & C 30 & 30 & 5 & 14.500 & 650 & 800 \\
Garapa & C 40 & 40 & 6 & 19.500 & 750 & 950 \\
Jatobá & C 60 & 60 & 8 & 24.500 & 800 & 1000 \\
Eucalipto Citriodora & C 60 & 60 & 8 & 24.500 & 800 & 1000 \\
\hline
\end{tabular}

As vigas de madeira foram numeradas de acordo com a espécie. De cada viga foram extraídos os corpos -de-prova para os ensaios de ligação e para a sua caracterização.

\subsection{2 - Métodos utilizados nos ensaios}

As peças foram acondicionadas em um tanque com água até atingirem o ponto de saturação das fibras. Para a preparação final dos corpos-de-prova, colocação dos relógios comparadores, as peças eram retiradas e trabalhadas até um tempo máximo de 24 horas antes da realização do ensaio.

Para o ensaio das ligações, os corpos-de-prova foram montados utilizando-se quatro pinos metálicos em corte duplo, compondo-se com três peças de madeira, sendo uma 
peça principal central e duas outras cobrejuntas, conforme fgura 22. Para o ensaio na direção paralela às fibras, a peça principal foi feita com $5 \mathrm{~cm}$ de espessura, $12 \mathrm{~cm}$ de largura e $20 \mathrm{~cm}$ de altura, enquanto as cobrejuntas foram feitas com $2,5 \mathrm{~cm}$ de espessura, $12 \mathrm{~cm}$ de largura e $20 \mathrm{~cm}$ de altura. Para o ensaio na direção normal às fibras, a peça principal teve as mesmas dimensões daquela descrita para o ensaio na direção paralela, e as cobrejuntas com 2,5 cm de espessura, $36 \mathrm{~cm}$ de comprimento e $12 \mathrm{~cm}$ de altura.

O espaçamento entre pinos e entre pino e borda da madeira dos corpos-de-prova seguiram a disposição mínima constante da figura 8 , tanto para o ensaio na direção paralela quanto na direção normal às fibras.

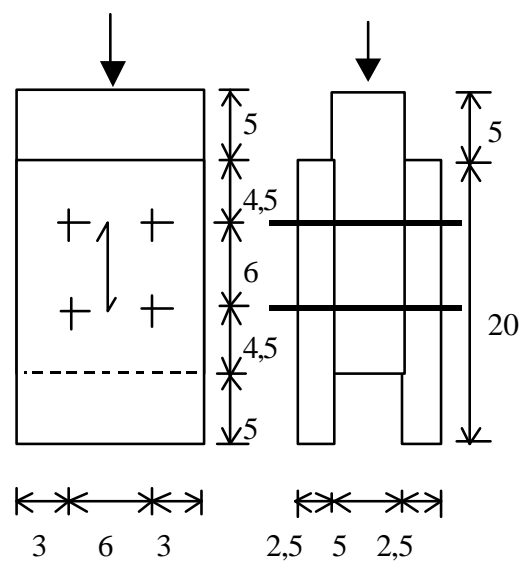

a) direção paralela às fibras

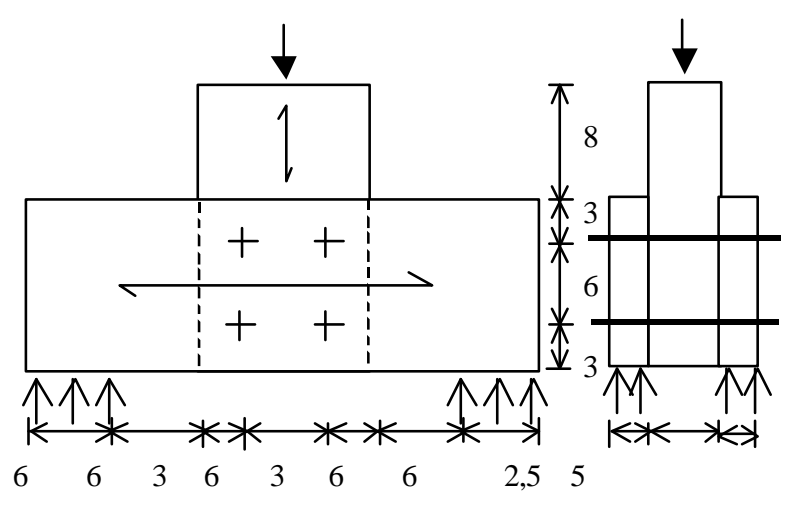

b) direção normal às fibras

FIGURA 22 - Arranjo dos corpos -de-prova para ensaios das ligações

Os ensaios foram realizados na Escola de Engenharia de São Carlos, Departamento de Estruturas, no LaMEM, em uma máquina universal de ensaios, marca AMSLER, com capacidade máxima de $250 \mathrm{kN}$. No ensaio da ligação na direção paralela, o carregamento foi aplicado, formando um ângulo de $0^{\circ}$ em relação às fibras da peça central e das cobrejuntas. Na direção normal, a força foi aplicada na peça central, formando ângulos de $0^{\circ}$ com as fibras desta e $90^{\circ}$ com as fbras das cobrejuntas. 
Para as medidas dos deslocamentos das ligações, as leituras foram feitas a cada incremento de força de $2 \mathrm{kN}$, com o uso de dois relógios comparadores instalados em lados opostos dos corpos-de-prova, sem a interrupção do carregamento, utilizandose, para cálculo, os valores médios. Foram usados relógios comparadores com sensibilidade de 0,01 mm. Também foi registrada a força máxima para cada ensaio.

Foram ensaiados dois corpos-de-prova para cada diâmetro de pregos e parafusos. Para cada tipo de ensaio, foram montados 3 (três) corpos-de-prova, sendo o terceiro utilizado apenas quando os valores obtidos nos dois primeiros apresentassem valores muito discrepantes entre $\mathrm{si}^{1}$.

Para o ensaio da ligação na direção normal às fibras, o corpo-de-prova foi centralizado em relação à aplicação da força, estando as cobrejuntas apoiadas nas extremidades, em uma extensão de $6 \mathrm{~cm}$. A distância entre as faces internas dos apoios é igual ao dobro da altura das cobrejuntas $(24 \mathrm{~cm})$. A figura 22 ilustra este detalhe.

Os diâmetros dos pinos utilizados para os dois tipos de ensaios, considerados como mínimos, segundo o projeto de norma de 1995, foram $10 \mathrm{~mm}, 12,5 \mathrm{~mm}$ e $16 \mathrm{~mm}$ para parafusos de aço e 4,4 mm, 5,4 mm e 6,4 mm para pregos de aço 1011-B, estando as demais dimensões de acordo com as normas NBR 8800 - Projeto e Execução de Estruturas de Aço de Edifícios - Métodos dos Estados Limites e NBR 6627 - Pregos Comuns e Arestas de Aço para Madeiras, respectivamente.

Para a colocação dos pinos nas ligações, foram observadas as recomendações sobre a pré-furação existentes à época. FUSCO (1995) propõe utilizar, como diâmetro de pré-furação para pregos, os valores de $0,85 \mathrm{~d}$ para coníferas e 0,95d para dicotiledôneas; para parafusos, um diâmetro não maior que o diâmetro d do parafuso acrescido de $0,5 \mathrm{~mm}$. O diâmetro proposto por $\mathrm{FUSCO}$, para a pré-furação das dicotiledôneas difere da recomendação atual, que estabelece o valor de 0,98d. Nos demais casos, os valores são os mesmos.

${ }^{1}$ CALIL JR, Carlito. (2000) (USP. Escola de Engenharia de São Carlos). Comunicação pessoal. 


\subsection{3 - Forma de obtenção da resistência e da rigidez das ligações pela equipe do}

\section{LaMEM}

A resistência da ligação foi determinada pela força aplicada ao corpo-de-prova padronizado, que provoca na ligação uma deformação especifica residual de $2 \%$. Para a sua obtenção, foi construído um diagrama força $\mathrm{x}$ deformação específica, conforme figura 23. A deformação específica $(\varepsilon)$ do mesmo diagrama foi obtida pela relação entre os deslocamentos e o comprimento da base de medida padronizada dos corpos-de-prova, apresentado na tabela 2. PINUS ELLIOTTII - PARAFUSO : $d=10 \mathrm{~mm}$ - COMPRESSÃO PARALELA
C.P.01 - Frup $=44,80 \mathrm{kN}$

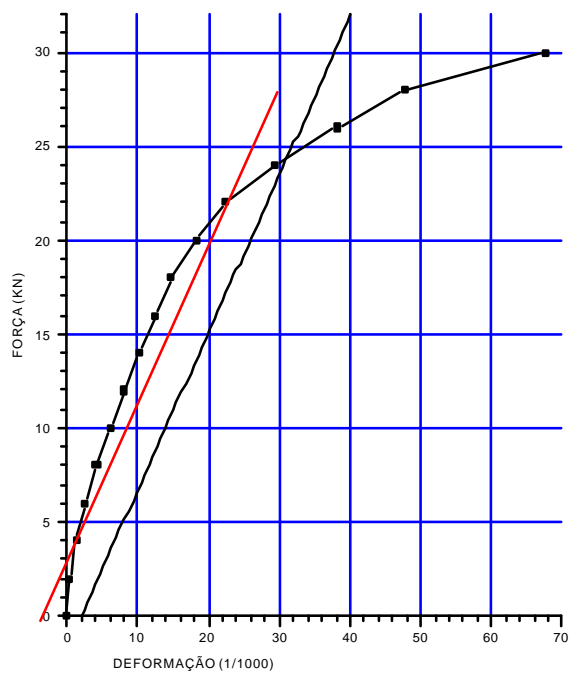

FIGURA 23 - Diagrama para determinação da resistência da ligação pelo critério adotado pela equipe do LaMEM

Inicialmente, obtém-se uma reta secante à curva do diagrama, fornecida pelos pontos correspondentes a $10 \%$ e $50 \%$, respectivamente, da força de ruptura dos corpos-deprova ensaiados. No diagrama, foi construída uma reta paralela à secante, passando pelo ponto $(2 \%$ ) e prolongada até o ponto de interseção com a curva do diagrama força $\mathrm{x}$ deformação específica, que define o valor da resistência da ligação (R). Esses dados podem ser observados na figura 23. 
A rigidez da ligação foi determinada pela relação entre o incremento de força e o deslocamento relativo, definidos no trecho compreendido entre $10 \%$ e $50 \%$ da força de ruptura dos corpos-de-prova ensaiados, obtendo-se esses valores em $\mathrm{kN} / \mathrm{mm}$.

TABELA 2 - Valores do comprimento da base de medida $\left(L_{0}\right)$

\begin{tabular}{|c|c|c|c|c|}
\hline Espécie & Tipo de pino & Direção & Corpos-de-prova & $\begin{array}{c}\mathbf{L}_{\mathbf{0}} \\
(\mathbf{m m})\end{array}$ \\
\hline \multirow{4}{*}{$\begin{array}{l}\text { Pinus } \\
\text { Elliottii }\end{array}$} & \multirow{2}{*}{ Parafuso } & Paralela & $01,20,07,09,05,08$ & 100 \\
\hline & & Normal & $01,05,02,07,05,09$ & 57 \\
\hline & \multirow{2}{*}{ Prego } & Paralela & $02,08,01,05,07,09$ & 100 \\
\hline & & Normal & $02,09,01,07,08,08 \mathrm{~b}$ & 60 \\
\hline \multirow{4}{*}{ Cupiúba } & \multirow{2}{*}{ Parafuso } & Paralela & $08,12,10,13,06,09$ & 100 \\
\hline & & Normal & $09,10,06,13,08,12$ & 60 \\
\hline & \multirow{2}{*}{ Prego } & Paralela & $12,13,06,08,09,10$ & 100 \\
\hline & & Normal & $06,08,12,13,09,10$ & 60 \\
\hline \multirow{4}{*}{ Garapa } & \multirow{2}{*}{ Parafuso } & Paralela & $17,18,12,16,13,14$ & 100 \\
\hline & & Normal & $12 \mathrm{a}, 16,12 \mathrm{~b}, 13,14,17$ & 60 \\
\hline & \multirow{2}{*}{ Prego } & Paralela & $14,16,17,18,12,13$ & 100 \\
\hline & & Normal & $16,18,14,17,12,13$ & 60 \\
\hline \multirow{7}{*}{$\begin{array}{l}\text { Eucalipto } \\
\text { Citriodora }\end{array}$} & \multirow[t]{2}{*}{ Parafuso } & Paralela & $07,05,10,13,09,12$ & 100 \\
\hline & & Normal & $10,13 b, 09,10,07,09$ & 57 \\
\hline & \multirow{5}{*}{ Prego } & \multirow{3}{*}{ Paralela } & 13 & 125 \\
\hline & & & 07 & 120 \\
\hline & & & $11,01,05$ & 100 \\
\hline & & \multirow{2}{*}{ Normal } & $10,09,11,13$ & 57 \\
\hline & & & 05 & 56 \\
\hline \multirow{5}{*}{ Jatobá } & \multirow{2}{*}{ Parafuso } & Paralela & $03,08,01,04,05,17$ & 100 \\
\hline & & Normal & $03,05,01, \mathrm{xx}, 04,08$ & 57 \\
\hline & \multirow{3}{*}{ Prego } & Paralela & $05,07,01,08,03,04$ & 100 \\
\hline & & \multirow{2}{*}{ Normal } & $01,03,05,07,04$ & 56 \\
\hline & & & 08 & 55 \\
\hline
\end{tabular}

\subsection{4 - Forma de obtenção da resistência e da rigidez das ligações por critério aproximado ao da norma NBR 7190/97}

O valor convencional para a resistência da ligação, segundo a NBR 7190/97, é definido pelo valor da força, que provoca uma deformação específica residual de $2 \%$ o determinada no diagrama força x deformação específica, a partir da reta secante, que passa pelos pontos $\left(\mathrm{F}_{71} ; \varepsilon_{71}\right)$ e $\left(\mathrm{F}_{85} ; \varepsilon_{85}\right)$ desse diagrama, equivalentes a $10 \%$ e $50 \%$ 
da força limite $\mathrm{F}_{\text {lim, }}$ pertencentes ao último ciclo de carregamento. Esse valor é definido pela interseção do diagrama com a reta secante deslocada $2 \%$.

Por falta da determinação do $F_{\text {lim }}$ nos ensaios realizados pela equipe do LaMEM, foi utilizado um procedimento aproximado para a obtenção de reta secante. Foi determinada por meio de regressão linear em um conjunto de pontos contidos no trecho reto do diagrama $\mathrm{F} x \varepsilon$. $\mathrm{O}$ restante do procedimento seguiu o especificado pela NBR 7190/97. Esses detalhes são mostrados na figura 24.

A rigidez da ligação foi definida de forma análoga ao descrito no item 3.1.3, relacionando o incremento de força ao deslocamento relativo, no mesmo trecho reto considerado para determinar a reta secante.

PINUS ELLIOTTII - PARAFUSO : $d=10 \mathrm{~mm}$ - COMPRESSÃO PARALELA

C.P. 01 - Frup $=44,80 \mathrm{kN}$

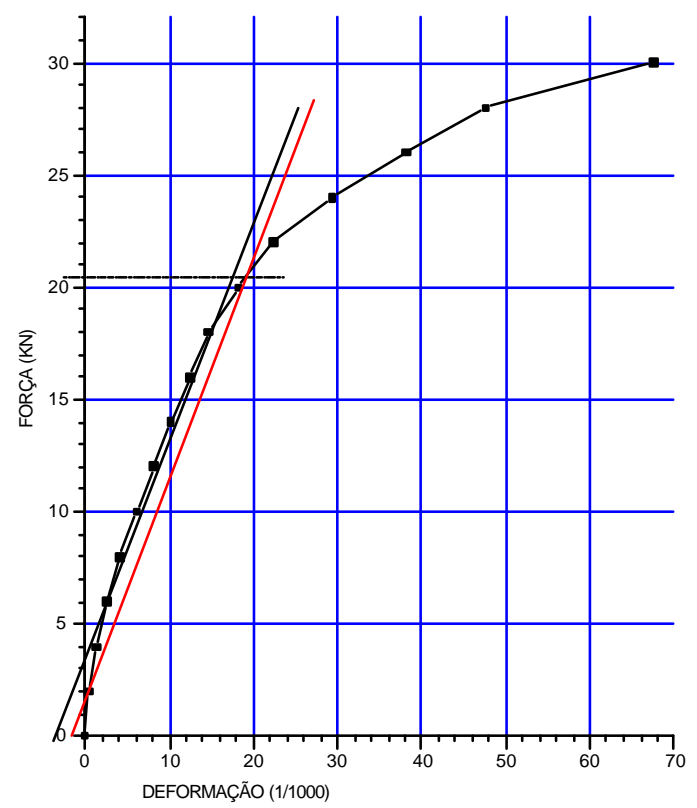

FIGURA 24 - Determinação da resistência da ligação com critério aproximado ao da NBR 7190/97 - ensaios LaMEM 


\section{2 - Ensaios complementares}

Estes ensaios compreendem a determinação da resistência das ligações na direção paralela às fibras, a caracterização das espécies de madeiras utilizadas e a resistência do aço ao escoamento.

A realização de ensaios de ligação apenas na direção paralela às fibras deve-se aos resultados experimentais obtidos nos ensaios LaMEM. Ao verificar a diferença entre os resultados experimentais e os resultados teóricos da ligações, observa-se que esta diferença é muito acentuada quando se trata da direção normal às fibras, enquanto na direção paralela os resultados apresentam diferenças com ordem de grandeza menor.

De cada viga, foram retirados corpos-de-prova para os ensaios de ligação, assim como para os ensaios de caracterização (embutimento, compressão paralela e umidade) da madeira. Foram utilizadas seis vigas para cada espécie de madeira na primeira série de ensaios e duas vigas por espécie na segunda série. Ao ensaiar corpos-de-prova provenientes de uma mesma viga, simultaneamente, foi obtido o teor de umidade destes, seguindo a metodologia da NBR 7190/97. As peças utilizadas foram inspecionadas para garantir a isenção de defeitos, conforme prescreve a norma brasileira.

\subsection{1 - Materiais utilizados}

$\mathrm{Na}$ realização dos ensaios complementares, inicialmente, foram selecionadas duas espécies de madeira: Pinus Elliottii (Pinus elliottii var. elliottii) e Cupiúba (Goupia glabra), por representarem classes de resistência e densidade distintas. Foram utilizadas seis vigas diferentes, sendo uma para cada diâmetro de pino e caracterizações correspondentes, na condição de umidade seca ao ar. 
Posteriormente, foram escolhidas mais duas espécies de madeira, a Cupiúba e o Jatobá (Hymenaea spp), para a realização de uma segunda série de ensaios, de forma a confirmar os primeiros resultados e verificar os resultados para uma espécie de elevada densidade. Nessa etapa, foram utilizadas duas vigas para cada espécie.

Os pinos utilizados foram parafusos com diâmetros nominais de $10 \mathrm{~mm}, 12,5 \mathrm{~mm} \mathrm{e}$ 16 mm e pregos de uso corrente da marca Gerdau com diâmetros nominais de 4,4 $\mathrm{mm}, 5,4 \mathrm{~mm}$ e $6,4 \mathrm{~mm}$. $\mathrm{O}$ aço dos parafusos não possui classificação estrutural, tendo sido adquiridos com a designação de tipo 1030 e 1045 , para a primeira e a segunda série de ensaios, respectivamente.

\subsection{2 - Métodos utilizados nos ensaios}

Para a caracterização das peças de madeira utilizadas, foram realizados ensaios a fim de determinar a sua resistência à compressão e ao embutimento, ambos na direção paralela às fibras. Esses ensaios foram feitos segundo a metodologia da norma NBR 7190/97 - Projeto de Estruturas de Madeira (Anexo B: Determinação das propriedades das madeiras para projeto de estruturas).

Para a determinação da resistência das ligações na direção paralela às fibras, foram realizados ensaios de acordo com a metodologia do anexo $\mathrm{C}$ da mesma norma, já descrita neste trabalho no item 2.6.1.1.

Os ensaios para a determinação da resistência da madeira ao embutimento, na direção paralela às fibras, seguiram o disposto na NBR 7190/97 e foram realizados na máquina de ensaios DARTEC, com capacidade de $100 \mathrm{kN}$, no LaMEM, da qual se obteve o stroke para leitura dos deslocamentos. O carregamento foi aplicado em ciclos de carga e descarga, de acordo com o procedimento especificado no diagrama da figura 19, com uma taxa de carregamento de $10 \mathrm{MPa} / \mathrm{min}$. A determinação da resistência estimada foi feita, preliminarmente, em um corpo-de-prova gêmeo. A 
figura 25 mostra o diagrama obtido para a determinação da resistência ao embutimento.

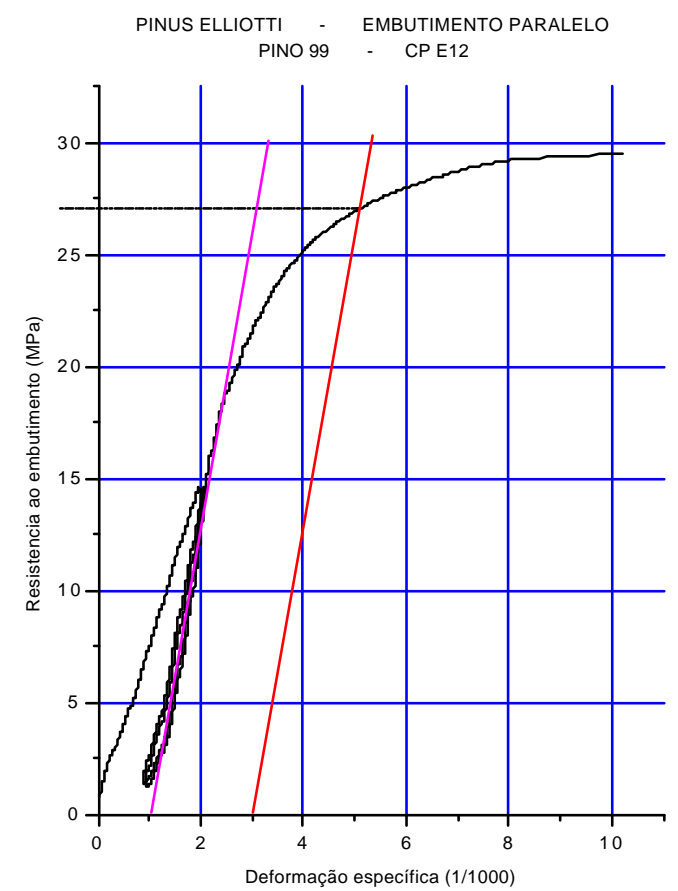

FIGURA 25 - Determinação da resistência da madeira ao embutimento

A caracterização da resistência da madeira à compressão paralela às fibras foi realizada seguindo o procedimento descrito no anexo B da NBR 7190/97, sendo determinada neste ensaio apenas a resistência à compressão da madeira. Os ensaios foram realizados na mesma máquina universal de ensaios AMSLER, do LaMEM, aplicando-se carregamento monotônico e crescente, com uma taxa de $10 \mathrm{MPa} / \mathrm{min}$, até atingir a força máxima de ruptura do corpo-de-prova.

A determinação do teor de umidade foi feita à medida que os demais ensaios foram sendo realizados, utilizando corpos-de-prova das respectivas vigas.

As tensões de escoamento do aço dos parafusos e pregos foram determinadas em ensaios realizados na máquina universal de ensaios AMSLER e na máquina de ensaios DARTEC, respectivamente. 
A numeração dos corpos-de-prova para caracterização das espécies seguem o padrão descrito para os ensaios de ligações no item 3.2.3.

\subsection{3 - Procedimentos gerais dos ensaios de ligações}

A numeração dos corpos-de-prova, nas duas séries de ensaios, foi feita utilizando um primeiro número, com um ou dois algarismos, para indicar a numeração seqüencial das amostras de corpos-de-prova e, em seguida e entre parênteses, uma letra e outro algarismo, que indicam a espécie de madeira e a viga correspondente. Os primeiros corpos-de-prova, para cada tipo de pino, foram utilizados para a determinação da força limite e, portanto, não aparecem nas tabelas de resultados. As letras P, C e J correspondem, respectivamente, às espécies Pinus Elliottii, Cupiúba e Jatobá.

Os corpos-de-prova, para ensaio de ligação na direção paralela às fibras, foram montados obedecendo às dimensões e espaçamentos mínimos constantes na norma brasileira, utilizando-se quatro pinos e duas seções de corte.

Algumas medidas foram padronizadas acima do mínimo. $\mathrm{Na}$ distância entre os centros de dois pinos situados em duas linhas paralelas à direção das fibras, medida perpendicularmente, foi deixada uma medida padrão de $50 \mathrm{~mm}$ em todos os corposde-prova, sendo que o estabelecido por norma é de três vezes o diâmetro do pino. A medida do centro do último pino até a borda lateral da peça foi padronizada em 25 $\mathrm{mm}$, enquanto que o mínimo recomendado pela norma brasileira é de 1,5 vezes o diâmetro do pino. Em ambos os casos, os valores atendem ao mínimo estabelecido para o pino de maior diâmetro.

As espessuras t das peças foram estabelecidas conforme item 8.3.4 da NBR 7190/97, sendo utilizada a espessura padrão de $25 \mathrm{~mm}$ para as cobrejuntas, exceto para o corpo-de-prova com parafuso de $16 \mathrm{~mm}$, em que a espessura foi a mínima de $32 \mathrm{~mm}$. As peças centrais foram construídas com o dobro da espessura das respectivas cobrejuntas. 
Para a montagem dos corpos-de-prova, conforme mostrado na figura 26 , foi usado um dispositivo metálico tipo sargento para manter as peças em posição, que, em seguida, receberam a pré-furação, procurando aproximar ao máximo dos valores recomendados pela NBR 7190 .

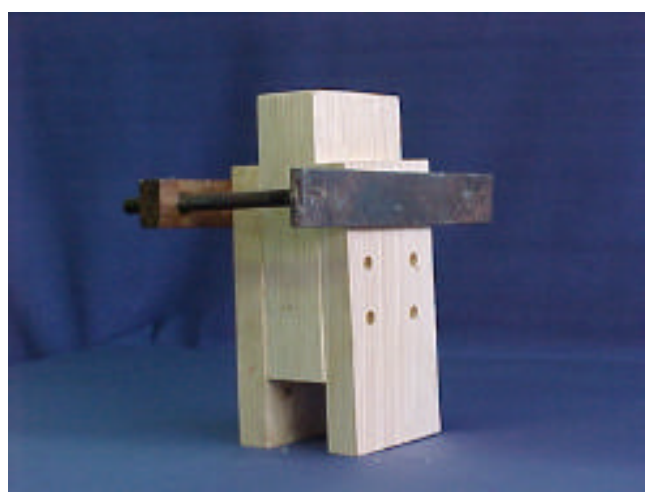

FIGURA 26 - Dispositivo de montagem e pré furação no corpo -de-prova

Mantendo o dispositivo, a cravação dos pinos deu-se com o uso de um martelo, conforme mostrado na figura 27 , observando-se o comportamento das peças quanto a possíveis fendilhamentos e outros defeitos que pudessem comprometer os resultados do ensaio.

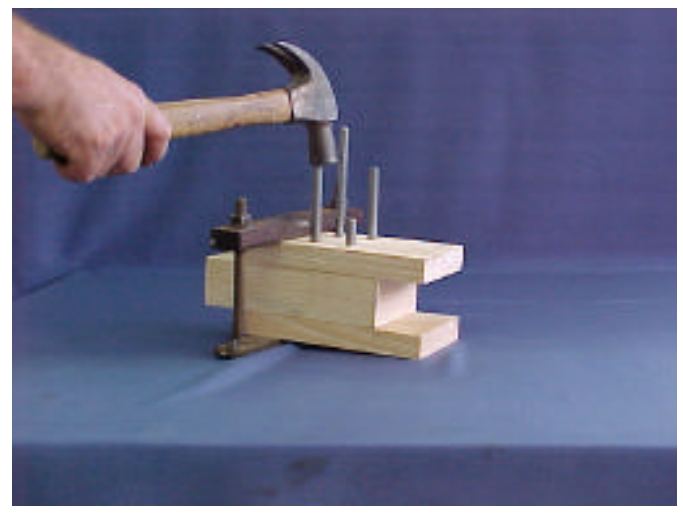

FIGURA 27 - Cravação dos pinos no corpo -de-prova de ligação 
Para as leituras das medidas de deslocamentos relativos, foram utilizados relógios comparadores com sensibilidade de $0,01 \mathrm{~mm}$, montados em dispositivos, constituídos de cantoneira metálica, colocados nas duas faces laterais dos corpos-deprova. Os deslocamentos foram medidos em relação a uma base de medida com comprimento $\mathrm{L}_{0}$ definido na NBR 7190/97. Foram utilizados os espaçamentos mínimos recomendados pela NBR 7190/97, indicados na figura 11a.

$\mathrm{Na}$ primeira série de ensaios de ligações, foram montados 4 corpos-de-prova gêmeos (obtidos da mesma viga) para cada diâmetro de parafuso ou prego. Para a segunda série, foram montados apenas três corpos-de-prova para cada diâmetro de parafuso ou prego, considerando a pequena variabilidade observada nos resultados de corposde-prova gêmeos.

Os ensaios foram realizados na máquina universal de ensaios AMSLER, com capacidade de $250 \mathrm{kN}$, efetuando-se os carregamentos apropriados para a obtenção força limite (figura 12) e da resistência da ligação (figura 13).

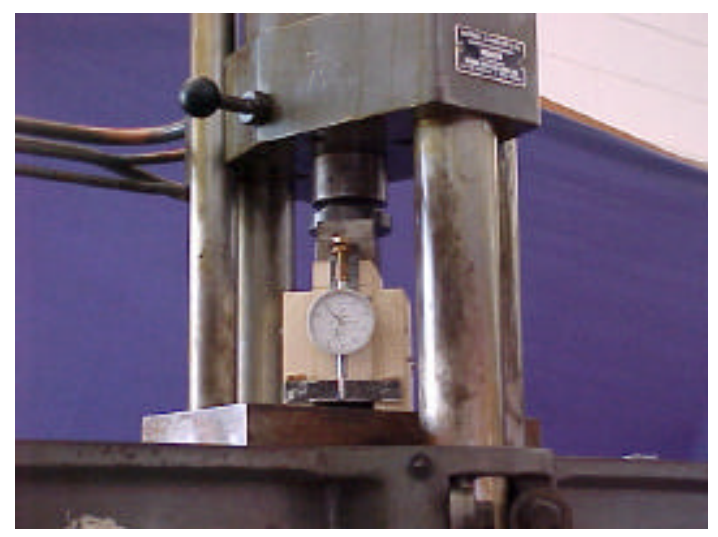

FIGURA 28 - Ensaio de ligação na direção paralela às fibras da madeira máquina universal AMSLER 
A partir do ponto 71 do diagrama de carregamento, foram registrados os deslocamentos a cada incremento de $0,1 \mathrm{~F}_{\text {lim }}$ até a força limite ser alcançada. Esses dados permitiram a obtenção de diagramas equivalentes ao da figura 29.

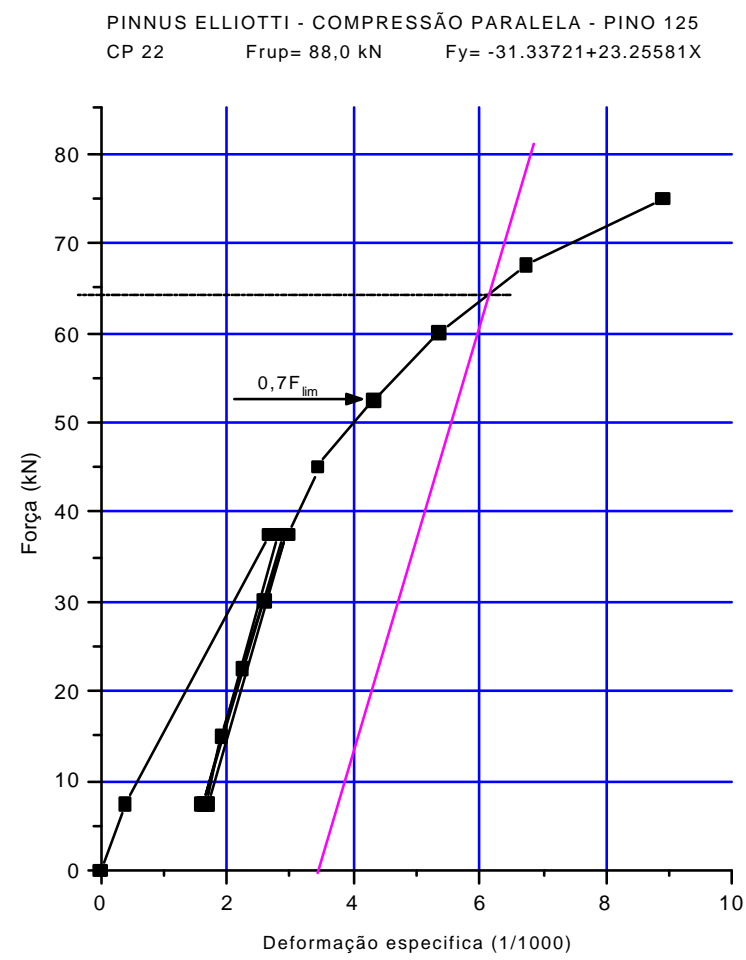

FIGURA 29 - Determinação da resistência da ligação - pontos registrados

A NBR 7190/97 recomenda efetuar as leituras dos deslocamentos até o carregamento correspondente a 0,7 $\mathrm{F}_{\text {lim. }}$. Durante os ensaios, foi observada a necessidade de continuar a registrar essas leituras até a força limite ser alcançada. Tais detalhes podem ser observados na figura 29. 


\section{4 - RESULTADOS OBTIDOS NOS ENSAIOS}

A seguir, são apresentados os resultados obtidos nos ensaios realizados pela equipe do LaMEM e nos ensaios complementares.

\section{1 - Ensaios realizados pela equipe do LaMEM}

No tem 4.1.1, são apresentados os resultados dos ensaios realizados no LaMEM para a caracterização da madeira e, nos itens 4.1.2 e 4.1.3, são mostrados os resultados dos ensaios realizados no LaMEM para a determinação da resistência das ligações, utilizando o critério da equipe do LaMEM e o critério aproximado da NBR 7190/97.

Para exemplificar, a figura 30 destaca os resultados obtidos para a resistência da ligação de um corpo-de-prova utilizando os critérios da equipe do LaMEM e da aproximação da NBR.

\subsection{1 - Caracterização da madeira}

Na tabela 3 são apresentados os resultados da resistência da madeira à compressão na direção paralela às fibras, cujos valores foram determinados pela equipe do LaMEM e coletados na dissertação de BARALDI (1996). Ao final dessa mesma tabela, acrescentaram-se a média e o coeficiente de variação (CV) dos valores obtidos para cada espécie. Esses ensaios de caracterização foram realizados nas mesmas 
condições de umidade dos ensaios de ligações e com os mesmos procedimentos recomendados na atual normalização.

TABELA 3 - Características das vigas - fonte: BARALDI (1996)

\begin{tabular}{|c|c|c|c|c|c|c|c|c|c|}
\hline \multicolumn{2}{|c|}{ Pinus Elliottii } & \multicolumn{2}{|c|}{ Cupiúba } & \multicolumn{2}{|c|}{ Garapa } & \multicolumn{2}{|c|}{$\begin{array}{l}\text { Eucalipto } \\
\text { Citriodora }\end{array}$} & \multicolumn{2}{|c|}{ Jatobá } \\
\hline $\mathbf{C P}$ & $\begin{array}{c}\mathbf{f}_{\mathbf{c}, 0} \\
(\mathbf{M P a})\end{array}$ & $\mathbf{C P}$ & $\begin{array}{c}\mathbf{f}_{\mathrm{c}, 0} \\
(\mathrm{MPa})\end{array}$ & $\mathbf{C P}$ & $\begin{array}{c}\mathbf{f}_{\mathbf{c}, 0} \\
(\mathrm{MPa})\end{array}$ & $\mathbf{C P}$ & $\begin{array}{c}\mathbf{f}_{\mathbf{c}, 0} \\
(\mathrm{MPa})\end{array}$ & $\mathbf{C P}$ & $\begin{array}{r}\mathbf{f}_{\mathbf{c}, 0} \\
(\mathrm{MPa}\end{array}$ \\
\hline 01 & 20,0 & 05 & 35,1 & 01 & 59,6 & 01 & 75,6 & 01 & 63,9 \\
\hline 05 & 20,0 & 06 & 36,2 & 02 & 46,6 & 04 & 75,1 & 02 & 54,6 \\
\hline 06 & 22,0 & 07 & 43,2 & 03 & 60,8 & 06 & 69,4 & 03 & 64,5 \\
\hline 07 & 23,0 & 08 & 35,3 & 04 & 51,2 & 08 & 55,8 & 05 & 56,2 \\
\hline 08 & 17,8 & 09 & 36,3 & 06 & 42,8 & 10 & 58,1 & 07 & 72,5 \\
\hline 09 & 17,1 & 10 & 38,8 & 07 & 47,8 & 12 & 61,9 & 09 & 57,1 \\
\hline 10 & 25,8 & 14 & 52,8 & 11 & 51,6 & 13 & 60,3 & 14 & 75,6 \\
\hline 14 & 22,6 & 15 & 52,9 & 19 & 61,1 & 14 & 71,0 & 15 & 77,5 \\
\hline 15 & 24,2 & 16 & 42,0 & 20 & 39,2 & 15 & 43,4 & 16 & 76,7 \\
\hline 16 & 19,1 & 17 & 48,6 & 25 & 47,7 & 16 & 65,0 & 17 & 92,3 \\
\hline 17 & 20,2 & 18 & 51,3 & 26 & 46,6 & 17 & 66,0 & 18 & 81,2 \\
\hline 18 & 13,1 & 19 & 52,1 & 27 & 48,1 & 19 & 68,6 & 19 & 71,1 \\
\hline 19 & 20,6 & 21 & 40,0 & 28 & 43,2 & 21 & 64,0 & 20 & 65,1 \\
\hline 20 & 17,3 & 24 & 47,7 & 30 & 44,0 & 22 & 65,6 & 21 & 79,7 \\
\hline 21 & 19,7 & & & 31 & 44,6 & 24 & 58,6 & 22 & 73,4 \\
\hline \multirow[t]{2}{*}{22} & 15,3 & & & 32 & 48,1 & & & & \\
\hline & & & & 33 & 42,8 & & & & \\
\hline Média & 20,0 & Média & 42,6 & Média & 47,8 & Média & 65,0 & Média & 72,5 \\
\hline$(\mathbf{C V})$ & $(16 \%)$ & $(\mathbf{C V})$ & $(16 \%)$ & $(\mathbf{C V})$ & $(14 \%)$ & $(\mathbf{C V})$ & $(13 \%)$ & $(\mathbf{C V})$ & $(15 \%)$ \\
\hline
\end{tabular}




\subsection{2 - Resistência e rigidez das ligações segundo critério da equipe do LaMEM}

Os resultados obtidos para a resistência $(\mathrm{R})$ e a força que provoca ruptura $\left(\mathrm{F}_{\text {rup }}\right)$ da ligação correspondente a quatro pinos com dois planos de corte cada um, segundo o método descrito nos itens 3.1.1, 3.1.2 e 3.1.3, estão apresentados nas tabelas 4 a 8 . Também são mostrados os valores da rigidez.

TABELA 4 - Ensaios em ligações com parafusos e pregos - Pinus Elliottii

\begin{tabular}{|c|c|c|c|c|c|c|}
\hline Tipo de pino & Solicitação & $\underset{(\mathbf{m m})}{\mathbf{d}}$ & $\begin{array}{l}\text { Número } \\
\text { do C. P. }\end{array}$ & $\underset{(\mathbf{k N})}{\mathbf{R}}$ & $\begin{array}{l}\text { Frup } \\
(\mathbf{k N})\end{array}$ & $\begin{array}{r}\text { Rigidez } \\
(\mathbf{k N} / \mathbf{m m})\end{array}$ \\
\hline \multirow{12}{*}{ Parafuso } & \multirow{6}{*}{$\begin{array}{l}\text { Direção } \\
\text { paralela }\end{array}$} & \multirow{2}{*}{10} & 01 & 24,40 & 44,80 & 8,38 \\
\hline & & & 20 & 27,40 & 45,20 & 16,45 \\
\hline & & \multirow{2}{*}{12,5} & 07 & 43,40 & 49,70 & 15,65 \\
\hline & & & 09 & 42,40 & 52,40 & 19,38 \\
\hline & & \multirow{2}{*}{16} & 05 & 50,30 & 57,00 & 12,33 \\
\hline & & & 08 & 40,80 & & 14,25 \\
\hline & \multirow{6}{*}{$\begin{array}{l}\text { Direção } \\
\text { Normal }\end{array}$} & \multirow{2}{*}{10} & 01 & 13,80 & 20,90 & 4,88 \\
\hline & & & 05 & 16,80 & 23,30 & 3,43 \\
\hline & & \multirow{2}{*}{12,5} & 02 & 21,80 & 31,00 & 7,70 \\
\hline & & & 07 & 21,80 & 27,50 & 5,32 \\
\hline & & \multirow{2}{*}{16} & 05 & 20,20 & 26,50 & 4,94 \\
\hline & & & 09 & 20,90 & & 4,09 \\
\hline \multirow{12}{*}{ Prego } & \multirow{6}{*}{$\begin{array}{l}\text { Direção } \\
\text { paralela }\end{array}$} & \multirow{2}{*}{4,4} & 02 & 11,30 & 20,50 & 10,73 \\
\hline & & & 08 & 11,50 & 21,00 & 6,77 \\
\hline & & \multirow{2}{*}{5,4} & 01 & 14,80 & 25,00 & 9,85 \\
\hline & & & 05 & 15,00 & 25,50 & 12,45 \\
\hline & & \multirow{2}{*}{6,4} & 07 & 18,90 & 33,00 & 12,24 \\
\hline & & & 09 & 18,50 & 32,80 & 11,15 \\
\hline & \multirow{6}{*}{$\begin{array}{l}\text { Direção } \\
\text { Normal }\end{array}$} & \multirow{2}{*}{4,4} & 02 & 13,40 & 24,90 & 1,58 \\
\hline & & & 09 & 12,40 & 20,50 & 1,14 \\
\hline & & \multirow{2}{*}{5,4} & 01 & 12,00 & 21,60 & 3,28 \\
\hline & & & 07 & 12,50 & 22,60 & 2,01 \\
\hline & & \multirow{2}{*}{6,4} & 08 & 11,80 & 19,80 & 5,31 \\
\hline & & & $08 \mathrm{~b}$ & 13,80 & 22,50 & 5,57 \\
\hline
\end{tabular}


TABELA 5 - Ensaios em ligações com parafusos e pregos - Cupiúba

\begin{tabular}{|c|c|c|c|c|c|c|}
\hline Tipo de pino & Solicitação & $\begin{array}{c}\mathrm{d} \\
(\mathrm{mm})\end{array}$ & $\begin{array}{l}\text { Número } \\
\text { do C. } P .\end{array}$ & $\underset{(\mathbf{k N})}{\mathbf{R}}$ & $\begin{array}{r}\text { Frup } \\
(\mathbf{k N})\end{array}$ & $\begin{array}{c}\text { Rigidez } \\
\text { (kN/mm) }\end{array}$ \\
\hline \multirow{12}{*}{ Parafuso } & \multirow{6}{*}{$\begin{array}{l}\text { Direção } \\
\text { paralela }\end{array}$} & \multirow{2}{*}{10} & 08 & 42,40 & 71,00 & 44,64 \\
\hline & & & 12 & 41,10 & 68,00 & 39,22 \\
\hline & & \multirow{2}{*}{12,5} & 10 & 59,80 & 93,50 & 59,52 \\
\hline & & & 13 & 65,00 & 99,20 & 81,97 \\
\hline & & \multirow{2}{*}{16} & 06 & 78,80 & 116,50 & 72,99 \\
\hline & & & 09 & 70,20 & 122,00 & 84,75 \\
\hline & \multirow{6}{*}{$\begin{array}{l}\text { Direção } \\
\text { Normal }\end{array}$} & \multirow{2}{*}{10} & 09 & 30,70 & 44,50 & 10,56 \\
\hline & & & 10 & 27,00 & 39,00 & 13,48 \\
\hline & & \multirow{2}{*}{12,5} & 06 & 45,70 & 51,00 & 14,05 \\
\hline & & & 13 & 46,00 & 53,60 & 15,04 \\
\hline & & \multirow{2}{*}{16} & 08 & 12,40 & 24,80 & 9,60 \\
\hline & & & 12 & 36,40 & 46,50 & 12,69 \\
\hline \multirow{12}{*}{ Prego } & \multirow{6}{*}{$\begin{array}{l}\text { Direção } \\
\text { paralela }\end{array}$} & \multirow{2}{*}{4,4} & 12 & 25,60 & 49,90 & 7,61 \\
\hline & & & 13 & 21,80 & 38,00 & 27,40 \\
\hline & & \multirow{2}{*}{5,4} & 06 & 31,00 & 56,00 & 15,77 \\
\hline & & & 08 & 26,60 & 48,60 & 19,88 \\
\hline & & \multirow{2}{*}{6,4} & 09 & 32,30 & 55,80 & 39,22 \\
\hline & & & 10 & 36,70 & 64,10 & 32,05 \\
\hline & \multirow{6}{*}{$\begin{array}{l}\text { Direção } \\
\text { Normal }\end{array}$} & \multirow{2}{*}{4,4} & 06 & 17,30 & 34,80 & 3,03 \\
\hline & & & 08 & 19,30 & 37,00 & 3,33 \\
\hline & & \multirow{2}{*}{5,4} & 12 & 23,60 & 42,30 & 6,63 \\
\hline & & & 13 & 19,80 & 34,30 & 11,93 \\
\hline & & \multirow{2}{*}{6,4} & 09 & 27,20 & 50,60 & 8,48 \\
\hline & & & 10 & 27,70 & 48,00 & 7,37 \\
\hline
\end{tabular}


TABELA 6 - Ensaios em ligações com parafusos e pregos - Garapa

\begin{tabular}{|c|c|c|c|c|c|c|}
\hline Tipo de pino & Solicitação & d (mm) & $\begin{array}{c}\text { Número } \\
\text { do C. P. } \\
17\end{array}$ & $\begin{array}{c}\mathbf{R} \\
(\mathbf{k N}) \\
51,20\end{array}$ & $\begin{array}{r}\text { Frup } \\
(\mathbf{k N}) \\
74,00\end{array}$ & $\begin{array}{c}\text { Rigidez } \\
\text { (kN/mm) } \\
78,74\end{array}$ \\
\hline \multirow{11}{*}{ Parafuso } & \multirow{5}{*}{$\begin{array}{l}\text { Direção } \\
\text { paralela }\end{array}$} & 10 & 18 & 48,10 & 77,00 & 77,52 \\
\hline & & \multirow{2}{*}{12,5} & 12 & 70,40 & 108,00 & 78,13 \\
\hline & & & 16 & 70,80 & 99,00 & 73,53 \\
\hline & & \multirow{2}{*}{16} & 13 & 77,80 & 128,00 & 93,46 \\
\hline & & & 14 & 82,70 & 136,00 & 85,47 \\
\hline & \multirow{6}{*}{$\begin{array}{l}\text { Direção } \\
\text { Normal }\end{array}$} & \multirow{2}{*}{10} & $12 \mathrm{a}$ & 36,00 & 48,50 & 15,92 \\
\hline & & & 16 & 37,10 & 60,00 & 12,67 \\
\hline & & \multirow{2}{*}{12,5} & $12 \mathrm{~b}$ & 51,00 & 65,00 & 15,36 \\
\hline & & & 13 & 51,50 & 60,20 & 15,20 \\
\hline & & \multirow{2}{*}{16} & 14 & 57,10 & 66,30 & 18,21 \\
\hline & & & 17 & 62,30 & 70,00 & 18,39 \\
\hline \multirow{12}{*}{ Prego } & \multirow{6}{*}{$\begin{array}{l}\text { Direção } \\
\text { paralela }\end{array}$} & \multirow{2}{*}{4,4} & 14 & 25,00 & 60,00 & 15,77 \\
\hline & & & 16 & 23,70 & 58,20 & 16,03 \\
\hline & & \multirow{2}{*}{5,4} & 17 & 35,20 & 61,80 & 44,25 \\
\hline & & & 18 & 34,50 & 61,00 & 36,90 \\
\hline & & \multirow{2}{*}{6,4} & 12 & 35,60 & 54,50 & 61,73 \\
\hline & & & 13 & 36,90 & 55,80 & 70,92 \\
\hline & \multirow{6}{*}{$\begin{array}{l}\text { Direção } \\
\text { Normal }\end{array}$} & \multirow{2}{*}{4,4} & 16 & 26,80 & 49,00 & 4,32 \\
\hline & & & 18 & 28,80 & 53,70 & 2,97 \\
\hline & & \multirow{2}{*}{5,4} & 14 & 28,90 & 51,50 & 9,77 \\
\hline & & & 17 & 33,60 & 61,00 & 9,74 \\
\hline & & \multirow{2}{*}{6,4} & 12 & 31,80 & 56,00 & 12,88 \\
\hline & & & 13 & 27,90 & 46,80 & 15,58 \\
\hline
\end{tabular}


TABELA 7 - Ensaios em ligações com parafusos e pregos - Eucalipto Citriodora

\begin{tabular}{|c|c|c|c|c|c|c|}
\hline Tipo de pino & Solicitação & $\begin{array}{c}\mathrm{d} \\
(\mathbf{m m})\end{array}$ & $\begin{array}{l}\text { Número } \\
\text { do C. } \mathbf{P} \text {. }\end{array}$ & $\underset{(k N)}{R}$ & $\begin{array}{r}\text { Frup } \\
(\mathbf{k N})\end{array}$ & $\begin{array}{c}\text { Rigidez } \\
(\mathrm{kN} / \mathbf{m m})\end{array}$ \\
\hline \multirow{12}{*}{ Parafuso } & \multirow{6}{*}{$\begin{array}{l}\text { Direção } \\
\text { paralela }\end{array}$} & \multirow{2}{*}{10} & 07 & 54,80 & 83,00 & 76,92 \\
\hline & & & 05 & 49,80 & 79,00 & 88,50 \\
\hline & & \multirow{2}{*}{12,5} & 10 & 74,30 & 109,80 & 92,59 \\
\hline & & & 13 & 74,00 & 110,50 & 101,01 \\
\hline & & \multirow{2}{*}{16} & 09 & 85,50 & 137,50 & 125,00 \\
\hline & & & 12 & 84,20 & 126,00 & 123,46 \\
\hline & \multirow{6}{*}{$\begin{array}{l}\text { Direção } \\
\text { Normal }\end{array}$} & \multirow{2}{*}{10} & 10 & 36,90 & 58,50 & $115,6.2$ \\
\hline & & & $13 b$ & 31,70 & 44,50 & 13,26 \\
\hline & & \multirow{2}{*}{12,5} & 09 & 32,50 & 65,00 & 16,10 \\
\hline & & & 10 & 33,80 & 67,60 & 15,24 \\
\hline & & \multirow{2}{*}{16} & 07 & 51,70 & 63,70 & 21,03 \\
\hline & & & 09 & 45,00 & 74,30 & 20,14 \\
\hline \multirow{11}{*}{ Prego } & \multirow{6}{*}{$\begin{array}{l}\text { Direção } \\
\text { paralela }\end{array}$} & \multirow{2}{*}{4,4} & 13 & 23,80 & 41,10 & 38,34 \\
\hline & & & 07 & 22,00 & 37,50 & 56,87 \\
\hline & & \multirow{2}{*}{5,4} & 11 & 27,10 & 41,00 & 42,82 \\
\hline & & & & & & \\
\hline & & \multirow{2}{*}{6,4} & 01 & 37,90 & 55,50 & 86,21 \\
\hline & & & 05 & 37,70 & 54,50 & 96,15 \\
\hline & \multirow{5}{*}{$\begin{array}{l}\text { Direção } \\
\text { Normal }\end{array}$} & 4,4 & 10 & 20,00 & 36,10 & 6,51 \\
\hline & & \multirow{2}{*}{5,4} & 09 & 26,20 & 44,50 & 11,93 \\
\hline & & & 11 & 29,20 & 48,70 & 7,15 \\
\hline & & \multirow{2}{*}{6,4} & 05 & 31,00 & 52,00 & 10,24 \\
\hline & & & 13 & 27,10 & 43,00 & 13,74 \\
\hline
\end{tabular}


TABELA 8 - Ensaios em ligações com parafusos e pregos - Jatobá

\begin{tabular}{|c|c|c|c|c|c|c|}
\hline Tipo de pino & Solicitação & $\begin{array}{c}\mathrm{d} \\
(\mathbf{m m})\end{array}$ & $\begin{array}{l}\text { Número } \\
\text { do } C . P \text {. }\end{array}$ & $\underset{(k N)}{R}$ & $\begin{array}{l}\text { Frup } \\
(\mathbf{k N})\end{array}$ & $\begin{array}{r}\text { Rigidez } \\
\text { (kN/mm) }\end{array}$ \\
\hline \multirow{12}{*}{ Parafuso } & \multirow{6}{*}{$\begin{array}{l}\text { Direção } \\
\text { paralela }\end{array}$} & \multirow{2}{*}{10} & 03 & 52,00 & 81,00 & 72,99 \\
\hline & & & 08 & 60,70 & 108,00 & 52,63 \\
\hline & & \multirow{2}{*}{12,5} & 01 & 66,50 & 134,00 & 86,03 \\
\hline & & & 04 & 80,20 & 133,00 & 113,64 \\
\hline & & \multirow{2}{*}{16} & 05 & 80,00 & 123,50 & 147,06 \\
\hline & & & 17 & 132,30 & 161,00 & 88,50 \\
\hline & \multirow{6}{*}{$\begin{array}{l}\text { Direção } \\
\text { Normal }\end{array}$} & \multirow{2}{*}{10} & 03 & 36,00 & 57,50 & 11,98 \\
\hline & & & 05 & 34,00 & 60,00 & 12,00 \\
\hline & & \multirow{2}{*}{12,5} & 01 & 50,60 & 77,50 & 16,77 \\
\hline & & & & 62,30 & 72,60 & 23,17 \\
\hline & & \multirow{2}{*}{16} & 04 & 64,40 & 87,70 & 23,08 \\
\hline & & & 08 & 64,00 & 77,00 & 22,35 \\
\hline \multirow{12}{*}{ Prego } & \multirow{6}{*}{$\begin{array}{l}\text { Direção } \\
\text { paralela }\end{array}$} & \multirow{4}{*}{4,4} & 05 & 29,10 & 52,70 & 16,00 \\
\hline & & & 07 & 33,00 & 66,00 & 26,81 \\
\hline & & & 01 & 32,80 & 57,80 & 38,61 \\
\hline & & & 08 & 35,40 & 65,50 & 31,25 \\
\hline & & \multirow{2}{*}{6,4} & 03 & 39,00 & 59,30 & 88,50 \\
\hline & & & 04 & 38,50 & 62,60 & 53,76 \\
\hline & \multirow{6}{*}{$\begin{array}{l}\text { Direção } \\
\text { Normal }\end{array}$} & \multirow{2}{*}{4,4} & 01 & 23,50 & 42,80 & 4,87 \\
\hline & & & 03 & 23,50 & 43,80 & 5,47 \\
\hline & & \multirow{2}{*}{5,4} & 05 & 29,50 & 53,40 & 9,29 \\
\hline & & & 07 & 35,00 & 59,70 & 16,28 \\
\hline & & \multirow{2}{*}{6,4} & 04 & 35,00 & 58,10 & 15,26 \\
\hline & & & 08 & 32,00 & 54,50 & 14,71 \\
\hline
\end{tabular}




\subsection{3 - Resistência e rigidez das ligações segundo o critério da NBR7190/97}

Nas tabelas 9 a 13, são expostos os resultados obtidos para a resistência (R) e a força que provoca a ruptura $\left(\mathrm{F}_{\text {rup}}\right)$ da ligação correspondente a quatro pinos e dois planos de corte cada um, segundo o método descrito nos itens 3.1.1, 3.1.2 e 3.1.4. Também são apresentados os valores da rigidez.

TABELA 9 - Resultados das ligações pelo critério NBR 7190/97 - Pinus Elliottii

\begin{tabular}{|c|c|c|c|c|c|c|}
\hline Tipo de pino & Solicitação & $\begin{array}{c}\text { d } \\
(\mathbf{m m})\end{array}$ & $\begin{array}{l}\text { Número } \\
\text { do } C . P \text {. }\end{array}$ & $\underset{(\mathbf{k N})}{\mathbf{R}}$ & $\begin{array}{r}\text { Frup } \\
(\mathbf{k N})\end{array}$ & $\begin{array}{r}\text { Rigidez } \\
(\mathrm{kN} / \mathrm{mm})\end{array}$ \\
\hline \multirow{12}{*}{ Parafuso } & \multirow{6}{*}{$\begin{array}{l}\text { Direção } \\
\text { paralela }\end{array}$} & \multirow{2}{*}{10} & 01 & 20,30 & 44,80 & 9,79 \\
\hline & & & 20 & 24,30 & 45,20 & 16,75 \\
\hline & & \multirow{2}{*}{12,5} & 07 & 40,30 & 49,70 & 15,80 \\
\hline & & & 09 & 37,00 & 52,40 & 17,79 \\
\hline & & \multirow{2}{*}{16} & 05 & 44,20 & 57,00 & 12,17 \\
\hline & & & 08 & 37,70 & & 14,39 \\
\hline & \multirow{6}{*}{$\begin{array}{l}\text { Direção } \\
\text { Normal }\end{array}$} & \multirow{2}{*}{10} & 01 & 10,90 & 20,90 & 6,80 \\
\hline & & & 05 & 14,70 & 23,30 & 3,52 \\
\hline & & \multirow{2}{*}{12,5} & 02 & 16,60 & 31,00 & 9,19 \\
\hline & & & 07 & 14,80 & 27,50 & 8,04 \\
\hline & & \multirow{2}{*}{16} & 05 & 19,10 & 26,50 & 5,06 \\
\hline & & & 09 & 18,70 & & 4,02 \\
\hline \multirow{12}{*}{ Prego } & \multirow{6}{*}{$\begin{array}{l}\text { Direção } \\
\text { paralela }\end{array}$} & \multirow{2}{*}{4,4} & 02 & 10,00 & 20,50 & 15,18 \\
\hline & & & 08 & 10,30 & 21,00 & 9,43 \\
\hline & & \multirow{2}{*}{5,4} & 01 & 11,20 & 25,00 & 16,26 \\
\hline & & & 05 & 10,70 & 25,50 & 19,61 \\
\hline & & \multirow{2}{*}{6,4} & 07 & 16,90 & 33,00 & 13,00 \\
\hline & & & 09 & 16,50 & 32,80 & 11,92 \\
\hline & \multirow{6}{*}{$\begin{array}{l}\text { Direção } \\
\text { Normal }\end{array}$} & \multirow{2}{*}{4,4} & 02 & 8,10 & 24,90 & 5,59 \\
\hline & & & 09 & 6,60 & 20,50 & 3,89 \\
\hline & & \multirow{2}{*}{5,4} & 01 & 8,70 & 21,60 & 5,75 \\
\hline & & & 07 & 8,20 & 22,60 & 3,62 \\
\hline & & \multirow{2}{*}{6,4} & 08 & 11,10 & 19,80 & 5,54 \\
\hline & & & $08 b$ & 10,60 & 22,50 & 9,29 \\
\hline
\end{tabular}


TABELA 10 - Resultados das ligações pelo critério NBR 7190/97 - Cupiúba

\begin{tabular}{|c|c|c|c|c|c|c|}
\hline Tipo de pino & Solicitação & $\begin{array}{c}\text { d } \\
(\mathbf{m m})\end{array}$ & $\begin{array}{l}\text { Número do } \\
\text { C. P. }\end{array}$ & $\underset{(\mathbf{k N})}{\mathbf{R}}$ & $\begin{array}{r}\text { Frup } \\
(\mathbf{k N})\end{array}$ & $\begin{array}{c}\text { Rigidez } \\
(\mathrm{kN} / \mathrm{mm})\end{array}$ \\
\hline \multirow{12}{*}{ Parafus o } & \multirow{6}{*}{$\begin{array}{l}\text { Direção } \\
\text { paralela }\end{array}$} & \multirow{2}{*}{10} & 08 & 39,50 & 71,00 & 39,84 \\
\hline & & & 12 & 37,50 & 68,00 & 38,17 \\
\hline & & \multirow{2}{*}{12,5} & 10 & 59,10 & 93,50 & 61,73 \\
\hline & & & 13 & 71,20 & 99,20 & 83,33 \\
\hline & & \multirow{2}{*}{16} & 06 & 72,10 & 116,50 & 78,74 \\
\hline & & & 09 & 68,30 & 122,00 & 98,04 \\
\hline & \multirow{6}{*}{$\begin{array}{l}\text { Direção } \\
\text { Normal }\end{array}$} & \multirow{2}{*}{10} & 09 & 28,20 & 44,50 & 98,85 \\
\hline & & & 10 & 27,40 & 39,00 & 11,49 \\
\hline & & \multirow{2}{*}{12,5} & 06 & 42,70 & 51,00 & 13,89 \\
\hline & & & 13 & 46,30 & 53,60 & 14,82 \\
\hline & & \multirow{2}{*}{16} & 08 & & 24,80 & 12,00 \\
\hline & & & 12 & 36,20 & 46,50 & 12,53 \\
\hline \multirow{12}{*}{ Prego } & \multirow{6}{*}{$\begin{array}{l}\text { Direção } \\
\text { paralela }\end{array}$} & \multirow{2}{*}{4,4} & 12 & 19,70 & 49,90 & 14,31 \\
\hline & & & 13 & 19,80 & 38,00 & 28,90 \\
\hline & & \multirow{2}{*}{5,4} & 06 & 26,30 & 56,00 & 13,74 \\
\hline & & & 08 & 23,00 & 48,60 & 23,26 \\
\hline & & \multirow{2}{*}{6,4} & 09 & 29,70 & 55,80 & 41,84 \\
\hline & & & 10 & 32,40 & 64,10 & 32,26 \\
\hline & \multirow{6}{*}{$\begin{array}{l}\text { Direção } \\
\text { Normal }\end{array}$} & \multirow{2}{*}{4,4} & 06 & 12,20 & 34,80 & 6,08 \\
\hline & & & 08 & 14,20 & 37,00 & 5,48 \\
\hline & & \multirow{2}{*}{5,4} & 12 & 15,80 & 42,30 & 19,05 \\
\hline & & & 13 & 19,00 & 34,30 & 10,75 \\
\hline & & \multirow{2}{*}{6,4} & 09 & 22,90 & 50,60 & 9,90 \\
\hline & & & 10 & 21,20 & 48,00 & 9,85 \\
\hline
\end{tabular}


TABELA 11 - Resultados das ligações pelo critério NBR 7190/97 - Garapa

\begin{tabular}{|c|c|c|c|c|c|c|}
\hline Tipo de pino & Solicitação & $\begin{array}{c}\mathrm{D} \\
(\mathbf{m m})\end{array}$ & $\begin{array}{l}\text { Número } \\
\text { do C. P. }\end{array}$ & $\begin{array}{c}\mathbf{R} \\
(\mathbf{k N})\end{array}$ & $\begin{array}{r}\text { Frup } \\
(\mathbf{k N})\end{array}$ & $\begin{array}{c}\text { Rigidez } \\
\text { (kN/mm) }\end{array}$ \\
\hline \multirow{12}{*}{ Parafuso } & \multirow{6}{*}{$\begin{array}{l}\text { Direção } \\
\text { paralela }\end{array}$} & \multirow{2}{*}{10} & 17 & 47,20 & 74,00 & 85,47 \\
\hline & & & 18 & 45,10 & 77,00 & 84,75 \\
\hline & & \multirow{2}{*}{12,5} & 12 & 66,30 & 108,00 & 81,97 \\
\hline & & & 16 & 67,70 & 99,00 & 73,53 \\
\hline & & \multirow{2}{*}{16} & 13 & 85,10 & 128,00 & 92,59 \\
\hline & & & 14 & 73,90 & 136,00 & 108,11 \\
\hline & \multirow{6}{*}{$\begin{array}{l}\text { Direção } \\
\text { Normal }\end{array}$} & \multirow{2}{*}{10} & $12 \mathrm{a}$ & 30,70 & 48,50 & 18,24 \\
\hline & & & 16 & 29,40 & 60,00 & 16,00 \\
\hline & & \multirow{2}{*}{12,5} & $12 \mathrm{~b}$ & 50,20 & 65,00 & 16,13 \\
\hline & & & 13 & 51,50 & 60,20 & 15,89 \\
\hline & & \multirow{2}{*}{16} & 14 & 59,50 & 66,30 & 18,99 \\
\hline & & & 17 & 64,30 & 70,00 & 19,67 \\
\hline \multirow{11}{*}{ Prego } & \multirow{5}{*}{$\begin{array}{l}\text { Direção } \\
\text { paralela }\end{array}$} & 4,4 & $\begin{array}{l}14 \\
16 \\
\end{array}$ & $\begin{array}{l}17,4 \\
17,7 \\
\end{array}$ & $\begin{array}{l}60,00 \\
58,20\end{array}$ & $\begin{array}{l}60,61 \\
36,63 \\
\end{array}$ \\
\hline & & \multirow{2}{*}{5,4} & 17 & 31,70 & 61,80 & 62,89 \\
\hline & & & 18 & 28,90 & 61,00 & 57,14 \\
\hline & & \multirow{2}{*}{6,4} & 12 & 30,30 & 54,50 & 81,30 \\
\hline & & & 13 & 33,00 & 55,80 & 81,97 \\
\hline & \multirow{6}{*}{$\begin{array}{l}\text { Direção } \\
\text { Normal }\end{array}$} & \multirow{2}{*}{4,4} & 16 & 16,80 & 49,00 & 8,51 \\
\hline & & & 18 & 16,60 & 53,70 & 7,70 \\
\hline & & \multirow{2}{*}{5,4} & 14 & 22,80 & 51,50 & 12,15 \\
\hline & & & 17 & 25,20 & 61,00 & 16,13 \\
\hline & & \multirow{2}{*}{6,4} & 12 & 23,70 & 56,00 & 22,73 \\
\hline & & & 13 & 24,90 & 46,80 & 17,14 \\
\hline
\end{tabular}


TABELA 12 - Resultados das ligações pelo critério NBR 7190/97 - Eucalipto

\section{Citriodora}

\begin{tabular}{|c|c|c|c|c|c|c|}
\hline Tipo de pino & Solicitação & $\begin{array}{c}\text { d } \\
(\mathbf{m m})\end{array}$ & $\begin{array}{l}\text { Número } \\
\text { do C. P. }\end{array}$ & $\begin{array}{c}\mathbf{R} \\
(\mathbf{k N})\end{array}$ & $\begin{array}{r}\text { Frup } \\
(\mathbf{k N})\end{array}$ & $\begin{array}{c}\text { Rigidez } \\
(\mathrm{kN} / \mathrm{mm})\end{array}$ \\
\hline \multirow{12}{*}{ Parafuso } & \multirow{6}{*}{$\begin{array}{l}\text { Direção } \\
\text { paralela }\end{array}$} & \multirow{2}{*}{10} & 07 & 47,20 & 83,00 & 86,96 \\
\hline & & & 05 & 51,20 & 79,00 & 100,00 \\
\hline & & \multirow{2}{*}{12,5} & 10 & 73,70 & 109,80 & 93,46 \\
\hline & & & 13 & 72,00 & 110,50 & 106,05 \\
\hline & & \multirow{2}{*}{16} & 09 & 95,00 & 137,50 & 132,45 \\
\hline & & & 12 & 88,00 & 126,00 & 126,74 \\
\hline & \multirow{6}{*}{$\begin{array}{l}\text { Direção } \\
\text { Normal }\end{array}$} & \multirow{2}{*}{10} & 10 & 33,30 & 58,50 & 12,18 \\
\hline & & & $13 b$ & 31,10 & 44,50 & 13,44 \\
\hline & & \multirow{2}{*}{12,5} & 09 & & 65,00 & 16,67 \\
\hline & & & 10 & & 67,60 & 15,57 \\
\hline & & \multirow{2}{*}{16} & 07 & & 63,70 & 20,96 \\
\hline & & & 09 & & 74,30 & 20,73 \\
\hline \multirow{10}{*}{ Prego } & \multirow{5}{*}{$\begin{array}{l}\text { Direção } \\
\text { paralela }\end{array}$} & \multirow{2}{*}{4,4} & 13 & 19,20 & 41,10 & 78,13 \\
\hline & & & 07 & 20,20 & 37,50 & 69,36 \\
\hline & & 5,4 & 11 & 23,30 & 41,00 & 57,80 \\
\hline & & \multirow{2}{*}{6,4} & 01 & 35,00 & 55,50 & 102,78 \\
\hline & & & 05 & 36,60 & 54,50 & 91,74 \\
\hline & \multirow{5}{*}{$\begin{array}{l}\text { Direção } \\
\text { Normal }\end{array}$} & 4,4 & 10 & 14,30 & 36,10 & 13,70 \\
\hline & & \multirow{2}{*}{5,4} & 09 & 21,60 & 44,50 & 15,79 \\
\hline & & & 11 & 22,40 & 48,70 & 9,30 \\
\hline & & \multirow{2}{*}{6,4} & 05 & 24,00 & 52,00 & 14,11 \\
\hline & & & 13 & 24,70 & 43,00 & 14,54 \\
\hline
\end{tabular}


TABELA 13 - Resultados das ligações pelo critério NBR 7190/97 - Jatobá

\begin{tabular}{|c|c|c|c|c|c|c|}
\hline Tipo de pino & Solicitação & $\begin{array}{c}\text { d } \\
(\mathrm{mm})\end{array}$ & $\begin{array}{l}\text { Número } \\
\text { do } C . P \text {. }\end{array}$ & $\begin{array}{c}\mathbf{R} \\
(\mathbf{k N})\end{array}$ & $\begin{array}{r}\text { Frup } \\
(\mathbf{k N})\end{array}$ & $\begin{array}{c}\text { Rigidez } \\
\text { (kN/mm) }\end{array}$ \\
\hline \multirow{12}{*}{ Parafuso } & \multirow{6}{*}{$\begin{array}{l}\text { Direção } \\
\text { paralela }\end{array}$} & \multirow{2}{*}{10} & 03 & 46,70 & 81,00 & 89,29 \\
\hline & & & 08 & 51,00 & 108,00 & 70,92 \\
\hline & & \multirow{2}{*}{12,5} & 01 & 69,30 & 134,00 & 103,84 \\
\hline & & & 04 & 78,00 & 133,00 & 130,89 \\
\hline & & \multirow{2}{*}{16} & 05 & 90,70 & 123,50 & 152,67 \\
\hline & & & 17 & 110,00 & 161,00 & 147,93 \\
\hline & \multirow{6}{*}{$\begin{array}{l}\text { Direção } \\
\text { Normal }\end{array}$} & \multirow{2}{*}{10} & 03 & 32,00 & 57,50 & 12,96 \\
\hline & & & 05 & 32,60 & 60,00 & 12,78 \\
\hline & & \multirow{2}{*}{12,5} & 01 & 53,20 & 77,50 & 17,02 \\
\hline & & & $\mathrm{xx}$ & 63,30 & 72,60 & 23,95 \\
\hline & & \multirow{2}{*}{16} & 04 & 69,00 & 87,70 & 24,05 \\
\hline & & & 08 & 66,00 & 77,00 & 22,35 \\
\hline \multirow{12}{*}{ Prego } & \multirow{6}{*}{$\begin{array}{l}\text { Direção } \\
\text { paralela }\end{array}$} & \multirow{2}{*}{4,4} & 05 & 23,40 & 52,70 & 24,39 \\
\hline & & & 07 & 30,40 & 66,00 & 30,77 \\
\hline & & \multirow{2}{*}{5,4} & 01 & 28,00 & 57,80 & 50,00 \\
\hline & & & 08 & 29,10 & 65,50 & 50,00 \\
\hline & & \multirow{2}{*}{6,4} & 03 & 35,50 & 59,30 & 111,11 \\
\hline & & & 04 & 31,60 & 62,60 & 86,96 \\
\hline & \multirow{6}{*}{$\begin{array}{l}\text { Direção } \\
\text { Normal }\end{array}$} & \multirow{2}{*}{4,4} & 01 & 16,20 & 42,80 & 8,76 \\
\hline & & & 03 & 16,20 & 43,80 & 9,66 \\
\hline & & \multirow{2}{*}{5,4} & 05 & 22,30 & 53,40 & 15,26 \\
\hline & & & 07 & 29,10 & 59,70 & 20,90 \\
\hline & & \multirow{2}{*}{6,4} & 04 & 28,00 & 58,10 & 19,72 \\
\hline & & & 08 & 26,80 & 54,50 & 20,15 \\
\hline
\end{tabular}




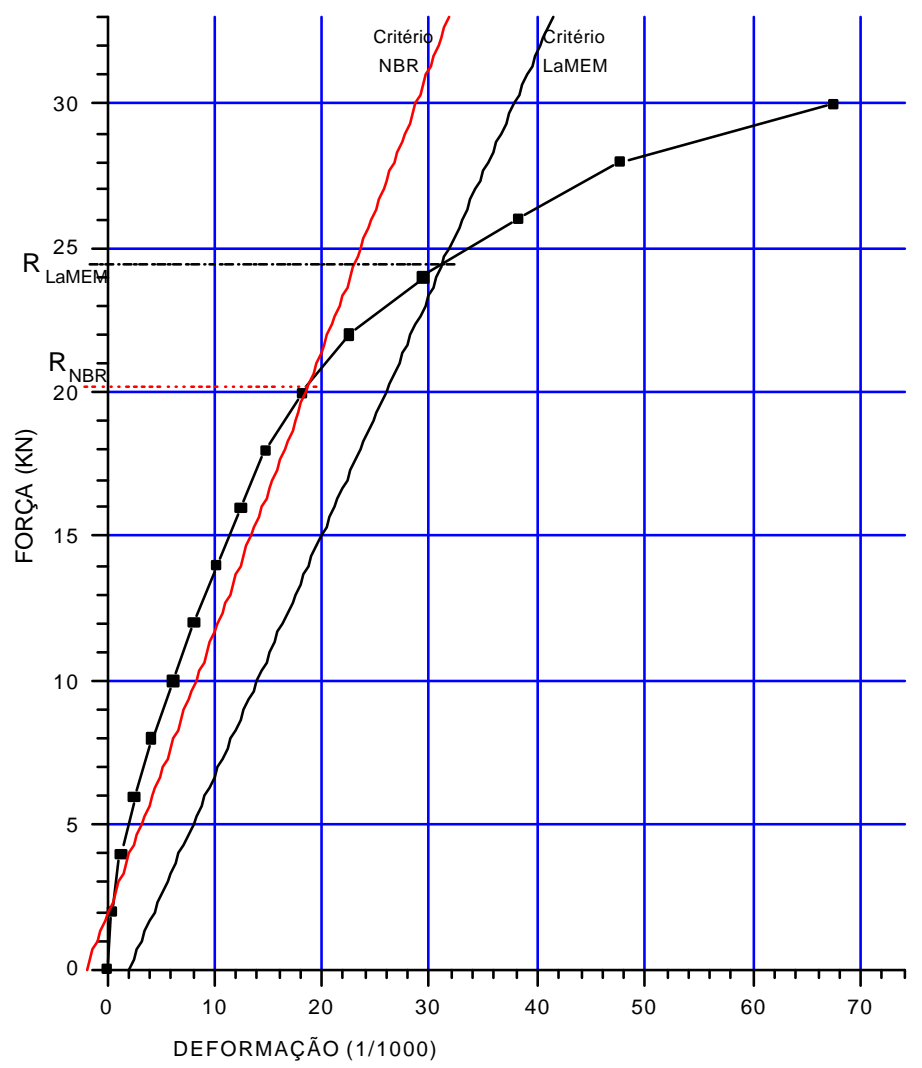

FIGURA 30 - Determinação das resistências das ligações pelo critério da equipe LaMEM e pelo critério NBR

\section{2 - Resultados obtidos nos ensaios complementares}

No item 4.2.1, são apresentadas tabelas com os resultados dos ensaios de caracterização das peças de madeira, conforme metodologia especificada no item 3.2. Também é exposto o resultado da resistência ao escoamento do aço e da resistência das ligações nas tabelas dos itens 4.2.2 e 4.2.3, respectivamente. 


\subsection{1 - Caracterização da madeira}

As tabelas 14 e 15 mostram os valores da resistência ao embutimento na direção paralela às fibras da madeira, para pregos e parafusos, conforme descrito no item 3.2.

TABELA 14 - Resistência ao embutimento paralelo às fibras - primeira série de ensaios

\begin{tabular}{|c|c|c|c|c|c|c|}
\hline \multirow[b]{2}{*}{ Solicitação } & \multirow[b]{2}{*}{ Tipo de pino } & \multirow{2}{*}{$\begin{array}{c}\mathrm{d} \\
(\mathrm{mm})\end{array}$} & \multicolumn{2}{|c|}{ Pinus Ellliottii } & \multicolumn{2}{|c|}{ Cupiúba } \\
\hline & & & C. $\mathbf{P}$. & $\begin{array}{c}\mathbf{f}_{\mathrm{e}, 0} \\
(\mathrm{MPa})\end{array}$ & C. $\mathbf{P}$. & $\begin{array}{c}\mathbf{f}_{\mathbf{e}, 0} \\
\text { (MPa) }\end{array}$ \\
\hline \multirow{12}{*}{$\begin{array}{l}\text { Direção } \\
\text { Paralela }\end{array}$} & \multirow{6}{*}{ Parafuso } & \multirow{2}{*}{10} & $2(\mathrm{P} 1)$ & 26,9 & $2 \mathrm{C} 1)$ & 61,9 \\
\hline & & & $3(\mathrm{P} 1)$ & 22,3 & $3(\mathrm{C} 1)$ & 65,9 \\
\hline & & \multirow{2}{*}{12.5} & $2(\mathrm{P} 2)$ & 41,3 & $2(\mathrm{C} 2)$ & 81,3 \\
\hline & & & $3(\mathrm{P} 2)$ & 41,5 & $3(\mathrm{C} 2)$ & 76,7 \\
\hline & & \multirow{2}{*}{16} & $2(\mathrm{P} 3)$ & 38,9 & $2(\mathrm{C} 3)$ & 59,4 \\
\hline & & & 3 (P3) & 41,1 & $3(\mathrm{C} 3)$ & 62,0 \\
\hline & \multirow{6}{*}{ Prego } & \multirow{2}{*}{4,4} & $2(\mathrm{P} 4)$ & 22,0 & $2(\mathrm{C} 4)$ & 41,8 \\
\hline & & & $3(\mathrm{P} 4)$ & 20,8 & $3(\mathrm{C} 4)$ & 40,0 \\
\hline & & \multirow{2}{*}{5,4} & 2 (P5) & 22,0 & $2(\mathrm{C} 5)$ & 46,7 \\
\hline & & & $3(\mathrm{P} 5)$ & 20,9 & $3(\mathrm{C} 5)$ & 49,0 \\
\hline & & \multirow{2}{*}{6,4} & $2(\mathrm{P} 6)$ & 23,2 & 2 (C6) & 42,7 \\
\hline & & & 3 (P6) & & 3 (C6) & 47,5 \\
\hline
\end{tabular}


TABELA 15 - Resistência ao embutimento paralelo às fibras - segunda série de ensaios

\begin{tabular}{|c|c|c|c|c|c|c|}
\hline \multirow[b]{2}{*}{ Solicitação } & \multirow[b]{2}{*}{ Tipo de pino } & \multirow{2}{*}{$\begin{array}{c}\text { d } \\
(\mathbf{m m})\end{array}$} & \multicolumn{2}{|c|}{ Jatobá } & \multicolumn{2}{|c|}{ Cupiúba } \\
\hline & & & C. $\mathbf{P}$. & $\begin{array}{c}\mathbf{f}_{\mathbf{e}, 0} \\
(\mathbf{M P a})\end{array}$ & C. $\mathbf{P}$. & $\begin{array}{c}\mathbf{f}_{\mathbf{e}, \mathbf{0}} \\
(\mathbf{M P a})\end{array}$ \\
\hline \multirow{12}{*}{$\begin{array}{l}\text { Direção } \\
\text { Paralela }\end{array}$} & \multirow{6}{*}{ Parafuso } & \multirow{2}{*}{10} & $2(\mathrm{~J} 2)$ & & 1 (C7) & 43,80 \\
\hline & & & $3 \quad(\mathrm{~J} 2)$ & 69,50 & 2 (C7) & 52,80 \\
\hline & & \multirow{2}{*}{12.5} & $5 \quad(\mathrm{~J} 2)$ & 86,60 & 4 (C8) & 51,00 \\
\hline & & & $6(\mathrm{~J} 2)$ & 88,50 & $5 \quad(\mathrm{C} 8)$ & 51,20 \\
\hline & & \multirow{2}{*}{16} & $8 \quad(\mathrm{~J} 2)$ & 74,70 & 7 (C8) & 38,50 \\
\hline & & & $9 \quad(\mathrm{~J} 2)$ & & 8 (C8) & 45,80 \\
\hline & \multirow{6}{*}{ Prego } & \multirow{2}{*}{4,4} & $2(\mathrm{~J} 1)$ & 85,10 & & \\
\hline & & & $3(\mathrm{~J} 1)$ & 86,10 & 3 (C7) & 48,30 \\
\hline & & \multirow{2}{*}{5,4} & $5 \quad(\mathrm{~J} 1)$ & 90,60 & & \\
\hline & & & $6(\mathrm{~J} 1)$ & 78,30 & 6 (C7) & 47,60 \\
\hline & & \multirow{2}{*}{6,4} & $8 \quad(\mathrm{~J} 1)$ & 84,50 & 8 (C7) & 40,40 \\
\hline & & & $9(\mathrm{~J} 1)$ & 86,10 & 9 (C7) & 41,20 \\
\hline
\end{tabular}

Nas tabelas 16 e 17, são exibidos os resultados obtidos para a caracterização da madeira correspondente à resistência à compressão paralela às fibras, segundo o método descrito no item 3.2. 
TABELA 16 - Resistência à compressão paralela às fibras - primeira série de ensaios

\begin{tabular}{|c|c|c|c|}
\hline \multicolumn{2}{|c|}{ Pinus Elliottii } & \multicolumn{2}{|c|}{ Cupiúba } \\
\hline $\mathbf{C P}$ & $\begin{array}{r}\mathbf{f}_{\mathrm{co}} \\
\mathrm{MPa}\end{array}$ & $\mathbf{C P}$ & $\begin{array}{c}\mathbf{f}_{\mathrm{c} 0} \\
\mathrm{MPa}\end{array}$ \\
\hline 1 (P1) & 32,80 & $1 \quad(\mathrm{C} 1)$ & 53,75 \\
\hline $2(\mathrm{P} 1)$ & 33,27 & $2(\mathrm{C} 1)$ & 52,42 \\
\hline $3(\mathrm{P} 1)$ & 33,25 & $3(\mathrm{C} 1)$ & 47,12 \\
\hline $1(\mathrm{P} 2)$ & 34,74 & $1(\mathrm{C} 2)$ & 59,36 \\
\hline $2(\mathrm{P} 2)$ & 34,42 & $2(\mathrm{C} 2)$ & 58,31 \\
\hline $3(\mathrm{P} 2)$ & 34,61 & $3(\mathrm{C} 2)$ & 58,38 \\
\hline 1 (P3) & 44,10 & 1 (C3) & 56,07 \\
\hline $2(\mathrm{P} 3)$ & 43,80 & $2(\mathrm{C} 3)$ & 56,56 \\
\hline 3 (P3) & 43,73 & 3 (C3) & 56,34 \\
\hline 1 (P4) & 34,40 & 1 (C4) & 51,55 \\
\hline $2(\mathrm{P} 4)$ & 32,71 & $2(\mathrm{C} 4)$ & 59,95 \\
\hline $3(\mathrm{P} 4)$ & 34,83 & 3 (C4) & 49,41 \\
\hline 1 (P5) & 27,44 & 1 (C5) & 47,70 \\
\hline 2 (P5) & 34,17 & $2(\mathrm{C} 5)$ & 46,08 \\
\hline 3 (P5) & 32,37 & 3 (C5) & 53,29 \\
\hline 1 (P6) & 36,77 & 1 (C6) & 50,10 \\
\hline 2 (P6) & 35,63 & 2 (C6) & 51,64 \\
\hline $3 \quad(\mathrm{P} 6)$ & 32,58 & 3 (C6) & 54,54 \\
\hline
\end{tabular}


TABELA 17 - Resistência à compressão paralela às fibras - segunda série de ensaios

\begin{tabular}{|c|c|c|c|}
\hline \multicolumn{2}{|c|}{ Jatobá } & \multicolumn{2}{c|}{ Cupiúba } \\
\hline $\mathbf{2}$ CP & $\begin{array}{c}\mathbf{f}_{\mathbf{c , 0}} \\
\mathbf{M P a}\end{array}$ & $\mathbf{C P}$ & $\mathbf{f}_{\mathbf{c}, \mathbf{0}} \mathbf{M P a}$ \\
$1(\mathrm{~J} 1)$ & 95,52 & $1(\mathrm{C} 7)$ & 48,19 \\
\hline $2 \mathrm{~J} 1)$ & 91,85 & & \\
\hline $3(\mathrm{~J} 1)$ & 87,48 & $3(\mathrm{C} 7)$ & 49,20 \\
\hline $4(\mathrm{~J} 1)$ & 86,60 & $1(\mathrm{C} 8)$ & 54,08 \\
\hline & & $2(\mathrm{C} 8)$ & 50,10 \\
\hline & & $3(\mathrm{C} 8)$ & 54,16 \\
\hline
\end{tabular}

Nas tabelas 18 e 19, são mostrados os teores de umidade das espécies utilizadas na primeira e segunda série de ensaios obtidos dentro dos preceitos descritos no item 3.2. 
TABELA 18 - Teor de umidade das vigas - primeira série de ensaios

\begin{tabular}{|c|c|c|c|}
\hline \multicolumn{2}{|c|}{ Pinus Elliottii } & \multicolumn{2}{|c|}{ Cupiúba } \\
\hline $\mathbf{C P}$ & $\mathrm{U}(\%)$ & $\mathbf{C P}$ & $\mathrm{U}(\%)$ \\
\hline $1 \quad(\mathrm{P} 1)$ & 11,37 & $1(\mathrm{C} 1)$ & 14,12 \\
\hline $2(\mathrm{P} 1)$ & 11,71 & $2(\mathrm{C} 1)$ & 13,13 \\
\hline $3 \quad(\mathrm{P} 1)$ & 11,53 & $3 \quad(\mathrm{C} 1)$ & 12,86 \\
\hline $1 \quad(\mathrm{P} 2)$ & 11,82 & $1 \quad(\mathrm{C} 2)$ & 12,79 \\
\hline $2(\mathrm{P} 2)$ & 11,69 & $2(\mathrm{C} 2)$ & 13,24 \\
\hline $3 \quad(\mathrm{P} 2)$ & 11,43 & $3(\mathrm{C} 2)$ & 13,08 \\
\hline $1 \quad(\mathrm{P} 3)$ & 11,58 & 1 (C3) & 13,26 \\
\hline 2 (P3) & 11,05 & 2 (C3) & 13,52 \\
\hline $3 \quad(\mathrm{P} 3)$ & 11,19 & 3 (C3) & 13,20 \\
\hline $1 \quad(\mathrm{P} 4)$ & 5,84 & $1 \quad(\mathrm{C} 4)$ & 14,70 \\
\hline $2(\mathrm{P} 4)$ & 11,03 & $2(\mathrm{C} 4)$ & 13,84 \\
\hline $3 \quad(\mathrm{P} 4)$ & 10,63 & $3(\mathrm{C} 4)$ & 14,47 \\
\hline $1 \quad(\mathrm{P} 5)$ & 21,26 & 1 (C5) & 13,97 \\
\hline 2 (P5) & 20,61 & 2 (C5) & 14,05 \\
\hline $3 \quad(\mathrm{P} 5)$ & 21,25 & 3 (C5) & 14,52 \\
\hline $1 \quad(\mathrm{P} 6)$ & 11,44 & 1 (C6) & 14,44 \\
\hline $2(\mathrm{P} 6)$ & 11,27 & 2 (C6) & 14,57 \\
\hline $3 \quad(\mathrm{P} 6)$ & 11,11 & $3(\mathrm{C} 6)$ & 14,16 \\
\hline
\end{tabular}

TABELA 19 -Teor de umidade das vigas - segunda série de ensaios

\begin{tabular}{|c|c|c|c|}
\hline \multicolumn{3}{|c|}{ Jatobá } & \multicolumn{2}{c|}{ Cupiúba } \\
\hline CP & $\mathbf{U}(\%)$ & CP & U (\%) \\
\hline $1(\mathrm{~J} 1)$ & 13,50 & $1(\mathrm{C} 7)$ & 20,13 \\
\hline $2(\mathrm{~J} 1)$ & 13,61 & $2(\mathrm{C} 7)$ & 15,87 \\
\hline $3(\mathrm{~J} 1)$ & 13,34 & $3(\mathrm{C} 7)$ & 18,07 \\
\hline $1(\mathrm{~J} 2)$ & 15,90 & $1(\mathrm{C} 8)$ & 32,34 \\
\hline $2(\mathrm{~J} 2)$ & 15,95 & $2(\mathrm{C} 8)$ & 30,97 \\
\hline $3(\mathrm{~J} 2)$ & 16,08 & $3(\mathrm{C} 8)$ & 31,14 \\
\hline
\end{tabular}




\subsection{2 - Pinos metálicos: resistência ao escoamento do aço}

Na tabela 20, são apresentados os valores obtidos para a resistência ao escoamento do aço, os quais correspondem às médias dos resultados de dois ensaios para cada tipo de pino, conforme disposto no item 3.2.

TABELA 20 - Resistência ao escoamento do aço dos pinos utilizados na primeira e segunda séries de ensaios

\begin{tabular}{|c|c|c|c|c|}
\hline Tipo de pino & $\begin{array}{c}\text { Série } \\
\text { ensaio }\end{array}$ & $\begin{array}{c}\mathbf{d} \\
(\mathbf{m m})\end{array}$ & $\mathbf{C P}$ & $\begin{array}{c}\mathbf{f}_{\mathbf{y}} \\
(\mathbf{M P a})\end{array}$ \\
\hline \multirow{6}{*}{$\begin{array}{c}\text { Primeira série: } \\
\text { Parafusos Aço } \\
1030\end{array}$} & \multirow{2}{*}{ 1a. } & \multirow{2}{*}{10} & 01 & 660,0 \\
\hline & & & 02 & 662,0 \\
\hline & \multirow{2}{*}{ 1a. e $2 a$. } & \multirow{2}{*}{12,5} & 03 & 570,0 \\
\hline & & & 04 & 583,0 \\
\hline & \multirow{2}{*}{ 1a. } & \multirow{2}{*}{16} & 05 & 556,0 \\
\hline & & & 06 & 556,0 \\
\hline \multirow{4}{*}{$\begin{array}{c}\text { Segunda série: } \\
\text { Parafuso Aço } \\
1045\end{array}$} & \multirow{2}{*}{$2 a}$. & \multirow{2}{*}{10} & 11 & 863,0 \\
\hline & & & 12 & 863,0 \\
\hline & \multirow{2}{*}{$2 \mathbf{a}}$. & \multirow{2}{*}{16} & 13 & 765,0 \\
\hline & & & 14 & 765,0 \\
\hline \multirow{6}{*}{$\begin{array}{l}\text { Prego } \\
\text { Gerdau }\end{array}$} & \multirow{2}{*}{ 1a.e 2a. } & \multirow{2}{*}{4,4} & 01 & 775,0 \\
\hline & & & 02 & 756,3 \\
\hline & \multirow{2}{*}{ 1a.e $2 a$. } & \multirow{2}{*}{5,4} & 03 & 769,0 \\
\hline & & & 04 & 786,2 \\
\hline & \multirow{2}{*}{ 1a. e $2 a$. } & \multirow{2}{*}{6,4} & 05 & 782,8 \\
\hline & & & 06 & 775,0 \\
\hline
\end{tabular}




\subsection{3 - Resultados obtidos nos ensaios de ligações}

Nas tabelas 21 a 24, são apresentados os resultados obtidos para a resistência (R) e a força que provoca a ruptura $\left(\mathrm{F}_{\text {rup }}\right)$ da ligação, correspondentes a quatro pinos com dois planos de corte cada um, segundo o método descrito no item 3.2.

Nas figuras 31 a 34, são expostos exemplos dos diagramas utilizados na determinação dos resultados da resistência convencional das ligações, representando ligações com pregos e parafusos em madeiras de densidades diferentes. Nessas figuras, são indicadas também as respectivas forças de ruptura. Como o método do ensaio não permitiu obter as deformações até a fase de ruptura, foi feita a projeção destas em linha tracejada.

TABELA 21 - Resistência e força de ruptura na direção paralela Pinus Eliottii - primeira série de ensaios

\begin{tabular}{|c|c|c|c|c|}
\hline Tipo de pino & $\begin{array}{c}\mathrm{d} \\
(\mathrm{mm})\end{array}$ & $\mathbf{C P}$ & $\begin{array}{c}\mathbf{R} \\
(\mathbf{k N})\end{array}$ & $\begin{array}{r}\text { Frup } \\
(\mathbf{k N})\end{array}$ \\
\hline \multirow{9}{*}{ Parafuso } & \multirow{3}{*}{10} & 2 (P1) & 35,30 & 54,50 \\
\hline & & $3(\mathrm{P} 1)$ & 34,00 & 55,00 \\
\hline & & 4 (P1) & 32,00 & 51,50 \\
\hline & \multirow{3}{*}{12,5} & $2(\mathrm{P} 2)$ & 64,10 & 88,00 \\
\hline & & $3(\mathrm{P} 2)$ & 61,80 & 88,50 \\
\hline & & $4 \quad(\mathrm{P} 2)$ & 60,00 & 73,50 \\
\hline & \multirow{3}{*}{16} & 2 (P3) & 75,60 & 104,50 \\
\hline & & $3 \quad(\mathrm{P} 3)$ & 76,10 & 102,00 \\
\hline & & 4 (P3) & 65,80 & 99,50 \\
\hline \multirow{9}{*}{ Prego } & \multirow{3}{*}{4,4} & $2(\mathrm{P} 4)$ & & 16,90 \\
\hline & & $3 \quad(\mathrm{P} 4)$ & 8,10 & 16,00 \\
\hline & & 4 (P4) & 8,20 & 16,65 \\
\hline & \multirow{3}{*}{5,4} & 2 (P5) & 11,95 & 24,10 \\
\hline & & 3 (P5) & 11,35 & 23,60 \\
\hline & & 4 (P5) & 10,60 & 23,40 \\
\hline & \multirow{3}{*}{6,4} & 2 (P6) & 13,60 & 28,40 \\
\hline & & 3 (P6) & 13,00 & 27,00 \\
\hline & & 4 (P6) & 13,40 & 26,00 \\
\hline
\end{tabular}


TABELA 22 - Resistência e força de ruptura na direção paralela - Cupiúba primeira série de ensaios

\begin{tabular}{|c|c|c|c|c|}
\hline Tipo de pino & $\begin{array}{c}\mathbf{d} \\
(\mathbf{m m})\end{array}$ & $\mathbf{C P}$ & $\underset{(\mathbf{k N})}{\mathbf{R}}$ & $\begin{array}{r}\text { Frup } \\
(\mathbf{k N})\end{array}$ \\
\hline \multirow{9}{*}{ Parafuso } & \multirow{3}{*}{10} & $2(\mathrm{C} 1)$ & 53,00 & 72,80 \\
\hline & & $3(\mathrm{C} 1)$ & 53,40 & 70,00 \\
\hline & & 4 (C1) & 52,70 & 72,40 \\
\hline & \multirow{3}{*}{12,5} & $2(\mathrm{C} 2)$ & 86,00 & 107,50 \\
\hline & & $3(\mathrm{C} 2)$ & 80,60 & 100,00 \\
\hline & & 4 (C2) & 82,50 & 107,50 \\
\hline & \multirow{3}{*}{16} & 2 (C3) & 107,00 & 146,00 \\
\hline & & 3 (C3) & 112,50 & 148,00 \\
\hline & & 4 (C3) & 131,60 & 158,00 \\
\hline \multirow{9}{*}{ Prego } & \multirow{3}{*}{4,4} & $2(\mathrm{C} 4)$ & 13,80 & 35,10 \\
\hline & & $3(\mathrm{C} 4)$ & 12,90 & 27,00 \\
\hline & & 4 (C4) & 12,20 & 26,50 \\
\hline & \multirow{3}{*}{5,4} & 2 (C5) & 20,60 & 35,20 \\
\hline & & 3 (C5) & 21,50 & 35,20 \\
\hline & & 4 (C5) & 22,90 & 41,30 \\
\hline & \multirow{3}{*}{6,4} & 2 (C6) & 20,00 & 43,40 \\
\hline & & 3 (C6) & 20,00 & 52,80 \\
\hline & & 4 (C6) & 21,10 & 46,50 \\
\hline
\end{tabular}


TABELA 23 - Resistência e força de ruptura na direção paralela - Cupiúba segunda série de ensaios

\begin{tabular}{|c|c|c|c|c|}
\hline Tipo de pino & $\begin{array}{c}\mathbf{d} \\
(\mathbf{m m})\end{array}$ & $\mathbf{C P}$ & $\underset{(\mathbf{k N})}{\mathbf{R}}$ & $\begin{array}{r}\text { Frup } \\
(\mathbf{k N})\end{array}$ \\
\hline \multirow{6}{*}{ Parafuso } & \multirow{2}{*}{10} & 1 (C7) & 53,20 & 77,00 \\
\hline & & 2 (C7) & 52,10 & 77,50 \\
\hline & \multirow{2}{*}{12,5} & 2 (C8) & 78,10 & 111,00 \\
\hline & & 3 (C8) & 89,10 & 112,50 \\
\hline & \multirow{2}{*}{16} & $5 \quad(\mathrm{C} 8)$ & 113,40 & 136,50 \\
\hline & & $6(\mathrm{C} 8)$ & 116,6 & 148,00 \\
\hline \multirow{5}{*}{ Prego } & \multirow{2}{*}{4,4} & $2(\mathrm{C} 7)$ & 16,90 & 33,7 \\
\hline & & 3 (C7) & 16,90 & 35,4 \\
\hline & 5,4 & 6 (C7) & 21,00 & 43,20 \\
\hline & \multirow{2}{*}{6,4} & 8 (C7) & 24,4 & 60,30 \\
\hline & & 9 (C7) & 23,60 & 61,80 \\
\hline
\end{tabular}

TABELA 24 - Resistência e força de ruptura na direção paralela - Jatobá segunda série de ensaios

\begin{tabular}{|c|c|c|c|c|}
\hline Tipo de pino & $\begin{array}{c}\mathrm{d} \\
(\mathrm{mm})\end{array}$ & $\begin{array}{c}\mathbf{C P} \\
2(\mathrm{~J} 2)\end{array}$ & $\begin{array}{c}\mathbf{R} \\
(\mathbf{k N}) \\
60,70\end{array}$ & $\begin{array}{r}\text { Frup } \\
(\mathbf{k N}) \\
75,00\end{array}$ \\
\hline \multirow{5}{*}{ Parafuso } & 10 & $3(\mathrm{~J} 2)$ & 57,70 & 76,00 \\
\hline & \multirow{2}{*}{12,5} & $5 \quad(J 2)$ & 101,20 & 114,00 \\
\hline & & $6 \quad(\mathrm{~J} 2)$ & 95,60 & 114,00 \\
\hline & \multirow{2}{*}{16} & $8 \quad(\mathrm{~J} 2)$ & 153,80 & 178,50 \\
\hline & & $9(\mathrm{~J} 2)$ & & 161,00 \\
\hline \multirow{6}{*}{ Prego } & \multirow{2}{*}{4,4} & $2(\mathrm{~J} 1)$ & 20,70 & 39,80 \\
\hline & & $3(\mathrm{~J} 1)$ & 19,70 & 40,00 \\
\hline & \multirow{2}{*}{5,4} & $5 \quad(\mathrm{~J} 1)$ & 28,90 & 40,80 \\
\hline & & $6(\mathrm{~J} 1)$ & 30,20 & 40,80 \\
\hline & \multirow{2}{*}{6,4} & $8(\mathrm{~J} 1)$ & 32,60 & 55,90 \\
\hline & & $9(\mathrm{~J} 1)$ & 30,80 & 57,50 \\
\hline
\end{tabular}




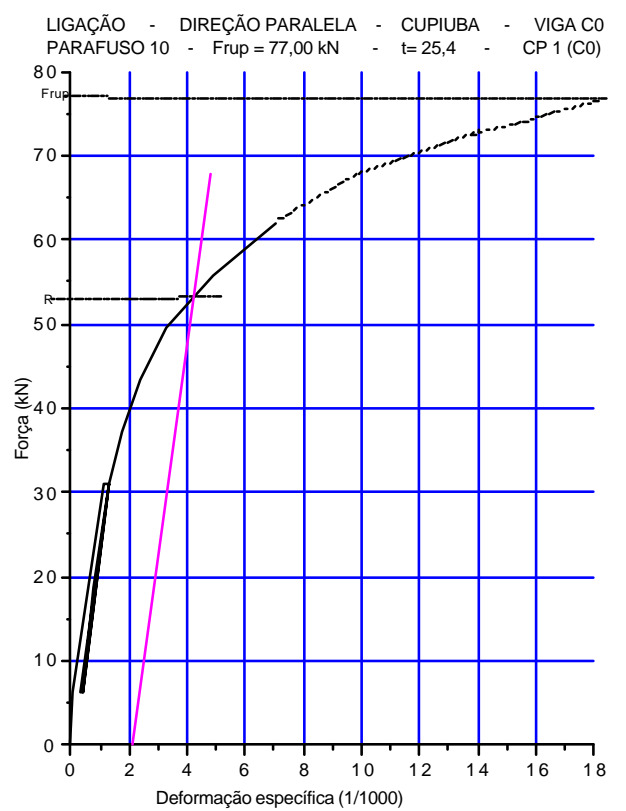

FIGURA 31 - Determinação da resistência da ligação - parafuso - Cupiúba

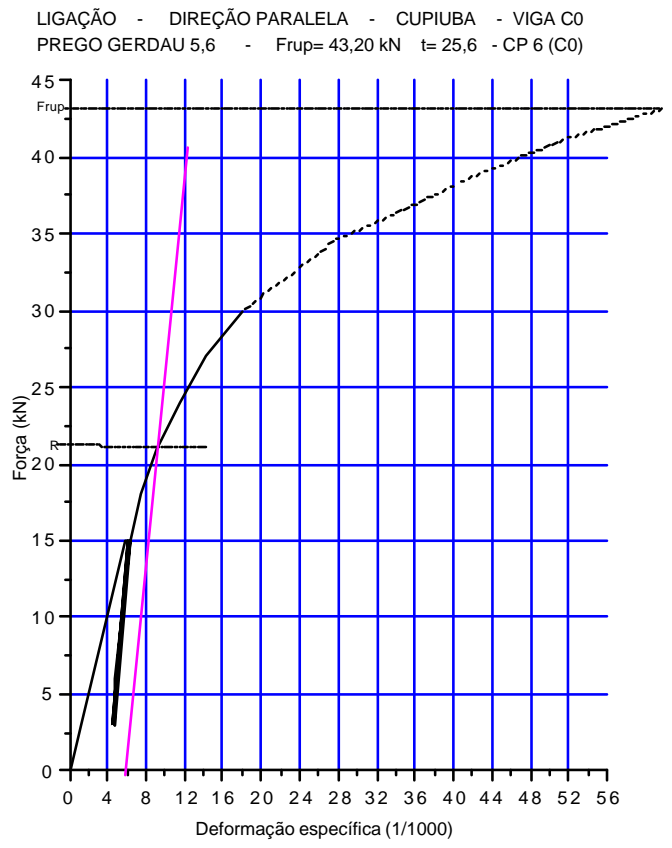

FIGURA 32 - Determinação da resistência da ligação - prego - Cupiúba 


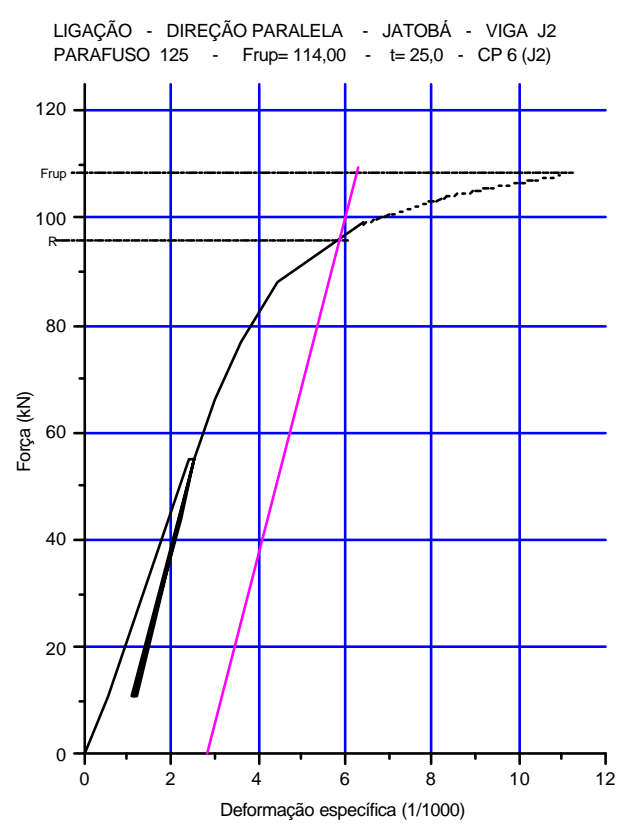

FIGURA 33 - Determinação da resistência da ligação - parafuso - Jatobá

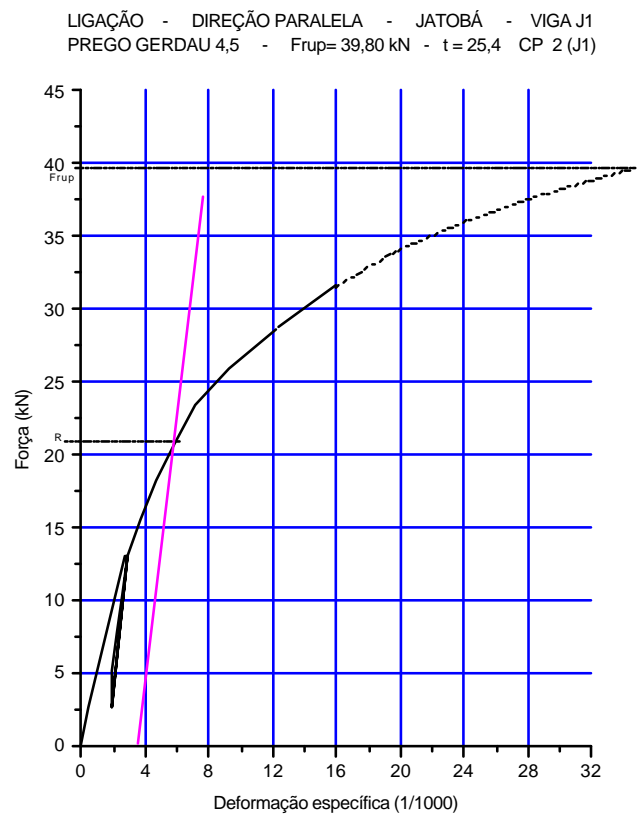

FIGURA 34 - Determinação da resistência da ligação - prego - Jatobá 


\section{5 - ANÁLISE DOS RESULTADOS}

A análise dos resultados LaMEM foi feita comparando-se os valores experimentais da resistência das ligações com os valores teóricos propostos pela NBR 7190/97. Os valores experimentais foram obtidos de duas maneiras: a primeira, pelo critério adotado pela equipe do LaMEM, e a Segunda, pelo critério da NBR 7190/97 aproximado. Também foi feita a comparação dos resultados da rigidez obtidos pelos critérios da equipe do LaMEM e da NBR 7190/97.

A análise dos resultados dos ensaios complementares foi efetuada comparando os valores experimentais com os valores obtidos pelo critério de dimensionamento da norma NBR 7190/97.

No texto da NBR 7190/97, não se apresentam indicativos referentes ao coeficiente de modificação e de minoração das resistências para a determinação do valor de cálculo das ligações obtido com base nos resultados experimentais. Foi considerado que devem ser utilizadas as mesmas premissas do caso da compressão paralela às fibras. Assim, a comparação entre os valores experimentais e teóricos da resistência das ligações foi feita diretamente, sem a aplicação dos coeficientes de modificação e minoração.

\section{1 - Resistência e rigidez das ligações obtidos nos ensaios LaMEM}

Os resultados experimentais das resistências das ligações foram comparados com os valores teóricos determinados de acordo com o critério de dimensionamento da NBR $7190 / 97$. 
O valor experimental da resistência correspondente a uma única seção de corte por pino $\left(\mathrm{R}_{1 \mathrm{v}}\right)$ foi obtida dividindo por 8 o valor da resistência da ligação, tendo em vista que todos os corpos-de-prova possuem quatro pinos, com dois planos de corte.

Para a obtenção dos valores teóricos da resistência das ligações $\left(\mathrm{R}_{1 \mathrm{v}}\right)$, pelo critério da norma NBR 7190/97, foi utilizada a resistência à compressão paralela da madeira $\left(\mathrm{f}_{\mathrm{c} 0}\right)$ tomada como a média daqueles encontrados nos ensaios correspondentes das

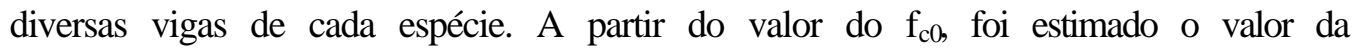
resistência ao embutimento paralelo e normal às fibras, de acordo com as recomendações da NBR 7190/97, que permite adotar as seguintes relações:

$\mathrm{f}_{\mathrm{e} 0}=\mathrm{f}_{\mathrm{c} 0}$

$\mathrm{f}_{\mathrm{e} 90}=0,25 \cdot \mathrm{f}_{\mathrm{c} 0} \cdot \alpha_{\mathrm{e}}$.

em que o coeficiente $\alpha_{e}$ é fornecido na tabela 14 da mesma norma.

Por falta de dados relativos à resistência ao escoamento $\left(\mathrm{f}_{\mathrm{y}}\right)$ dos pinos utilizados, não foi possível fazer a análise do parâmetro $\beta_{\lim }$ para verificação da ocorrência dos tipos de ruptura considerados pela NBR 7190/97: pelo embutimento na madeira ( $\beta \leq \beta_{\text {lim }}$ ) ou da flexão do pino $\left(\beta>\beta_{\text {lim) }}\right.$, em que são fornecidas as respectivas equações, conforme visto no item 2.5.1 deste trabalho. Assim, foi considerada apenas a ocorrência de embutimento do pino na madeira. Observa-se que, se for considerada a flexão do pino, o valor teórico obtido será menor que no caso do embutimento, o que levaria ao aumento das relações entre os valores experimentais e teóricos das resistências das ligações.

Nas tabelas 25 a 29, são apresentados e comparados os resultados experimentais e teóricos, tratados pelo critério da equipe do LaMEM, conforme descrito no item 3.1.3, e também a comparação dos resultados experimentais obtidos pela reavaliação dos dados dos ensaios realizados no LaMEM sob critério da NBR 7190/97, conforme descrito no item 3.1.4. 
Nas tabelas 30 a 34, são apresentados e comparados os valores obtidos para a rigidez das ligações pelo critério da equipe do LaMEM e pelo critério aproximado da NBR 7190/97.

TABELA 25 - Comparação entre os resultados experimentais e teóricos das resistências das ligações $\left(\mathbf{R}_{1 \mathrm{v}}\right)$ - Pinus Elliottii

\begin{tabular}{|c|c|c|c|c|c|c|c|c|}
\hline \multirow{3}{*}{$\begin{array}{c}\text { Tipo de } \\
\text { pino }\end{array}$} & \multirow{3}{*}{ Solicitação } & \multirow{3}{*}{$\begin{array}{c}\mathrm{d} \\
(\mathbf{m m})\end{array}$} & \multirow{3}{*}{$\mathbf{C P}$} & \multirow{3}{*}{$\begin{array}{c}\mathbf{R}_{1 \mathbf{v}}(\mathbf{k N}) \\
\text { Valor } \\
\text { Teórico }\end{array}$} & \multicolumn{2}{|c|}{$\begin{array}{c}\mathbf{R}_{1 \mathrm{v}}(\mathrm{kN}) \\
\text { Critério LaMEM }\end{array}$} & \multicolumn{2}{|c|}{$\begin{array}{c}\mathbf{R}_{1 \mathrm{v}}(\mathbf{k N}) \\
\text { Critério NBR }\end{array}$} \\
\hline & & & & & \multirow{2}{*}{ Exp. } & Exp. & \multirow{2}{*}{ Exp. } & Exp. \\
\hline & & & & & & Teórico & & Teórico \\
\hline \multirow{12}{*}{ Parafuso } & \multirow{6}{*}{$\begin{array}{l}\text { Direção } \\
\text { paralela }\end{array}$} & \multirow{2}{*}{10} & 01 & 1,99 & 3,05 & 1,54 & 2,54 & 1,28 \\
\hline & & & 20 & 1,99 & 3,43 & 1,73 & 3,04 & 1,53 \\
\hline & & \multirow{2}{*}{12,5} & 07 & 2,48 & 5,43 & 2,19 & 5,04 & 2,03 \\
\hline & & & 09 & 2,48 & 5,30 & 2,14 & 4,63 & 1,86 \\
\hline & & \multirow{2}{*}{16} & 05 & 3,18 & 6,29 & 1,98 & 5,53 & 1,74 \\
\hline & & & 08 & 3,18 & 5,10 & 1,61 & 4,71 & 1,48 \\
\hline & \multirow{6}{*}{$\begin{array}{l}\text { Direção } \\
\text { normal }\end{array}$} & \multirow{2}{*}{10} & 01 & 0,97 & 1,73 & 1,78 & 1,36 & 1,41 \\
\hline & & & 05 & 0,97 & 2,10 & 2,17 & 1,84 & 1,90 \\
\hline & & \multirow{2}{*}{12,5} & 02 & 1,04 & 2,73 & 2,61 & 2,08 & 1,99 \\
\hline & & & 07 & 1,04 & 2,73 & 2,61 & 1,85 & 1,77 \\
\hline & & \multirow{2}{*}{16} & 05 & 1,21 & 2,53 & 2,09 & 2,39 & 1,98 \\
\hline & & & 09 & 1,21 & 2,61 & 2,16 & 2,34 & 1,94 \\
\hline \multirow{12}{*}{ Prego } & \multirow{6}{*}{$\begin{array}{l}\text { Direção } \\
\text { paralela }\end{array}$} & \multirow{2}{*}{4,4} & 02 & 0,87 & 1,41 & 1,62 & 1,25 & 1,43 \\
\hline & & & 08 & 0,87 & 1,44 & 1,65 & 1,29 & 1,47 \\
\hline & & \multirow{2}{*}{5,4} & 01 & 1,07 & 1,85 & 1,73 & 1,40 & 1,31 \\
\hline & & & 05 & 1,07 & 1,88 & 1,75 & 1,34 & 1,25 \\
\hline & & \multirow{2}{*}{6,4} & 07 & 1,27 & 2,36 & 1,86 & 2,11 & 1,66 \\
\hline & & & 09 & 1,27 & 2,31 & 1,82 & 2,06 & 1,62 \\
\hline & \multirow{6}{*}{$\begin{array}{l}\text { Direção } \\
\text { normal }\end{array}$} & \multirow{2}{*}{4,4} & 02 & 0,55 & 1,68 & 3,07 & 1,01 & 1,85 \\
\hline & & & 09 & 0,55 & 1,55 & 2,84 & 0,83 & 1,51 \\
\hline & & \multirow{2}{*}{5,4} & 01 & 0,67 & 1,50 & 2,24 & 1,09 & 1,62 \\
\hline & & & 07 & 0,67 & 1,56 & 2,33 & 1,03 & 1,53 \\
\hline & & \multirow{2}{*}{6,4} & 08 & 0,79 & 1,48 & 1,86 & 1,39 & 1,75 \\
\hline & & & $08 b$ & 0,79 & 1,73 & 2,17 & 1,33 & 1,67 \\
\hline
\end{tabular}


TABELA 26 - Comparação entre os resultados experimentais e teóricos das resistências das ligações $\left(\mathbf{R}_{1 v}\right)$ - Cupiúba

\begin{tabular}{|c|c|c|c|c|c|c|c|c|}
\hline \multirow{2}{*}{$\begin{array}{c}\text { Tipo de } \\
\text { pino }\end{array}$} & \multirow{2}{*}{ Solicitação } & \multirow{2}{*}{$\underset{(\mathrm{mm})}{\mathrm{d}}$} & \multirow{2}{*}{$\mathbf{C P}$} & \multirow{2}{*}{$\begin{array}{c}\mathbf{R}_{1 \mathbf{v}}(\mathbf{k N}) \\
\text { Valor } \\
\text { Teórico }\end{array}$} & \multicolumn{2}{|c|}{$\begin{array}{c}\mathbf{R}_{1 \mathrm{v}}(\mathrm{kN}) \\
\text { Critério LaMEM } \\
\end{array}$} & \multicolumn{2}{|c|}{$\begin{array}{c}\mathbf{R}_{1 \mathrm{v}}(\mathbf{k N}) \\
\text { Critério NBR }\end{array}$} \\
\hline & & & & & Exp. & $\begin{array}{c}\text { Exp. } \\
\text { Teórico }\end{array}$ & Exp. & $\begin{array}{c}\text { Exp. } \\
\text { Teórico } \\
\end{array}$ \\
\hline \multirow{11}{*}{ Parafuso } & \multirow{6}{*}{$\begin{array}{l}\text { Direção } \\
\text { paralela }\end{array}$} & \multirow{2}{*}{10} & 08 & 4,37 & 5,30 & 1,21 & 4,94 & 1,13 \\
\hline & & & 12 & 4,37 & 5,14 & 1,18 & 4,69 & 1,07 \\
\hline & & \multirow{2}{*}{12,5} & 10 & 5,47 & 7,48 & 1,37 & 7,39 & 1,35 \\
\hline & & & 13 & 5,47 & 8,13 & 1,49 & 8,90 & 1,63 \\
\hline & & \multirow{2}{*}{16} & 06 & 7,00 & 9,85 & 1,41 & 9,01 & 1,29 \\
\hline & & & 09 & 7,00 & 8,78 & 1,25 & 8,54 & 1,22 \\
\hline & \multirow{5}{*}{$\begin{array}{l}\text { Direção } \\
\text { normal }\end{array}$} & \multirow{2}{*}{10} & 09 & 2,13 & 3,84 & 1,80 & 3,53 & 1,65 \\
\hline & & & 10 & 2,13 & 3,38 & 1,58 & 3,43 & 1,61 \\
\hline & & \multirow{2}{*}{12,5} & 06 & 2,30 & 5,71 & 2,49 & 5,34 & 2,32 \\
\hline & & & 13 & 2,30 & 5,75 & 2,50 & 5,79 & 2,52 \\
\hline & & 16 & 12 & 2,66 & 4,55 & 1,71 & 4,53 & 1,70 \\
\hline \multirow{12}{*}{ Prego } & \multirow{6}{*}{$\begin{array}{l}\text { Direção } \\
\text { paralela }\end{array}$} & \multirow{2}{*}{4,4} & 12 & 1,92 & 3,20 & 1,66 & 2,46 & 1,28 \\
\hline & & & 13 & 1,92 & 2,73 & 1,42 & 2,48 & 1,29 \\
\hline & & \multirow{2}{*}{5,4} & 06 & 2,36 & 3,88 & 1,64 & 3,29 & 1,39 \\
\hline & & & 08 & 2,36 & 3,33 & 1,41 & 2,88 & 1,22 \\
\hline & & \multirow{2}{*}{6,4} & 09 & 2,80 & 4,04 & 1,44 & 3,71 & 1,33 \\
\hline & & & 10 & 2,80 & 4,59 & 1,64 & 4,05 & 1,45 \\
\hline & \multirow{6}{*}{$\begin{array}{l}\text { Direção } \\
\text { normal }\end{array}$} & \multirow{2}{*}{4,4} & 06 & 1,20 & 2,16 & 1,80 & 1,53 & 1,27 \\
\hline & & & 08 & 1,20 & 2,41 & 2,01 & 1,78 & 1,48 \\
\hline & & \multirow{2}{*}{5,4} & 12 & 1,48 & 2,95 & 2,00 & 1,98 & 1,34 \\
\hline & & & 13 & 1,48 & 2,48 & 1,68 & 2,38 & 1,61 \\
\hline & & \multirow{2}{*}{6,4} & 09 & 1,75 & 3,40 & 1,94 & 2,86 & 1,64 \\
\hline & & & 10 & 1,75 & 3,40 & 1,94 & 2,65 & 1,52 \\
\hline
\end{tabular}


TABELA 27 - Comparação entre os resultados experimentais e teóricos das resistências das ligações $\left(\mathbf{R}_{\mathrm{v} 1}\right)$ - Garapa

\begin{tabular}{|c|c|c|c|c|c|c|c|c|}
\hline \multirow{2}{*}{$\begin{array}{c}\text { Tipo de } \\
\text { pino }\end{array}$} & \multirow{2}{*}{ Solicitação } & \multirow{2}{*}{$\begin{array}{c}\mathrm{d} \\
(\mathrm{mm})\end{array}$} & \multirow{2}{*}{$\mathbf{C P}$} & \multirow{2}{*}{$\begin{array}{c}\mathbf{R}_{1 \mathrm{v}}(\mathbf{k N}) \\
\text { Valor } \\
\text { Teórico }\end{array}$} & \multicolumn{2}{|c|}{$\begin{array}{c}\mathbf{R}_{1 \mathbf{v}}(\mathbf{k N}) \\
\text { Critério LaMEM }\end{array}$} & \multicolumn{2}{|c|}{$\begin{array}{c}\mathbf{R}_{1 v}(\mathbf{k N}) \\
\text { Critério NBR }\end{array}$} \\
\hline & & & & & Exp. & $\begin{array}{c}\text { Exp. } \\
\text { Teórico }\end{array}$ & Exp. & $\begin{array}{c}\text { Exp. } \\
\text { Teórico }\end{array}$ \\
\hline \multirow{12}{*}{ Parafuso } & \multirow{6}{*}{$\begin{array}{l}\text { Direção } \\
\text { paralela }\end{array}$} & \multirow{2}{*}{10} & 17 & 4,86 & 6,40 & 1,32 & 5,90 & 1,21 \\
\hline & & & 18 & 4,86 & 6,01 & 1,24 & 5,64 & 1,16 \\
\hline & & \multirow{2}{*}{12,5} & 12 & 6,07 & 8,80 & 1,45 & 8,29 & 1,37 \\
\hline & & & 16 & 6,07 & 8,85 & 1,46 & 8,46 & 1,39 \\
\hline & & \multirow{2}{*}{16} & 13 & 7,77 & 9,73 & 1,25 & 10,64 & 1,37 \\
\hline & & & 14 & 7,77 & 10,34 & 1,33 & 9,24 & 1,19 \\
\hline & \multirow{6}{*}{$\begin{array}{r}\text { Direção } \\
\text { normal }\end{array}$} & \multirow{2}{*}{10} & $12 \mathrm{a}$ & 2,37 & 4,50 & 1,90 & 3,84 & 1,62 \\
\hline & & & 16 & 2,37 & 4,64 & 1,96 & 3,68 & 1,55 \\
\hline & & \multirow{2}{*}{12,5} & $12 \mathrm{~b}$ & 2,55 & 6,38 & 2,50 & 6,28 & 2,46 \\
\hline & & & 13 & 2,55 & 6,44 & 2,52 & 6,44 & 2,52 \\
\hline & & \multirow{2}{*}{16} & 14 & 2,95 & 7,14 & 2,42 & 7,44 & 2,52 \\
\hline & & & 17 & 2,95 & 7,79 & 2,64 & 8,04 & 2,72 \\
\hline \multirow{12}{*}{ Prego } & \multirow{6}{*}{$\begin{array}{l}\text { Direção } \\
\text { paralela }\end{array}$} & \multirow{2}{*}{4,4} & 14 & 2,14 & 3,13 & 1,46 & 2,18 & 1,02 \\
\hline & & & 16 & 2,14 & 2,96 & 1,39 & 2,21 & 1,04 \\
\hline & & \multirow{2}{*}{5,4} & 17 & 2,62 & 4,40 & 1,68 & 3,96 & 1,51 \\
\hline & & & 18 & 2,62 & 4,31 & 1,64 & 3,61 & 1,38 \\
\hline & & \multirow{2}{*}{6,4} & 12 & 3,11 & 4,45 & 1,43 & 3,79 & 1,22 \\
\hline & & & 13 & 3,11 & 4,61 & 1,48 & 4,13 & 1,33 \\
\hline & \multirow{6}{*}{$\begin{array}{r}\text { Direção } \\
\text { normal }\end{array}$} & \multirow{2}{*}{4,4} & 16 & 1,34 & 3,35 & 2,51 & 2,10 & 1,57 \\
\hline & & & 18 & 1,34 & 3,60 & 2,70 & 2,08 & 1,55 \\
\hline & & \multirow{2}{*}{5,4} & 14 & 1,64 & 3,61 & 2,20 & 2,85 & 1,74 \\
\hline & & & 17 & 1,64 & 4,20 & 2,56 & 3,15 & 1,92 \\
\hline & & \multirow{2}{*}{6,4} & 12 & 1,94 & 3,98 & 2,05 & 2,96 & 1,53 \\
\hline & & & 13 & 1,94 & 3,49 & 1,80 & 3,11 & 1,60 \\
\hline
\end{tabular}


TABELA 28 - Comparação entre os resultados experimentais e teóricos das resistências das ligações $\left(\mathbf{R}_{1 \mathbf{v}}\right)$ - Eucalipto Citriodora

\begin{tabular}{|c|c|c|c|c|c|c|c|c|}
\hline \multirow{3}{*}{$\begin{array}{c}\text { Tipo de } \\
\text { pino }\end{array}$} & \multirow{3}{*}{ Solicitação } & \multirow{3}{*}{$\underset{(\mathbf{m m})}{\mathbf{d}}$} & \multirow{3}{*}{$\mathbf{C P}$} & \multirow{3}{*}{$\begin{array}{c}\mathbf{R}_{1 \mathrm{v}}(\mathrm{kN}) \\
\text { Valor } \\
\text { Teórico }\end{array}$} & \multicolumn{2}{|c|}{$\begin{array}{c}\mathbf{R}_{1 \mathrm{v}}(\mathbf{k N}) \\
\text { Critério LaMEM }\end{array}$} & \multicolumn{2}{|c|}{$\begin{array}{c}\mathbf{R}_{1 \mathrm{v}}(\mathbf{k N}) \\
\text { Critério NBR }\end{array}$} \\
\hline & & & & & Fxn & Exp. & Fxn & Exp. \\
\hline & & & & & & Teórico & & Teórico \\
\hline \multirow{12}{*}{ Parafuso } & \multirow{6}{*}{$\begin{array}{l}\text { Direção } \\
\text { paralela }\end{array}$} & \multirow{2}{*}{10} & 07 & 6,39 & 6,85 & 1,07 & 5,90 & 0,92 \\
\hline & & & 05 & 6,39 & 6,23 & 0,97 & 6,40 & 1,00 \\
\hline & & \multirow{2}{*}{12,5} & 10 & 7,99 & 9,29 & 1,16 & 9,21 & 1,15 \\
\hline & & & 13 & 7,99 & 9,25 & 1,16 & 9,00 & 1,13 \\
\hline & & \multirow{2}{*}{16} & 09 & 10,22 & 10,69 & 1,05 & 11,88 & 1,16 \\
\hline & & & 12 & 10,22 & 10,53 & 1,03 & 11,00 & 1,08 \\
\hline & \multirow{6}{*}{$\begin{array}{r}\text { Direção } \\
\text { normal }\end{array}$} & \multirow{2}{*}{10} & 10 & 3,11 & 4,61 & 1,48 & 4,16 & 1,34 \\
\hline & & & $13 b$ & 3,11 & 3,96 & 1,27 & 3,89 & 1,25 \\
\hline & & \multirow{2}{*}{12,5} & 09 & 3,35 & 4,06 & 1,21 & & \\
\hline & & & 10 & 3,35 & 4,23 & 1,26 & & \\
\hline & & \multirow{2}{*}{16} & 07 & 3,88 & 6,46 & 1,66 & & \\
\hline & & & 09 & 3,88 & 5,63 & 1,45 & & \\
\hline \multirow{11}{*}{ Prego } & \multirow{6}{*}{$\begin{array}{l}\text { Direção } \\
\text { paralela }\end{array}$} & \multirow{2}{*}{4,4} & 13 & 2,81 & 2,98 & 1,06 & 2,40 & 0,85 \\
\hline & & & 07 & 2,81 & 2,75 & 0,98 & 2,53 & 0,90 \\
\hline & & \multirow{2}{*}{5,4} & 11 & 3,45 & 3,39 & 0,98 & 2,91 & 0,84 \\
\hline & & & & & & & & \\
\hline & & \multirow{2}{*}{6,4} & 01 & 4,09 & 4,74 & 1,16 & 4,38 & 1,07 \\
\hline & & & 05 & 4,09 & 4,71 & 1,15 & 4,58 & 1,12 \\
\hline & \multirow{5}{*}{$\begin{array}{r}\text { Direção } \\
\text { normal }\end{array}$} & 4,4 & 10 & 1,76 & 2,50 & 1,42 & 1,79 & 1,02 \\
\hline & & \multirow{2}{*}{5,4} & 09 & 2,16 & 3,28 & 1,52 & 2,70 & 1,25 \\
\hline & & & 11 & 2,16 & 3,65 & 1,69 & 2,80 & 1,30 \\
\hline & & \multirow{2}{*}{6,4} & 05 & 2,56 & 3,88 & 1,52 & 3,00 & 1,17 \\
\hline & & & 13 & 2,56 & 3,39 & 1,33 & 3,09 & 1,21 \\
\hline
\end{tabular}


TABELA 29 - Comparação entre os resultados experimentais e teóricos das resistências das ligações $\left(\mathbf{R}_{1 \mathrm{v}}\right)$ - Jatobá

\begin{tabular}{|c|c|c|c|c|c|c|c|c|}
\hline \multirow{2}{*}{$\begin{array}{c}\text { Tipo de } \\
\text { pino }\end{array}$} & \multirow[t]{2}{*}{ Solicitação } & \multirow{2}{*}{$\begin{array}{c}\mathrm{d} \\
(\mathrm{mm})\end{array}$} & \multirow[t]{2}{*}{$\mathbf{C P}$} & \multirow{2}{*}{$\begin{array}{c}\mathbf{R}_{1 \mathrm{v}}(\mathbf{k N}) \\
\text { Valor } \\
\text { Teórico }\end{array}$} & \multicolumn{2}{|c|}{$\begin{array}{c}\mathbf{R}_{1 \mathrm{v}}(\mathrm{kN}) \\
\text { Critério LaMEM }\end{array}$} & \multicolumn{2}{|c|}{$\begin{array}{c}\mathbf{R}_{\mathbf{1 v}}(\mathbf{k N}) \\
\text { Critério NBR }\end{array}$} \\
\hline & & & & & Exp. & $\begin{array}{c}\text { Exp. } \\
\text { Teórico }\end{array}$ & Exp. & $\frac{\text { Exp. }}{\text { Teórico }}$ \\
\hline \multirow{12}{*}{ Parafuso } & \multirow{6}{*}{$\begin{array}{l}\text { Direção } \\
\text { paralela }\end{array}$} & \multirow{2}{*}{10} & 03 & 7,08 & 6,50 & 0,92 & 5,84 & 0,82 \\
\hline & & & 08 & 7,08 & 7,59 & 1,07 & 6,38 & 0,76 \\
\hline & & \multirow{2}{*}{12,5} & 01 & 8,85 & 8,31 & 0,94 & 8,66 & 0,98 \\
\hline & & & 04 & 8,85 & 10,03 & 1,13 & 9,75 & 1,10 \\
\hline & & \multirow{2}{*}{16} & 05 & & 10,00 & 0,88 & 11,34 & 1,00 \\
\hline & & & 17 & 11,32 & 16,54 & 1,46 & 13,75 & 1,21 \\
\hline & \multirow{6}{*}{$\begin{array}{r}\text { Direção } \\
\text { normal }\end{array}$} & \multirow{2}{*}{10} & 03 & 3,45 & 4,50 & 1,31 & 4,00 & 1,16 \\
\hline & & & 05 & 3,45 & 4,25 & 1,23 & 4,08 & 1,18 \\
\hline & & \multirow{2}{*}{12,5} & 01 & 3,71 & 6,33 & 1,70 & 6,65 & 1,79 \\
\hline & & & $\mathrm{xx}$ & 3,71 & 7,79 & 2,10 & 7,91 & 2,13 \\
\hline & & \multirow{2}{*}{16} & 04 & 4,30 & 8,05 & 1,87 & 8,63 & 2,01 \\
\hline & & & 08 & 4,30 & 8,00 & 1,86 & 8,25 & 1,92 \\
\hline \multirow{12}{*}{ Prego } & \multirow{6}{*}{$\begin{array}{l}\text { Direção } \\
\text { paralela }\end{array}$} & \multirow{2}{*}{4,4} & 05 & 3,11 & 3,64 & 1,17 & 2,93 & 0,94 \\
\hline & & & 07 & 3,11 & 4,13 & 1,33 & 3,80 & 1,22 \\
\hline & & \multirow{2}{*}{5,4} & 01 & 3,82 & 4,10 & 1,07 & 3,50 & 0,92 \\
\hline & & & 08 & 3,82 & 4,43 & 1,16 & 3,64 & 0,95 \\
\hline & & \multirow{2}{*}{6,4} & 03 & 4,53 & 4,88 & 1,08 & 4,44 & 0,98 \\
\hline & & & 04 & 4,53 & 4,81 & 1,07 & 3,95 & 0,87 \\
\hline & \multirow{6}{*}{$\begin{array}{r}\text { Direção } \\
\text { normal }\end{array}$} & \multirow{2}{*}{4,4} & 01 & 1,95 & 2,94 & 1,51 & 2,03 & 1,04 \\
\hline & & & 03 & 1,95 & 2,94 & 1,51 & 2,03 & 1,04 \\
\hline & & \multirow{2}{*}{5,4} & 05 & 2,39 & 3,69 & 1,54 & 2,79 & 1,17 \\
\hline & & & 07 & 2,39 & 4,38 & 1,83 & 3,64 & 1,52 \\
\hline & & \multirow{2}{*}{6,4} & 04 & 2,83 & 4,38 & 1,55 & 3,50 & 1,24 \\
\hline & & & 08 & 2,83 & 4,00 & 1,41 & 3,35 & 1,18 \\
\hline
\end{tabular}


TABELA 30 - Comparação entre os valores da rigidez das ligações - Pinus Elliottii

\begin{tabular}{|c|c|c|c|c|c|}
\hline \multirow{2}{*}{ Tipo de pino } & \multirow{2}{*}{ Solicitação } & \multirow{2}{*}{$\begin{array}{c}\mathrm{d} \\
(\mathbf{m m})\end{array}$} & \multirow{2}{*}{$\mathbf{C P}$} & \multicolumn{2}{|c|}{ Rigidez (kN/mm) } \\
\hline & & & & Critério LaMEM & Critério NBR \\
\hline \multirow{12}{*}{ Parafuso } & \multirow{6}{*}{$\begin{array}{l}\text { Direção } \\
\text { paralela }\end{array}$} & \multirow{2}{*}{10} & 01 & 8,38 & 9,79 \\
\hline & & & 20 & 16,45 & 16,75 \\
\hline & & \multirow{2}{*}{12,5} & 07 & 15,65 & 15,80 \\
\hline & & & 09 & 19,38 & 17,79 \\
\hline & & \multirow{2}{*}{16} & 05 & 12,33 & 12,17 \\
\hline & & & 08 & 14,25 & 14,39 \\
\hline & \multirow{6}{*}{$\begin{array}{c}\text { Direção } \\
\text { normal }\end{array}$} & \multirow{2}{*}{10} & 01 & 4,88 & 6,80 \\
\hline & & & 05 & 3,43 & 3,52 \\
\hline & & \multirow{2}{*}{12,5} & 02 & 7,70 & 9,19 \\
\hline & & & 07 & 5,32 & 8,04 \\
\hline & & \multirow{2}{*}{16} & 05 & 4,94 & 5,06 \\
\hline & & & 09 & 4,09 & 4,02 \\
\hline \multirow{12}{*}{ Prego } & \multirow{6}{*}{$\begin{array}{l}\text { Direção } \\
\text { paralela }\end{array}$} & \multirow{2}{*}{4,4} & 02 & 10,73 & 15,18 \\
\hline & & & 08 & 6,77 & 9,43 \\
\hline & & \multirow{2}{*}{5,4} & 01 & 9,85 & 16,26 \\
\hline & & & 05 & 12,45 & 19,61 \\
\hline & & \multirow{2}{*}{6,4} & 07 & 12,24 & 13,00 \\
\hline & & & 09 & 11,15 & 11,92 \\
\hline & \multirow{6}{*}{$\begin{array}{r}\text { Direção } \\
\text { normal }\end{array}$} & \multirow{2}{*}{4,4} & 02 & 1,58 & 5,59 \\
\hline & & & 09 & 1,14 & 3,89 \\
\hline & & \multirow{2}{*}{5,4} & 01 & 3,28 & 5,75 \\
\hline & & & 07 & 2,01 & 3,62 \\
\hline & & \multirow{2}{*}{6,4} & 08 & 5,31 & 5,54 \\
\hline & & & $08 b$ & 5,57 & 9,29 \\
\hline
\end{tabular}


TABELA 31 - Comparação entre os valores da rigidez das ligações - Cupiúba

\begin{tabular}{|c|c|c|c|c|c|}
\hline \multirow{2}{*}{ Tipo de pino } & \multirow{2}{*}{ Solicitação } & \multirow{2}{*}{$\begin{array}{c}\mathbf{d} \\
(\mathbf{m m})\end{array}$} & \multirow{2}{*}{$\mathbf{C P}$} & \multicolumn{2}{|c|}{ Rigidez (kN/mm) } \\
\hline & & & & Critério LaMEM & Critério NBR \\
\hline \multirow{12}{*}{ Parafuso } & \multirow{6}{*}{$\begin{array}{l}\text { Direção } \\
\text { paralela }\end{array}$} & \multirow{2}{*}{10} & 08 & 44,64 & 39,84 \\
\hline & & & 12 & 39,22 & 38,17 \\
\hline & & \multirow{2}{*}{12,5} & 10 & 59,52 & 61,73 \\
\hline & & & 13 & 81,97 & 83,33 \\
\hline & & \multirow{2}{*}{16} & 06 & 72,99 & 78,74 \\
\hline & & & 09 & 84,75 & 98,04 \\
\hline & \multirow{6}{*}{$\begin{array}{r}\text { Direção } \\
\text { normal }\end{array}$} & \multirow{2}{*}{10} & 09 & 10,56 & 9,89 \\
\hline & & & 10 & 13,48 & 11,49 \\
\hline & & \multirow{2}{*}{12,5} & 06 & 14,05 & 13,89 \\
\hline & & & 13 & 15,04 & 14,82 \\
\hline & & \multirow{2}{*}{16} & 08 & 9,60 & 12,00 \\
\hline & & & 12 & 12,69 & 12,53 \\
\hline \multirow{12}{*}{ Prego } & \multirow{6}{*}{$\begin{array}{l}\text { Direção } \\
\text { paralela }\end{array}$} & \multirow{2}{*}{4,4} & 12 & 7,61 & 14,31 \\
\hline & & & 13 & 27,40 & 28,90 \\
\hline & & \multirow{2}{*}{5,4} & 06 & 15,77 & 13,74 \\
\hline & & & 08 & 19,88 & 23,26 \\
\hline & & \multirow{2}{*}{6,4} & 09 & 39,22 & 41,84 \\
\hline & & & 10 & 32,05 & 32,26 \\
\hline & \multirow{6}{*}{$\begin{array}{r}\text { Direção } \\
\text { normal }\end{array}$} & \multirow{2}{*}{4,4} & 06 & 3,03 & 6,08 \\
\hline & & & 08 & 3,33 & 5,48 \\
\hline & & \multirow{2}{*}{5,4} & 12 & 6,63 & 19,05 \\
\hline & & & 13 & 11,93 & 10,75 \\
\hline & & \multirow{2}{*}{6,4} & 09 & 8,48 & 9,90 \\
\hline & & & 10 & 7,37 & 9,85 \\
\hline
\end{tabular}


TABELA 32 - Comparação entre os valores da rigidez das ligações - Garapa

\begin{tabular}{|c|c|c|c|c|c|}
\hline \multirow{2}{*}{ Tipo de pino } & \multirow{2}{*}{ Solicitação } & \multirow{2}{*}{$\underset{(\mathbf{m m})}{\mathbf{d}}$} & \multirow{2}{*}{$\mathbf{C P}$} & \multicolumn{2}{|c|}{ Rigidez (kN/mm) } \\
\hline & & & & Critério LaMEM & Critério NBR \\
\hline \multirow{12}{*}{ Parafuso } & \multirow{6}{*}{$\begin{array}{l}\text { Direção } \\
\text { paralela }\end{array}$} & \multirow{2}{*}{10} & 17 & 78,74 & 85,47 \\
\hline & & & 18 & 77,52 & 84,75 \\
\hline & & \multirow{2}{*}{12,5} & 12 & 78,13 & 81,97 \\
\hline & & & 16 & 73,53 & 73,53 \\
\hline & & \multirow{2}{*}{16} & 13 & 93,46 & 92,59 \\
\hline & & & 14 & 85,47 & 108,11 \\
\hline & \multirow{6}{*}{$\begin{array}{c}\text { Direção } \\
\text { normal }\end{array}$} & \multirow{2}{*}{10} & $12 \mathrm{a}$ & 15,92 & 18,24 \\
\hline & & & 16 & 12,67 & 16,00 \\
\hline & & \multirow{2}{*}{12,5} & $12 \mathrm{~b}$ & 15,36 & 16,13 \\
\hline & & & 13 & 15,20 & 15,89 \\
\hline & & \multirow{2}{*}{16} & 14 & 18,21 & 18,99 \\
\hline & & & 17 & 18,39 & 19,67 \\
\hline \multirow{12}{*}{ Prego } & \multirow{6}{*}{$\begin{array}{l}\text { Direção } \\
\text { paralela }\end{array}$} & \multirow{2}{*}{4,4} & 14 & 15,77 & 60,61 \\
\hline & & & 16 & 16,03 & 36,63 \\
\hline & & \multirow{2}{*}{5,4} & 17 & 44,25 & 62,89 \\
\hline & & & 18 & 36,90 & 57,14 \\
\hline & & \multirow{2}{*}{6,4} & 12 & 61,73 & 81,30 \\
\hline & & & 13 & 70,92 & 81,97 \\
\hline & \multirow{6}{*}{$\begin{array}{r}\text { Direção } \\
\text { normal }\end{array}$} & \multirow{2}{*}{4,4} & 16 & 4,32 & 8,51 \\
\hline & & & 18 & 2,97 & 7,70 \\
\hline & & \multirow{2}{*}{5,4} & 14 & 9,77 & 12,15 \\
\hline & & & 17 & 9,74 & 16,13 \\
\hline & & \multirow{2}{*}{6,4} & 12 & 12,88 & 22,73 \\
\hline & & & 13 & 15,58 & 17,14 \\
\hline
\end{tabular}


TABELA 33 - Comparação entre os valores da rigidez das ligações - Eucalipto Citriodora

\begin{tabular}{|c|c|c|c|c|c|}
\hline \multirow{2}{*}{ Tipo de pino } & \multirow{2}{*}{ Sol icitação } & \multirow{2}{*}{$\begin{array}{c}\text { d } \\
(\mathbf{m m})\end{array}$} & \multirow{2}{*}{$\mathbf{C P}$} & \multicolumn{2}{|c|}{ Rigidez (kN/mm) } \\
\hline & & & & Critério LaMEM & Critério NBR \\
\hline \multirow{12}{*}{ Parafuso } & \multirow{6}{*}{$\begin{array}{l}\text { Direção } \\
\text { paralela }\end{array}$} & \multirow{2}{*}{10} & 07 & 76,92 & 86,96 \\
\hline & & & 05 & 88,50 & 100,00 \\
\hline & & \multirow{2}{*}{12,5} & 10 & 92,59 & 93,46 \\
\hline & & & 13 & 101,01 & 106,05 \\
\hline & & \multirow{2}{*}{16} & 09 & 125,00 & 132,45 \\
\hline & & & 12 & 123,46 & 126,74 \\
\hline & \multirow{6}{*}{$\begin{array}{r}\text { Direção } \\
\text { normal }\end{array}$} & \multirow{2}{*}{10} & 10 & 11,56 & 12,18 \\
\hline & & & $13 b$ & 13,26 & 13,44 \\
\hline & & \multirow{2}{*}{12,5} & 09 & 16,10 & 16,67 \\
\hline & & & 10 & 15,24 & 15,57 \\
\hline & & \multirow{2}{*}{16} & 07 & 21,03 & 20,96 \\
\hline & & & 09 & 20,14 & 20,73 \\
\hline \multirow{11}{*}{ Prego } & \multirow{6}{*}{$\begin{array}{l}\text { Direção } \\
\text { paralela }\end{array}$} & \multirow{2}{*}{4,4} & 13 & 38,34 & 78,13 \\
\hline & & & 07 & 56,87 & 69,36 \\
\hline & & \multirow{2}{*}{5,4} & 11 & 42,82 & 57,80 \\
\hline & & & & & \\
\hline & & \multirow{2}{*}{6,4} & 01 & 86,21 & 102,78 \\
\hline & & & 05 & 96,15 & 91,74 \\
\hline & \multirow{5}{*}{$\begin{array}{r}\text { Direção } \\
\text { normal }\end{array}$} & 4,4 & 10 & 6,51 & 13,70 \\
\hline & & \multirow{2}{*}{5,4} & 09 & 11,93 & 15,79 \\
\hline & & & 11 & 7,15 & 9,30 \\
\hline & & \multirow{2}{*}{6,4} & 05 & 10,24 & 14,11 \\
\hline & & & 13 & 13,74 & 14,54 \\
\hline
\end{tabular}


TABELA 34 - Comparação entre os valores da rigidez das ligações - Jatobá

\begin{tabular}{|c|c|c|c|c|c|}
\hline \multirow{2}{*}{ Tipo de pino } & \multirow{2}{*}{ Solicitação } & \multirow{2}{*}{$\underset{(\mathbf{m m})}{\mathbf{d}}$} & \multirow{2}{*}{$\mathbf{C P}$} & \multicolumn{2}{|c|}{ Rigidez (kN/mm) } \\
\hline & & & & Critério LaMEM & Critério NBR \\
\hline \multirow{12}{*}{ Parafuso } & \multirow{6}{*}{$\begin{array}{l}\text { Direção } \\
\text { paralela }\end{array}$} & \multirow{2}{*}{10} & 03 & 72,99 & 89,29 \\
\hline & & & 08 & 52,63 & 70,92 \\
\hline & & \multirow{2}{*}{12,5} & 01 & 86,03 & 103,84 \\
\hline & & & 04 & 113,64 & 130,89 \\
\hline & & \multirow{2}{*}{16} & 05 & 147,06 & 152,67 \\
\hline & & & 17 & 88,50 & 147,93 \\
\hline & \multirow{6}{*}{$\begin{array}{r}\text { Direção } \\
\text { normal }\end{array}$} & \multirow{2}{*}{10} & 03 & 11,98 & 12,96 \\
\hline & & & 05 & 12,00 & 12,78 \\
\hline & & \multirow{2}{*}{12,5} & 01 & 16,77 & 17,02 \\
\hline & & & $\mathrm{xx}$ & 23,17 & 23,95 \\
\hline & & \multirow{2}{*}{16} & 04 & 23,08 & 24,05 \\
\hline & & & 08 & 22,35 & 22,35 \\
\hline \multirow{12}{*}{ Prego } & \multirow{6}{*}{$\begin{array}{l}\text { Direção } \\
\text { paralela }\end{array}$} & \multirow{2}{*}{4,4} & 05 & 16,00 & 24,39 \\
\hline & & & 07 & 26,81 & 30,77 \\
\hline & & \multirow{2}{*}{5,4} & 01 & 38,61 & 50,00 \\
\hline & & & 08 & 31,25 & 50,00 \\
\hline & & \multirow{2}{*}{6,4} & 03 & 88,50 & 111,11 \\
\hline & & & 04 & 53,76 & 86,96 \\
\hline & \multirow{6}{*}{$\begin{array}{r}\text { Direção } \\
\text { normal }\end{array}$} & \multirow{2}{*}{4,4} & 01 & 4,87 & 8,76 \\
\hline & & & 03 & 5,47 & 9,66 \\
\hline & & \multirow{2}{*}{5,4} & 05 & 9,29 & 15,26 \\
\hline & & & 07 & 16,28 & 20,90 \\
\hline & & \multirow{2}{*}{6,4} & 04 & 15,26 & 19,72 \\
\hline & & & 08 & 14,71 & 20,15 \\
\hline
\end{tabular}

Nas tabelas de números 25 a 29 , pode ser observado que os resultados das resistências das ligações pelo critério da equipe LaMEM são sistematicamente maiores do que os obtidos pelo critério da NBR 7190/97 (aproximado). Os valores 
maiores ocorrem devido à menor inclinação para a reta secante, que intercepta o diagrama força $\mathrm{x}$ deformação específica em ponto mais alto da curva. Considerando que a resistência foi obtida a partir dos pontos de $10 \%$ e $50 \%$ da força de ruptura, esse aumento nos resultados se verifica.

Também se constata que os resultados experimentais indicam diferenças significativas para a resistência da ligação na direção normal às fibras, mesmo nas espécies de maior densidade, variando de $21 \%$ a $173 \%$ a mais dos valores obtidos nos cálculos utilizando o critério da NBR 7190/97. No caso da espécie Jatobá, os valores, na direção paralela, em média, praticamente se eqüivalem. Na direção normal às fibras, os valores variam de $4 \%$ a $112 \%$ acima dos resultados teóricos obtidos pelo critério da mesma norma.

Nas figuras 35 e 36, são apresentadas as comparações do critério LaMEM das tabelas 25 a 29 para resultados na direção paralela, para cada madeira e tipo de pino. Tanto nestas como nas figuras 37 e 38, os gráficos foram elaborados com base na média de dois ensaios análogos.

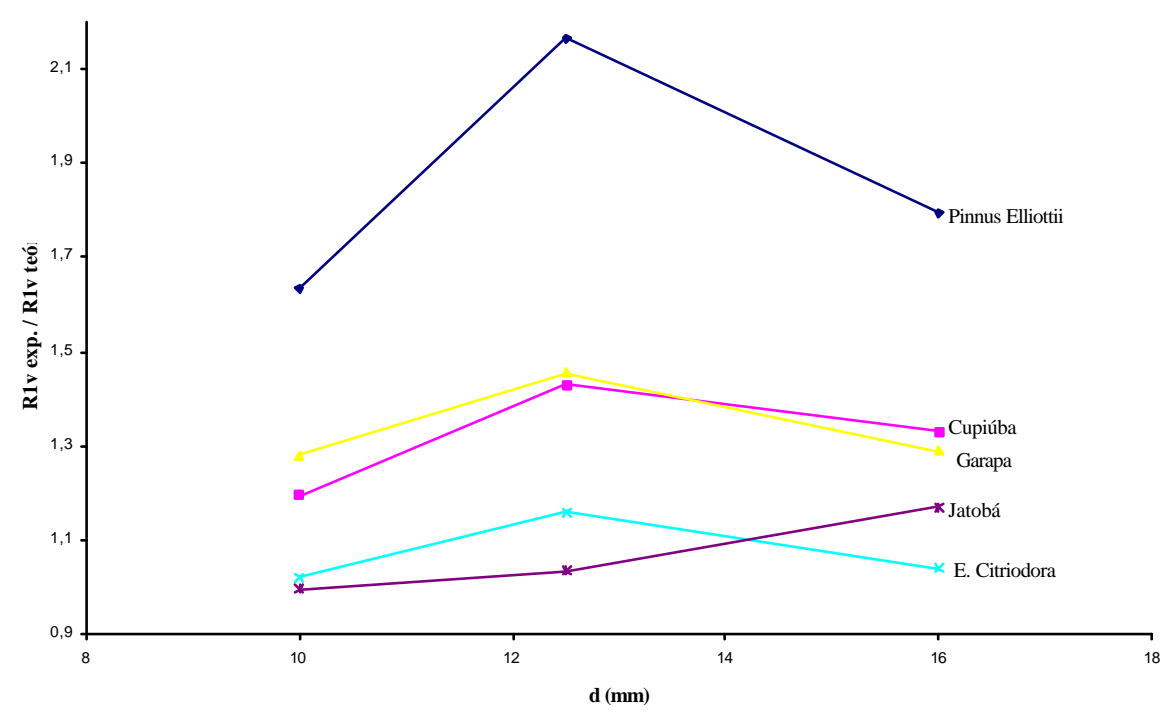

FIGURA 35 - Comparação entre os resultados experimentais e teóricos das resistências das ligações na direção paralela sob o critério LaMEM- parafusos 


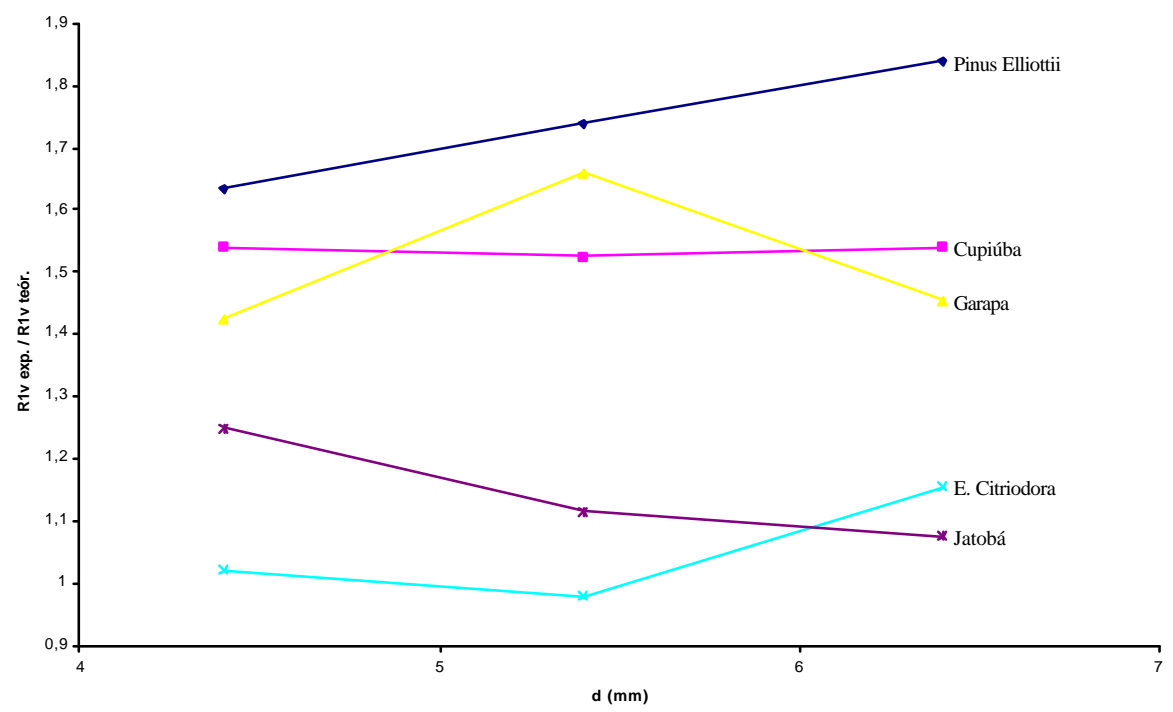

FIGURA 36 - Comparação entre os resultados experimentais e teóricos das resistências das ligações na direção paralela sob o critério LaMEM -pregos

Ainda nas tabelas de 25 a 29, pelo critério NBR, observa-se que os valores apurados para a resistência experimental da ligação foram maiores do que os valores teóricos obtidos. Os resultados experimentais das ligações apresentaram diferença significativa para a resistência na direção normal às fibras da madeira, variando de $4 \%$ a $172 \%$ a mais dos valores obtidos nos cálculos, utilizando o critério da norma brasileira.

Ainda nas tabelas 25 a 29, na direção paralela às fibras, no critério NBR, os valores experimentais obtidos variaram até $103 \%$ acima dos resultados dos cálculos fornecidos pelo critério teórico da mesma norma. No caso das espécies de grande densidade (Eucalipto Citriodora e Jatobá), essa variação praticamente não ocorreu, sendo que na maioria dos valores os resultados foram inferiores àqueles obtidos pelo 
critério teórico da NBR. Para as espécies de baixa e média densidade, como Pinus, Cupiúba e Garapa, os valores variaram de $2 \%$ a $103 \%$ acima aqueles obtidos pelo critério teórico da norma.

De acordo com as tabelas de 30 a 34, os valores encontrados para a rigidez pelo critério NBR foram maiores do que aqueles obtidos pelo critério da equipe LaMEM, tendo em vista a consideração, neste último caso, da força última como sendo o parâmetro para definir os pontos da reta secante.

Nas figuras 37 e 38, são apresentadas as comparações do critério NBR das tabelas 25 a 29 para cada madeira e tipo de pino, considerando os resultados na direção paralela às fibras.

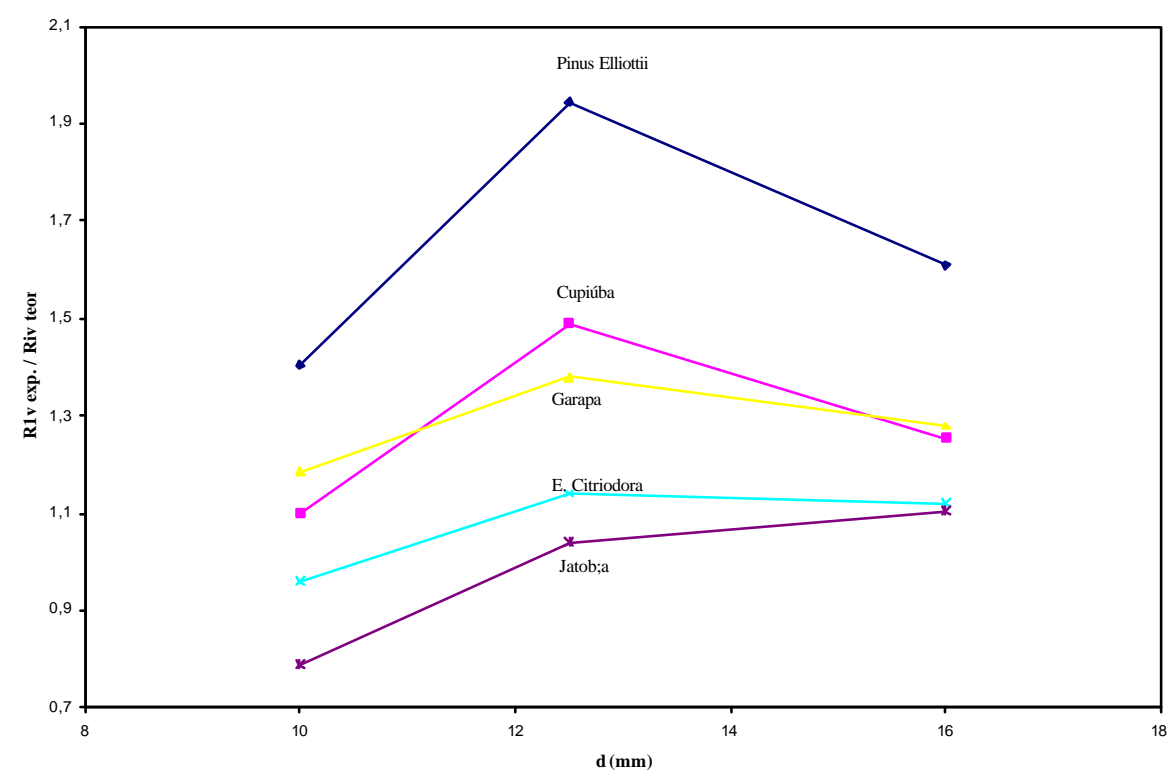

FIGURA 37 - Comparação entre os resultados experimentais e teóricos das resistências das ligações na direção paralela sob o critério NBR - parafusos 


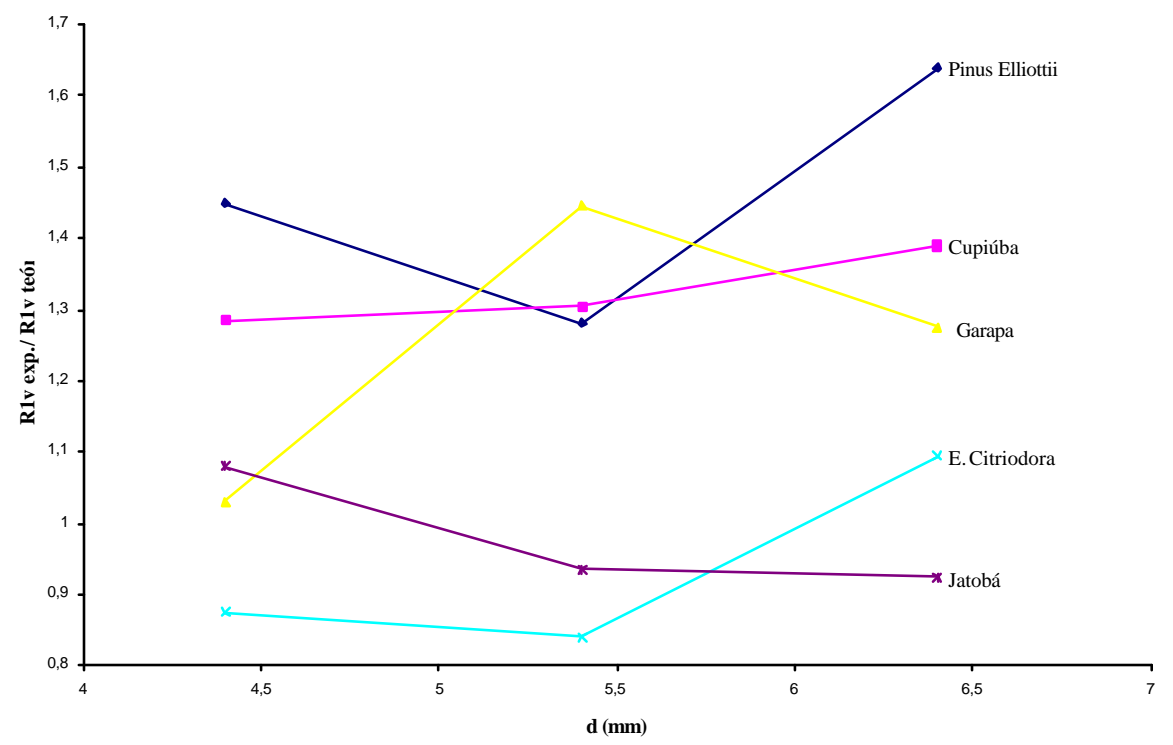

FIGURA 38 - Comparação entre os resultados experimentais e teóricos das resistências das ligações na direção paralela sob o critério NBR - pregos

\section{2 - Resistência das ligações obtidas nos ensaios complementares}

Para análise dos resultados dos ensaios complementares, foram comparados os valores obtidos nos ensaios para as ligações com os valores teóricos do critério da norma obtidos com base nos resultados experimentais da resistência ao embutimento e à compressão às fibras da madeira.

Para permitir uma comparação mais eficaz entre os valores experimentais e os valores teóricos, os corpos-de-prova utilizados para a determinação da resistência ao embutimento, da resistência à compressão paralela e das ligações, foram extraídos da mesma viga. 
Obtiveram-se os valores das resistências das ligações em corpos-de-prova com quatro pinos em dois planos de corte e reduzidos a um único plano de corte para um pino, pela divisão dos mesmos por 8 .

Para a obtenção da resistência da ligação pelo critério teórico, utilizaram-se valores obtidos diretamente nos ensaios de resistência ao embutimento paralelo às fibras da madeira $\left(f_{e 0}\right)$ e da resistência ao escoamento $\left(f_{y}\right)$ dos pinos e pregos. Foram usados os valores efetivos das dimensões das peças e pinos dos corpos-de-prova.

Para cada corpo-de-prova, foi feita a comparação entre $\beta$ e $\beta_{\lim }$, determinando a forma adequada de cálculo da resistência, ou seja: por embutimento do pino na madeira ou por flexão do pino.

Os valores das resistências de embutimento médio ( $f_{e, \text { médio }}$ e os $\beta_{\text {lim médios são }}$ mostrados nas tabelas 35 a 38 .

Nas tabelas 39 a 42, são mostrados e comparados os valores experimentais e os valores das resistências das ligações (R1v), para um único plano de corte e um parafuso, apresentados nas tabelas 21 a 24 . 
TABELA 35 - Resistência de embutimento médio e valor médio do $\beta_{\text {lim }}$ primeira série de ensaios - Pinus Elliottii

\begin{tabular}{|c|c|c|c|c|c|c|}
\hline \multirow{2}{*}{ Viga } & \multirow{2}{*}{$\begin{array}{c}\mathbf{f}_{\mathbf{e}} \\
\mathbf{M P a}\end{array}$} & \multirow{2}{*}{$\begin{array}{c}\mathbf{f}_{\mathbf{e}, \text { médio }} \\
\text { MPa }\end{array}$} & \multirow{2}{*}{$\begin{array}{c}\mathbf{f}_{\mathbf{y}} \\
\mathbf{M P a}\end{array}$} & \multirow[t]{2}{*}{$\boldsymbol{\beta}_{\text {lim }}$} & \multicolumn{2}{|c|}{$\begin{array}{l}\text { Obs: } \quad \text { viga usada no } \\
\text { seguinte tipo de ligação }\end{array}$} \\
\hline & & & & & Tipo de pino & d $(\mathrm{mm})$ \\
\hline \multirow{2}{*}{ P1 } & 26,9 & \multirow{2}{*}{24,6} & \multirow{2}{*}{661} & \multirow{2}{*}{6,480} & \multirow{6}{*}{ Parafuso } & \multirow{2}{*}{10} \\
\hline & 22,3 & & & & & \\
\hline \multirow{2}{*}{$\mathrm{P} 2$} & 41,3 & \multirow{2}{*}{41,4} & \multirow{2}{*}{577} & \multirow{2}{*}{4,667} & & \multirow{2}{*}{12,5} \\
\hline & 41,5 & & & & & \\
\hline \multirow{2}{*}{ P3 } & 38,9 & \multirow{2}{*}{40,0} & \multirow{2}{*}{556} & \multirow{2}{*}{4,660} & & \multirow{2}{*}{16} \\
\hline & 41,1 & & & & & \\
\hline \multirow{2}{*}{ P4 } & 22,0 & \multirow{2}{*}{21,4} & \multirow{2}{*}{766} & \multirow{2}{*}{7,479} & \multirow{6}{*}{ Prego } & \multirow{2}{*}{4,4} \\
\hline & 20,8 & & & & & \\
\hline \multirow{2}{*}{ P5 } & 22,0 & \multirow{2}{*}{21,5} & \multirow{2}{*}{778} & \multirow{2}{*}{7,519} & & \multirow{2}{*}{5,4} \\
\hline & 20,9 & & & & & \\
\hline \multirow{2}{*}{ P6 } & 23,2 & \multirow{2}{*}{23,2} & \multirow{2}{*}{779} & \multirow{2}{*}{7,243} & & \multirow{2}{*}{6,4} \\
\hline & & & & & & \\
\hline
\end{tabular}

TABELA 36 - Resistência de embutimento médio e valor médio do $\beta_{\text {lim }}$ primeira série de ensaios - Cupiúba

\begin{tabular}{|c|c|c|c|c|c|c|}
\hline \multirow{2}{*}{ Viga } & \multirow{2}{*}{$\begin{array}{c}\mathbf{f}_{\mathrm{e}} \\
\mathbf{M P a}\end{array}$} & \multirow{2}{*}{$\begin{array}{l}\mathbf{f}_{\text {emédio }} \\
\text { M Pa }\end{array}$} & \multirow{2}{*}{$\begin{array}{c}\mathbf{f}_{\mathbf{y}} \\
\text { MPa }\end{array}$} & \multirow[t]{2}{*}{$\boldsymbol{\beta}_{\text {lim }}$} & \multicolumn{2}{|c|}{$\begin{array}{l}\text { Obs: viga usada no } \\
\text { seguinte tipo de ligação }\end{array}$} \\
\hline & & & & & Tipo de pino & d $(\mathrm{mm})$ \\
\hline $\mathrm{C} 1$ & $\begin{array}{l}61,9 \\
65,9\end{array}$ & 63,9 & 661 & 4,020 & \multirow{5}{*}{ Parafuso } & 10 \\
\hline \multirow{2}{*}{$\mathrm{C} 2$} & 81,3 & \multirow{2}{*}{79,0} & \multirow{2}{*}{577} & \multirow{2}{*}{3,378} & & \multirow{2}{*}{12,5} \\
\hline & 76,7 & & & & & \\
\hline \multirow{2}{*}{$\mathrm{C} 3$} & 59,4 & \multirow{2}{*}{60,7} & \multirow{2}{*}{556} & \multirow{2}{*}{3,783} & & \multirow{2}{*}{16} \\
\hline & 62,0 & & & & & \\
\hline \multirow{2}{*}{$\mathrm{C} 4$} & 41,8 & \multirow{2}{*}{40,9} & \multirow{2}{*}{766} & \multirow{2}{*}{5,410} & \multirow{6}{*}{ Prego } & \multirow{2}{*}{4,4} \\
\hline & 40,0 & & & & & \\
\hline \multirow{2}{*}{$\mathrm{C} 5$} & 46,7 & \multirow{2}{*}{47,9} & \multirow{2}{*}{778} & \multirow{2}{*}{5,038} & & \multirow{2}{*}{5,4} \\
\hline & 49,0 & & & & & \\
\hline \multirow{2}{*}{ C6 } & 42,7 & \multirow{2}{*}{45,1} & \multirow{2}{*}{779} & \multirow{2}{*}{5,195} & & \multirow{2}{*}{6,4} \\
\hline & 47,5 & & & & & \\
\hline
\end{tabular}


TABELA 37 - Resistência de embutimento médio e valor médio do $\beta_{\text {lim }}$ segunda série de ensaios - Cupiúba

\begin{tabular}{|c|c|c|c|c|c|c|}
\hline \multirow{2}{*}{ Viga } & \multirow{2}{*}{$\begin{array}{c}\mathbf{f}_{\mathbf{e}} \\
\mathbf{M P a}\end{array}$} & \multirow{2}{*}{$\begin{array}{l}\mathbf{f}_{\text {emédio }} \\
\text { MPa }\end{array}$} & \multirow{2}{*}{$\begin{array}{c}\mathbf{f}_{\mathbf{y}} \\
\text { MPa }\end{array}$} & \multirow[t]{2}{*}{$\boldsymbol{\beta}_{\text {lim }}$} & \multicolumn{2}{|c|}{$\begin{array}{ll}\text { Obs: } & \text { viga usada no } \\
\text { seguinte tipo de ligação }\end{array}$} \\
\hline & & & & & Tipo de pino & d $(\mathrm{mm})$ \\
\hline \multirow{2}{*}{$\mathrm{C} 7$} & 43,8 & \multirow{2}{*}{48,3} & \multirow{2}{*}{863} & \multirow{2}{*}{5,284} & \multirow{6}{*}{ Parafuso } & \multirow{2}{*}{10} \\
\hline & 52,8 & & & & & \\
\hline \multirow{2}{*}{$\mathrm{C} 8$} & 51,0 & \multirow{2}{*}{51,1} & \multirow{2}{*}{577} & \multirow{2}{*}{4,200} & & \multirow{2}{*}{12,5} \\
\hline & 51,2 & & & & & \\
\hline \multirow{2}{*}{ C8 } & 38,5 & \multirow{2}{*}{42,2} & \multirow{2}{*}{765} & \multirow{2}{*}{5,325} & & \multirow{2}{*}{16} \\
\hline & 45,8 & & & & & \\
\hline $\mathrm{C} 7$ & & 48,3 & 766 & 4,978 & \multirow{4}{*}{ Prego } & 4,4 \\
\hline \multirow{2}{*}{ C7 } & & \multirow{2}{*}{47,6} & \multirow{2}{*}{778} & \multirow{2}{*}{5,054} & & \multirow{2}{*}{5,4} \\
\hline & 47,6 & & & & & \\
\hline $\mathrm{C} 7$ & $\begin{array}{l}40,4 \\
41,2\end{array}$ & 40,8 & 779 & 5,462 & & 6,4 \\
\hline
\end{tabular}

TABELA 38 - Resistência de embutimento médio e valor médio do $\boldsymbol{\beta}_{\text {lim }}$ segunda série de ensaios - Jatobá

\begin{tabular}{|c|c|c|c|c|c|c|}
\hline \multirow{2}{*}{ Viga } & \multirow{2}{*}{$\begin{array}{c}\mathbf{f}_{\mathrm{e}} \\
\mathbf{M P a}\end{array}$} & \multirow{2}{*}{$\begin{array}{r}\mathbf{f}_{\text {emédio }} \\
\text { MPa }\end{array}$} & \multirow{2}{*}{$\begin{array}{c}\mathbf{f}_{\mathbf{y}} \\
\mathbf{M P a}\end{array}$} & \multirow[t]{2}{*}{$\boldsymbol{\beta}_{\text {lim }}$} & \multicolumn{2}{|c|}{$\begin{array}{ll}\text { Obs: viga usada no } \\
\text { seguinte tipo de ligação }\end{array}$} \\
\hline & & & & & Tipo de pino & d $(\mathrm{mm})$ \\
\hline $\mathrm{J} 1$ & & 69,5 & 863 & 4,405 & \multirow{4}{*}{ Parafuso } & 10 \\
\hline \multirow[b]{2}{*}{$\mathrm{J} 2$} & 866 & \multirow[b]{2}{*}{87,6} & \multirow[b]{2}{*}{577} & \multirow[b]{2}{*}{3,209} & & \multirow[b]{2}{*}{12,5} \\
\hline & $\begin{array}{l}86,6 \\
88,5\end{array}$ & & & & & \\
\hline $\mathrm{J} 2$ & 74,7 & 74,7 & 765 & 4,000 & & 16 \\
\hline \multirow{2}{*}{$\mathrm{J} 1$} & 44,9 & \multirow{2}{*}{85,6} & \multirow{2}{*}{766} & \multirow{2}{*}{3,740} & \multirow{6}{*}{ Prego } & \multirow{2}{*}{4,4} \\
\hline & 46,8 & & & & & \\
\hline \multirow{2}{*}{$\mathrm{J} 1$} & 90,6 & \multirow{2}{*}{84,5} & \multirow{2}{*}{778} & \multirow{2}{*}{3,793} & & \multirow{2}{*}{5,4} \\
\hline & 78,3 & & & & & \\
\hline \multirow{2}{*}{$\mathrm{J} 1$} & 84,5 & \multirow{2}{*}{85,3} & \multirow{2}{*}{779} & \multirow{2}{*}{3,777} & & \multirow{2}{*}{6,4} \\
\hline & 86,1 & & & & & \\
\hline
\end{tabular}


$\mathrm{Na}$ verificação da forma de ruptura dos corpos-de-prova de ligação, observa-se que somente ocorreu a condição $\beta>\beta_{\lim }$ (flexão do pino) apenas nos ensaios da segunda série, nos corpos-de-prova ligados por pregos. Para todos os diâmetros de pregos $(4,4$ $\mathrm{mm}, 5,4 \mathrm{~mm}$ e $6,4 \mathrm{~mm}$ ), nos corpos-de-prova de Jatobá e em um corpo-de-prova da espécie Cupiúba (prego de 4,4 $\mathrm{mm}$ de diâmetro), utilizou-se a segunda formulação pela ocorrência da forma de ruptura por flexão do pino.

Nos demais casos, foi considerado nos cálculos que a ruptura ocorre por embutimento.

TABELA 39 - Comparação entre os resultados experimentais e teóricos -

Primeira série de ensaios - Pinus Elliottii

\begin{tabular}{|c|c|c|c|c|c|c|c|c|}
\hline \multirow{2}{*}{$\begin{array}{c}\text { Tipo de } \\
\text { pino }\end{array}$} & \multirow{2}{*}{$\begin{array}{c}\mathbf{d} \\
(\mathbf{m m})\end{array}$} & \multicolumn{4}{|c|}{ Cálculo do valor teórico } & \multirow{2}{*}{$\begin{array}{c}\begin{array}{c}\text { Valor } \\
\text { Experimental }\end{array} \\
\mathbf{R}_{\mathbf{1 v}} \\
(\mathbf{k N})\end{array}$} & \multirow{2}{*}{$\frac{\text { Exp. }}{\text { Teórico }}$} & \multirow{2}{*}{$\begin{array}{c}\text { Média } \\
\text { Exp. } \\
\text { Teórico }\end{array}$} \\
\hline & & $\begin{array}{c}\mathbf{d}_{\mathrm{ef}} \\
(\mathbf{m m})\end{array}$ & $\begin{array}{c}\mathrm{t} \\
(\mathbf{m m})\end{array}$ & $\boldsymbol{\beta}$ & $\underset{(\mathbf{k N})}{\mathbf{R}_{1 \mathbf{v}}}$ & & & \\
\hline \multirow{9}{*}{ Parafuso } & \multirow{3}{*}{10} & 9,9 & 24,7 & 2,495 & 2,41 & 4,41 & 1,83 & \multirow{3}{*}{1,77} \\
\hline & & 9,9 & 24,3 & 2,455 & 2,37 & 4,25 & 1,79 & \\
\hline & & 9,9 & 24,5 & 2,475 & 2,39 & 4,00 & 1,67 & \\
\hline & \multirow{3}{*}{12,5} & 12,5 & 24,0 & 1,920 & 4,97 & 8,01 & 1,61 & \multirow{3}{*}{1,55} \\
\hline & & 12,5 & 25,1 & 2,008 & 5,20 & 7,73 & 1,49 & \\
\hline & & 12,5 & 23,2 & 1,856 & 4,80 & 7,50 & 1,56 & \\
\hline & \multirow{3}{*}{16} & 15,8 & 31,6 & 2,000 & 7,99 & 9,45 & 1,18 & \multirow{3}{*}{1,14} \\
\hline & & 15,8 & 31,2 & 1,975 & 7,89 & 9,51 & 1,21 & \\
\hline & & 15,8 & 31,7 & 2,006 & 8,01 & 8,23 & 1,03 & \\
\hline \multirow{9}{*}{ Prego } & \multirow{3}{*}{4,4} & 4,6 & 25,3 & 5,500 & 1,00 & 1,00 & 1,00 & \multirow{3}{*}{1,01} \\
\hline & & 4,6 & 25,2 & 5,478 & 0,99 & 1,01 & 1,02 & \\
\hline & & 4,6 & 25,3 & 5,500 & 1,00 & 1,02 & 1,02 & \\
\hline & \multirow{3}{*}{5,4} & 5,7 & 25,2 & 4,421 & 1,24 & 1,49 & 1,21 & \multirow{3}{*}{1,20} \\
\hline & & 5,7 & 25,2 & 4,421 & 1,24 & 1,42 & 1,15 & \\
\hline & & 5,7 & 22,0 & 3,860 & 1,08 & 1,33 & 1,23 & \\
\hline & \multirow{3}{*}{6,4} & 6,3 & 24,4 & 3,873 & 1,43 & 1,70 & 1,19 & \multirow{3}{*}{1,16} \\
\hline & & 6,3 & 24,6 & 3,905 & 1,44 & 1,63 & 1,13 & \\
\hline & & 6,3 & 24,8 & 3,937 & 1,45 & 1,68 & 1,16 & \\
\hline
\end{tabular}


TABELA 40 - Comparação entre os resultados experimentais e teóricos Primeira série de ensaios - Cupiúba

\begin{tabular}{|c|c|c|c|c|c|c|c|c|}
\hline \multirow{2}{*}{$\begin{array}{c}\text { Tipo de } \\
\text { pino }\end{array}$} & \multirow{2}{*}{$\begin{array}{c}\text { d } \\
(\mathrm{mm})\end{array}$} & \multicolumn{4}{|c|}{ Cálculo do valor teórico } & \multirow{2}{*}{$\begin{array}{c}\begin{array}{c}\text { Valor } \\
\text { Experimental }\end{array} \\
\mathbf{R}_{\mathbf{1 v}} \\
(\mathbf{k N})\end{array}$} & \multirow{2}{*}{$\frac{\text { Exp. }}{\text { Teórico }}$} & \multirow{2}{*}{$\begin{array}{c}\text { Média } \\
\text { Exp. } \\
\text { Teórico }\end{array}$} \\
\hline & & $\begin{array}{c}\mathbf{d}_{\mathrm{ef}} \\
(\mathbf{m m})\end{array}$ & $\begin{array}{c}\mathbf{t} \\
(\mathbf{m m})\end{array}$ & $\boldsymbol{\beta}$ & $\begin{array}{l}R_{1 v} \\
(k N)\end{array}$ & & & \\
\hline \multirow{9}{*}{ Parafuso } & \multirow{3}{*}{10} & 9,9 & 23,7 & 2,394 & 6,00 & 6,63 & 1,11 & \multirow{3}{*}{1,11} \\
\hline & & 9,9 & 23,5 & 2,374 & 5,95 & 6,68 & 1,12 & \\
\hline & & 9,9 & 23,7 & 2,394 & 6,00 & 6,59 & 1,10 & \\
\hline & \multirow{3}{*}{12,5} & 12,5 & 23,7 & 1,896 & 9,36 & 10,75 & 1,15 & \multirow{3}{*}{1,07} \\
\hline & & 12,5 & 25,2 & 2,016 & 9,95 & 10,08 & 1,01 & \\
\hline & & 12,5 & 25,0 & 2,000 & 9,88 & 10,31 & 1,04 & \\
\hline & \multirow{3}{*}{16} & 15,8 & 30,7 & 1,943 & 11,78 & 13,38 & 1,14 & \multirow{3}{*}{1,24} \\
\hline & & 15,8 & 30,5 & 1,930 & 11,70 & 14,06 & 1,20 & \\
\hline & & 15,8 & 31,1 & 1,968 & 11,93 & 16,45 & 1,38 & \\
\hline \multirow{9}{*}{ Prego } & \multirow{3}{*}{4,4} & 4,6 & 24,3 & 5,283 & 1,83 & 1,73 & 0,95 & \multirow{3}{*}{0,88} \\
\hline & & 4,6 & 24,7 & 5,370 & 1,86 & 1,61 & 0,87 & \\
\hline & & 4,6 & 24,6 & 5,348 & 1,85 & 1,53 & 0,83 & \\
\hline & \multirow{3}{*}{5,4} & 5,7 & 24,3 & 4,263 & 2,65 & 2,58 & 0,97 & \multirow{3}{*}{1,01} \\
\hline & & 5,7 & 24,5 & 4,298 & 2,68 & 2,69 & 1,01 & \\
\hline & & 5,7 & 24,7 & 4,333 & 2,70 & 2,86 & 1,06 & \\
\hline & \multirow{3}{*}{6,4} & 6,3 & 23,9 & 3,794 & 2,72 & 2,50 & 0,92 & \multirow{3}{*}{0,92} \\
\hline & & 6,3 & 24,7 & 3,921 & 2,81 & 2,50 & 0,89 & \\
\hline & & 6,3 & 24,6 & 3,905 & 2,80 & 2,64 & 0,94 & \\
\hline
\end{tabular}


TABELA 41 - Comparação entre os resultados experimentais e teóricos segunda série de ensaios - Cupiúba

\begin{tabular}{|c|c|c|c|c|c|c|c|c|}
\hline \multirow{2}{*}{$\begin{array}{c}\text { Tipo de } \\
\text { pino }\end{array}$} & \multirow{2}{*}{$\begin{array}{c}\mathbf{d} \\
(\mathbf{m m})\end{array}$} & \multicolumn{4}{|c|}{ Cálculo do valor teórico } & \multirow{2}{*}{$\begin{array}{c}\begin{array}{c}\text { Valor } \\
\text { Experimental }\end{array} \\
\mathbf{R}_{\mathbf{1 v}} \\
(\mathbf{k N})\end{array}$} & \multirow{2}{*}{$\frac{\text { Exp. }}{\text { Teórico }}$} & \multirow{2}{*}{$\begin{array}{c}\text { Média } \\
\text { Exp. } \\
\text { Teórico }\end{array}$} \\
\hline & & $\begin{array}{c}\text { def } \\
(\mathbf{m m})\end{array}$ & $\begin{array}{c}\mathrm{t} \\
(\mathbf{m m})\end{array}$ & $\boldsymbol{\beta}$ & $\begin{array}{l}\mathbf{R}_{1 \mathbf{v}} \\
(\mathbf{k N})\end{array}$ & & & \\
\hline \multirow{6}{*}{ Parafuso } & \multirow{2}{*}{10} & 9,4 & 25,4 & 2,702 & 4,61 & 6,65 & 1,44 & \multirow{2}{*}{1,42} \\
\hline & & 9,4 & 25,7 & 2,734 & 4,67 & 6,51 & 1,39 & \\
\hline & \multirow{2}{*}{12,5} & 12,5 & 25,7 & 2,056 & 6,57 & 9,76 & 1,49 & \multirow{2}{*}{1,60} \\
\hline & & 12,5 & 25,6 & 2,048 & 6,54 & 11,14 & 1,70 & \\
\hline & \multirow{2}{*}{16} & 15,8 & 29,6 & 1,873 & 7,89 & 14,18 & 1,80 & \multirow{2}{*}{1,82} \\
\hline & & 15,8 & 29,9 & 1,892 & 7,97 & 14,58 & 1,83 & \\
\hline \multirow{6}{*}{ Prego } & \multirow{2}{*}{4,4} & 4,5 & 23,3 & 5,178 & 1,95 & 2,11 & 1,08 & \multirow{2}{*}{1,08} \\
\hline & & 4,5 & 25,5 & 5,667 & 1,95 & 2,11 & 1.08 & \\
\hline & \multirow{2}{*}{5,4} & 5,6 & 25,6 & 4,571 & 2,73 & 2,63 & 0,96 & \multirow{2}{*}{0,96} \\
\hline & & 5,6 & & & & & & \\
\hline & \multirow{2}{*}{6,4} & 6,3 & 25,6 & 4,063 & 2,63 & 3,05 & 1,16 & \multirow{2}{*}{1,14} \\
\hline & & 6,3 & 25,5 & 4,048 & 2,62 & 2,95 & 1,13 & \\
\hline
\end{tabular}


TABELA 42 - Comparação entre os resultados experimentais e teóricos Segunda série de ensaios - Jatobá

\begin{tabular}{|c|c|c|c|c|c|c|c|c|}
\hline \multirow{2}{*}{$\begin{array}{c}\text { Tipo de } \\
\text { pino }\end{array}$} & \multirow{2}{*}{$\begin{array}{c}\text { d } \\
(\mathbf{m m})\end{array}$} & \multicolumn{4}{|c|}{ Cálculo do valor teórico } & \multirow{2}{*}{$\begin{array}{c}\begin{array}{c}\text { Valor } \\
\text { Experimental }\end{array} \\
\mathbf{R}_{\mathbf{1 v}} \\
(\mathbf{k N})\end{array}$} & \multirow{2}{*}{$\frac{\text { Exp. }}{\text { Teórico }}$} & \multirow{2}{*}{$\begin{array}{c}\text { Média } \\
\text { Exp. } \\
\text { Teórico }\end{array}$} \\
\hline & & $\begin{array}{c}\mathbf{d}_{\mathbf{e f}} \\
(\mathbf{m m})\end{array}$ & $\begin{array}{c}\mathbf{t} \\
(\mathbf{m m})\end{array}$ & $\boldsymbol{\beta}$ & $\begin{array}{l}\mathbf{R}_{1 \mathbf{v}} \\
(\mathbf{k N})\end{array}$ & & & \\
\hline \multirow{6}{*}{ Parafuso } & \multirow{2}{*}{10} & 9,4 & 25,0 & 2,660 & 6,53 & 7,59 & 1,16 & \multirow{2}{*}{1,12} \\
\hline & & 9,4 & 25,5 & 2,713 & 6,66 & 7,21 & 1,08 & \\
\hline & \multirow{2}{*}{12,5} & 12,5 & 25,0 & 2,000 & 10,95 & $12,, 65$ & 1,16 & \multirow{2}{*}{1,13} \\
\hline & & 12,5 & 25,0 & 2,000 & 10,95 & 11,95 & 1,09 & \\
\hline & \multirow{2}{*}{16} & 15,8 & 30,8 & 1,949 & 14,54 & 19,23 & 1,32 & \multirow{2}{*}{1,30} \\
\hline & & 15,8 & 30,5 & 1,930 & 14,40 & 18,50 & 1,28 & \\
\hline \multirow{6}{*}{ Prego } & \multirow{2}{*}{4,4} & 4,5 & 25,4 & 5,644 & 2,59 & 2,59 & 1,00 & \multirow{2}{*}{0,98} \\
\hline & & 4,5 & 25,3 & 5,622 & 2,59 & 2,46 & 0,95 & \\
\hline & \multirow{2}{*}{5,4} & 5,6 & 25,3 & 4,518 & 4,02 & 3,61 & 0,90 & \multirow{2}{*}{0,92} \\
\hline & & 5,6 & 25,5 & 4,554 & 4,02 & 3,78 & 0,94 & \\
\hline & \multirow{2}{*}{6,4} & 6,3 & 25,2 & 4,000 & 5,12 & 4,08 & 0,80 & \multirow{2}{*}{0,78} \\
\hline & & 6,3 & 25,2 & 4,000 & 5,12 & 3,85 & 0,75 & \\
\hline
\end{tabular}

Nas tabelas 39 a 42, pode ser observado o quanto é maior a resistência da ligação em relação àquela estabelecida pelo critério teórico da NBR 7190/97. Para as duas espécies de média e alta densidade, os valores das relações menores que a unidade indicam que a resistência obtida nos ensaios de ligações foi menor que a obtida pelo critério de dimensionamento teórico da norma brasileira. Apesar dos valores de resistência verificados nos ensaios de ligação serem superiores, no caso da espécie Pinus Elliottii, é importante notar que, para as ligações com pregos, a diferenças apresentadas não são tão elevadas como no caso dos parafusos.

$\mathrm{Na}$ espécie Jatobá, em ligações com pregos, os valores teóricos apresentaram-se ligeiramente superiores aos resultados experimentais. Verifica-se, neste caso, que a análise do $\beta_{\text {lim }}$ conduz ao modo de ruptura por flexão do pino.

Nas figuras 39 e 40, pode ser observada a variação ocorrida entre os valores de comparação para cada madeira e tipo de pino. 


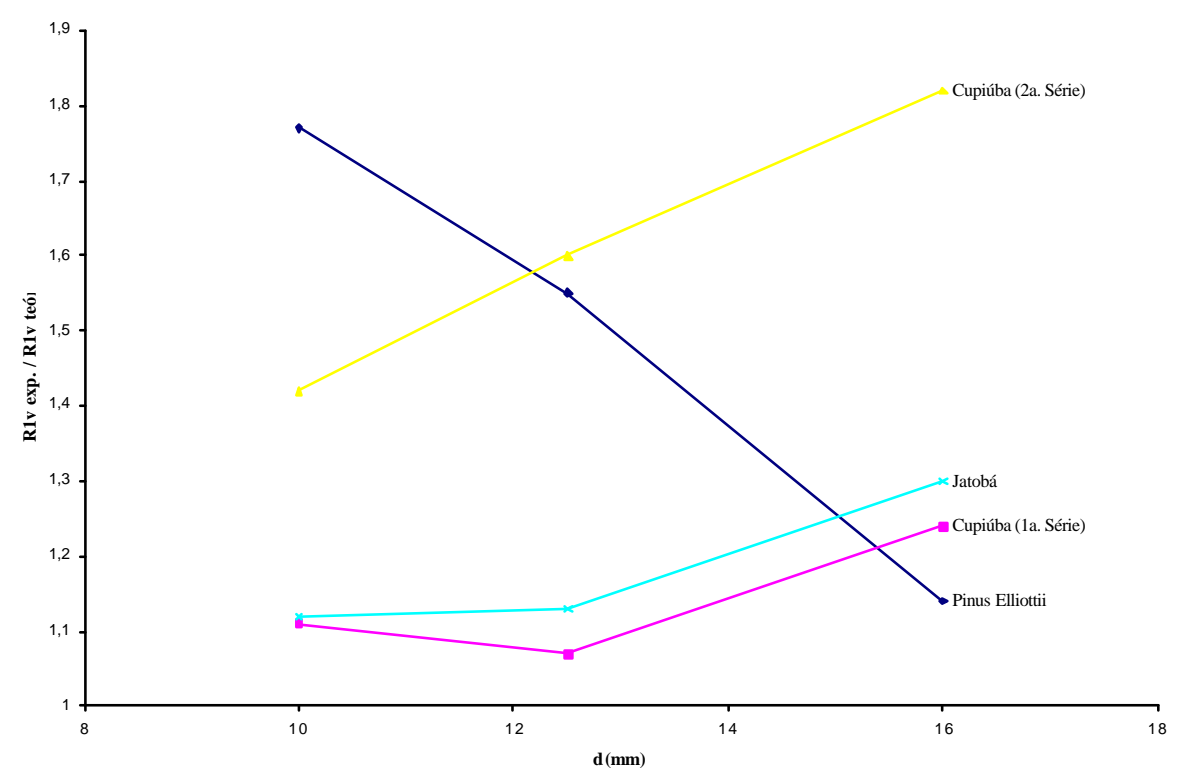

FIGURA 39 - Comparação entre os resultados experimentais e teóricos das resistências das ligações na direção paralela - ensaios complementaresparafusos

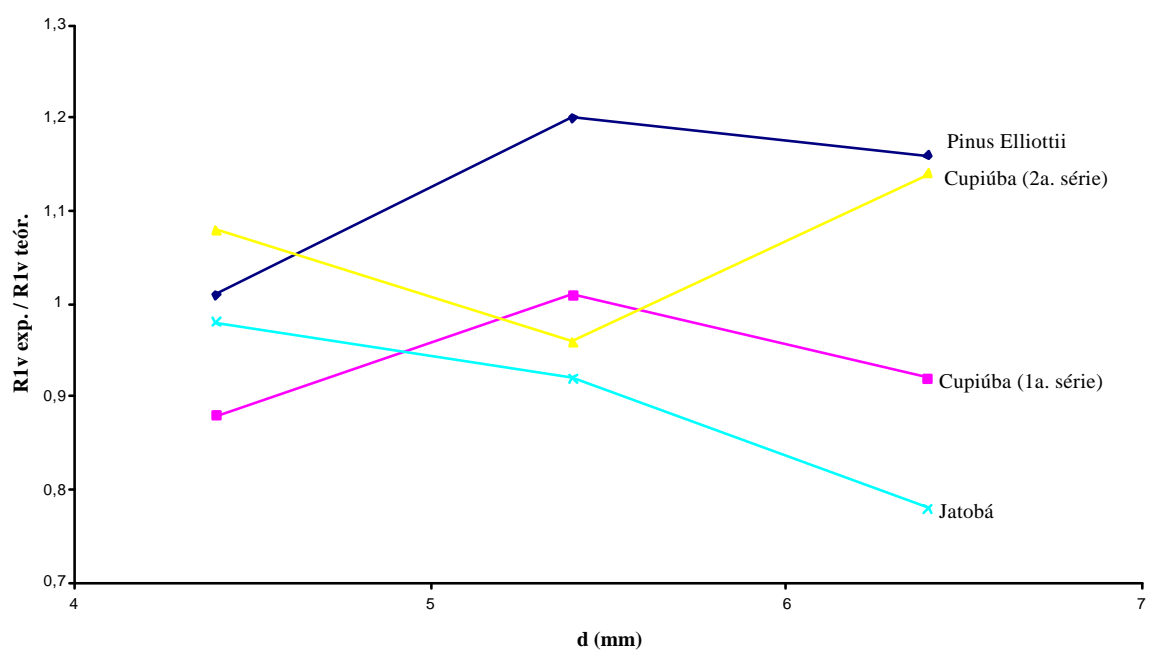

FIGURA 40 - Comparação entre os resultados experimentais e teóricos das resistências das ligações na direção paralela - ensaios complementares - pregos 


\section{3 - Comparação dos valores de resistência com as forças de ruptura das ligações}

A resistência da ligação é definida mediante a força que provoca no corpo-de-prova uma deformação específica residual de $2 \%$. Observa-se diferença significativa entre os valores desta resistência e a carga de ruptura das ligações. Para essa discussão, são apresentados, nos itens 5.3.1 e 5.3.2, valores obtidos pela relação da carga de ruptura da ligação dividida pela resistência da mesma.

\subsection{1 - Ensaios realizados pela equipe LaMEM}

Utilizando os resultados apresentados segundo ensaios e critério do LaMEM, nas tabelas 4 a 8 , chega-se às relações da tabela 43 . A tabela 44 mostra a relação entre as mesmas grandezas, utilizando os ensaios LaMEM e o critério da NBR 7190/97, tomadas com base nas tabelas 9 a 13 . 
TABELA 43 - Relação entre os valores médios da força de ruptura e da resistência da ligação - critério equipe LaMEM

\begin{tabular}{|c|c|c|c|c|c|c|c|}
\hline \multirow[b]{2}{*}{ Solicitaçãa } & \multirow{2}{*}{$\begin{array}{l}\text { Tipo de } \\
\text { pino }\end{array}$} & \multirow{2}{*}{$\underset{(\mathbf{m m})}{\mathbf{d}}$} & \multicolumn{5}{|c|}{ Relação $\mathbf{F}_{\text {rup }}$ / R } \\
\hline & & & $\begin{array}{c}\text { Pinus } \\
\text { Elliottii }\end{array}$ & Cupiúba & Garapa & $\begin{array}{l}\text { Eucalipto } \\
\text { Citriodora }\end{array}$ & Jatobá \\
\hline \multirow{3}{*}{$\begin{array}{l}\text { Direção } \\
\text { paralela }\end{array}$} & \multirow{6}{*}{ Parafuso } & 10 & 1,74 & 1,66 & 1,52 & 1,55 & 1,68 \\
\hline & & 12,5 & 1,19 & 1,54 & 1,47 & 1,49 & 1,82 \\
\hline & & 16 & 1,25 & 1,60 & 1,64 & 1,55 & 1,34 \\
\hline \multirow{3}{*}{$\begin{array}{l}\text { Direção } \\
\text { normal }\end{array}$} & & 10 & 1,44 & 1,45 & 1,48 & 1,49 & 1,68 \\
\hline & & 12,5 & 1,34 & 1,14 & 1,22 & 2,00 & 1,33 \\
\hline & & 16 & 1,29 & 1,46 & 1,14 & 1,43 & 1,28 \\
\hline \multirow{3}{*}{$\begin{array}{l}\text { Direção } \\
\text { paralela }\end{array}$} & \multirow{6}{*}{ Prego } & 4,4 & 1,82 & 1,85 & 2,43 & 1,72 & 1,91 \\
\hline & & 5,4 & 1,69 & 1,82 & 1,76 & 1,51 & 1,81 \\
\hline & & 6,4 & 1,76 & 1,74 & 1,52 & 1,46 & 1,57 \\
\hline \multirow{3}{*}{$\begin{array}{l}\text { Direção } \\
\text { normal }\end{array}$} & & 4,4 & 1,76 & 1,96 & 1,85 & 1,81 & 1,84 \\
\hline & & 5,4 & 1,80 & 1,76 & 1,80 & 1,68 & 1,75 \\
\hline & & 6,4 & 1,65 & 1,80 & 1,72 & 1,64 & 1,68 \\
\hline
\end{tabular}

TABELA 44 - Relação entre os valores médios da força de ruptura e da resistência da ligação - critério aproximado NBR 7190/97

\begin{tabular}{|c|c|c|c|c|c|c|c|}
\hline \multirow{2}{*}{ Solicitação } & \multirow{2}{*}{$\begin{array}{c}\text { Tipo de } \\
\text { pino }\end{array}$} & \multirow{2}{*}{$\underset{(\mathbf{m m})}{\mathbf{d}}$} & \multicolumn{5}{|c|}{ Relação $\mathbf{F}_{\text {rup }} / \mathbf{R}$} \\
\hline & & & $\begin{array}{c}\text { Pinus } \\
\text { Elliottii }\end{array}$ & Cupiúba & & $\begin{array}{l}\text { Eucalipto } \\
\text { Citriodora }\end{array}$ & Jatobá \\
\hline \multirow{3}{*}{$\begin{array}{l}\text { Direção } \\
\text { paralela }\end{array}$} & \multirow{6}{*}{ Parafuso } & 10 & 2,02 & 1,81 & 1,64 & 1,65 & 1,93 \\
\hline & & 12,5 & 1,32 & 1,48 & 1,54 & 1,51 & 1,81 \\
\hline & & 16 & 1,39 & 1,70 & 1,66 & 1,44 & 1,42 \\
\hline \multirow{3}{*}{$\begin{array}{r}\text { Direção } \\
\text { normal }\end{array}$} & & 10 & 1,73 & 1,50 & 1,81 & 1,60 & 1,82 \\
\hline & & 12,5 & 1,86 & 1,18 & 1,23 & & 1,29 \\
\hline & & 16 & 1,40 & 1,28 & 1,10 & & 1,22 \\
\hline \multirow{3}{*}{$\begin{array}{l}\text { Direção } \\
\text { paralela }\end{array}$} & \multirow{6}{*}{ Prego } & 4,4 & 2,04 & 1,21 & 3,37 & 1,99 & 2,21 \\
\hline & & 5,4 & 2,31 & 2,12 & 2,03 & 1,76 & 2,16 \\
\hline & & 6,4 & 1,97 & 1,93 & 1,74 & 1,54 & 1,82 \\
\hline \multirow{3}{*}{$\begin{array}{c}\text { Direção } \\
\text { normal }\end{array}$} & & 4,4 & 3,08 & 2,72 & 3,07 & 2,52 & 2,67 \\
\hline & & 5,4 & 2,62 & 2,20 & 2,34 & 2,18 & 2,20 \\
\hline & & 6,4 & 1,95 & 2,24 & 2,12 & 1,95 & 2,05 \\
\hline
\end{tabular}


Nota-se que a diferença foi mais acentuada quando se tratou de ligações executadas com pregos, tanto para solicitação na direção paralela quanto para direção normal às fibras da madeira.

Nas ligações com pregos, solicitadas na direção paralela, conforme mostrado na tabela 43, a diferença variou, em média, de $46 \%$ (Eucalipto Citriodora) a 91\% (Jatobá). Nas ligações com parafusos, a variação média foi de 19\% (Pinus Elliottii) a $82 \%$ (Jatobá).

$\mathrm{Na}$ análise dos valores reavaliados por critério aproximado ao da NBR 7190, observa-se, pela tabela 44, um acréscimo na diferença entre as cargas de ruptura e as resistências da ligações. Essa diferença, nas ligações solicitadas na direção paralela às fibras, variou: para pregos de 54\% (Eucalipto Citriodora) a 131\% (Pinus Elliottii) e, para parafusos, de 32\% (Pinus Elliottii) a 93\% (Jatobá).

\subsection{2 - Ensaios Complementares}

Nas tabehs 20 a 23, para os ensaios complementares de ligações, são apresentados os resultados da resistência na direção paralela às fibras $(R)$ e as cargas de ruptura dessas ligações ( $F_{\text {rup }}$ ), cuja relação $\mathrm{F}_{\text {rup }} / \mathrm{R}$, fornece os dados da tabela 45. 
TABELA 45 - Relação entre os valores médios da carga de ruptura e da resistência da ligação nos ensaios complementares - média por pino.

\begin{tabular}{|c|c|c|c|c|c|c|}
\hline \multirow{3}{*}{ Solicitação } & \multirow{3}{*}{$\begin{array}{c}\text { Tipo de } \\
\text { pino }\end{array}$} & \multirow{3}{*}{$\begin{array}{c}\mathrm{d} \\
(\mathrm{mm})\end{array}$} & \multicolumn{4}{|c|}{ Relação $\mathbf{F}_{\text {rup }} / \mathbf{R}$} \\
\hline & & & \multicolumn{2}{|c|}{ Primeira série } & \multicolumn{2}{|c|}{ Segunda série } \\
\hline & & & $\begin{array}{c}\text { Pinus } \\
\text { Elliottii }\end{array}$ & Cupiúba & Cupiúba & Jatobá \\
\hline \multirow{6}{*}{ Direção paralela } & \multirow{3}{*}{ Parafusos } & 10 & 1,62 & 1,35 & 1,47 & 1,28 \\
\hline & & 12,5 & 1,34 & 1,26 & 1,34 & 1,16 \\
\hline & & 16 & 1,41 & 1,29 & 1,24 & 1,16 \\
\hline & \multirow{3}{*}{ Pregos } & 4,4 & 2,06 & 2,31 & 2,04 & 1,98 \\
\hline & & 5,4 & 2,10 & 1,72 & 2,06 & 1,39 \\
\hline & & 6,4 & 2,04 & 2,34 & 2,55 & 1,79 \\
\hline
\end{tabular}

Pela tabela 45, tais relações se mantiveram mais expressivas, quando se tratou das ligações com pregos, variando, em média, de 72\% (Jatobá) a 122\% (Cupiúba). Enquanto isso, para parafusos, os valores variaram de 20\% (Jatobá) a 46\% (Pinus Elliottii).

\section{4 - Comparação entre a resistência ao embutimento e a resistência à compressão paralela às fibras da madeira}

Conforme discutido anteriormente, a norma brasileira permite a caracterização simplificada da resistência da madeira serrada, admitindo, para a resistência ao embutimento paralelo às fibras da madeira, o mesmo valor da resistência à compressão paralela. Dessa maneira, para efeito da discussão dos resultados apresentados nos ensaios de ligação e nos cálculos de dimensionamento pelo critério da mesma norma, foi utilizado, para a resistência ao embutimento da madeira, o 
valor da resistência à compressão paralela, ao serem analisados os ensaios realizados pelo LaMEM.

Tendo em vista a importância desse valor nos resultados apresentados e discutidos, é importante a sua comparação. Esses valores são mostrados na tabela 46.

TABELA 46 - Comparação entre a resistência à compressão $\left(\mathbf{f}_{c 0}\right)$ e a resistência ao embutimento $\left(f_{\mathrm{e} 0}\right)$ da madeira - ensaios complementares

\begin{tabular}{|c|c|c|c|c|c|c|c|c|c|}
\hline \multirow{3}{*}{$\begin{array}{c}\text { Tipo de } \\
\text { pino }\end{array}$} & \multirow{3}{*}{$\begin{array}{c}\mathbf{d} \\
\mathbf{m m}\end{array}$} & \multicolumn{4}{|c|}{ PRIMEIRA SÉRIE DE ENSAIOS } & \multicolumn{4}{|c|}{ SEGUNDA SÉRIE DE ENSAIOS } \\
\hline & & \multicolumn{2}{|c|}{$\begin{array}{c}\text { PINUS } \\
\text { ELLIOTTII }\end{array}$} & \multicolumn{2}{|c|}{ CUPIÚBA } & \multicolumn{2}{|c|}{ CUPIÚBA } & \multicolumn{2}{|c|}{ JATOBÁ } \\
\hline & & $\begin{array}{c}\mathbf{f}_{\mathbf{c 0 , m}} \\
(\mathrm{MPa})\end{array}$ & $\begin{array}{l}\mathbf{f}_{\mathbf{e 0 , m}} \\
(\mathrm{MPa})\end{array}$ & $\begin{array}{l}\mathbf{f}_{\mathbf{c 0 , m}} \\
(\mathrm{MPa})\end{array}$ & $\begin{array}{r}\mathbf{f}_{\mathbf{e 0 , m}} \\
(\mathrm{MPa})\end{array}$ & $\begin{array}{r}\mathbf{f}_{\mathbf{c 0 , m}} \\
(\mathrm{MPa})\end{array}$ & $\begin{array}{l}\mathbf{f}_{\mathbf{e} 0, \mathbf{m}} \\
(\mathrm{MPa})\end{array}$ & $\begin{array}{r}\mathbf{f}_{\mathbf{c 0 , m}} \\
(\mathrm{MPa})\end{array}$ & $\begin{array}{l}\mathbf{f}_{\mathbf{e 0 , m}} \\
(\mathrm{MPa})\end{array}$ \\
\hline \multirow{5}{*}{ Parafuso } & 10 & 33,11 & 24,60 & 51,10 & 63,90 & 53,46 & 48,30 & & 69,50 \\
\hline & & viga P1 & viga P1 & viga $\mathrm{C} 1$ & viga $\mathrm{C} 1$ & viga $\mathrm{C} 7$ & viga $\mathrm{C} 7$ & & viga $\mathrm{J} 2$ \\
\hline & 125 & 34,59 & 41,40 & 58,69 & 79,00 & \multirow{3}{*}{$\begin{array}{r}52,78 \\
\text { viga } C 8\end{array}$} & 51,10 & & 87,55 \\
\hline & & viga $\mathrm{P} 2$ & viga $\mathrm{P} 2$ & viga $\mathrm{C} 2$ & viga $\mathrm{C} 2$ & & viga C8 & & viga $\mathbf{J} 2$ \\
\hline & 16 & $\begin{array}{r}43,88 \\
\text { viga } P 3\end{array}$ & $\begin{array}{r}40,00 \\
\text { viga } P 3\end{array}$ & $\begin{array}{r}56,33 \\
\text { viga C3 }\end{array}$ & $\begin{array}{r}60,70 \\
\text { viga } C 3\end{array}$ & & $\begin{array}{r}42,15 \\
\text { viga } C 8\end{array}$ & & $\begin{array}{l}74,70 \\
\text { viga } \mathrm{J} 2\end{array}$ \\
\hline \multirow{5}{*}{ Prego } & 44 & 33,98 & 21,40 & 53,64 & 40,90 & \multirow{5}{*}{$\begin{array}{r}53,46 \\
\text { viga } C 7\end{array}$} & 48,30 & \multirow{5}{*}{$\begin{array}{l}90,36 \\
\text { viga J1 }\end{array}$} & 85,60 \\
\hline & & viga P4 & viga P4 & viga $\mathrm{C} 4$ & viga $\mathrm{C} 4$ & & viga $\mathrm{C} 7$ & & viga $\mathrm{J} 1$ \\
\hline & 5,4 & 31,33 & 21,50 & 49,03 & 47,85 & & 47,60 & & 84,45 \\
\hline & & viga $\mathrm{P} 5$ & viga P5 & viga $\mathrm{C} 5$ & viga $\mathrm{C} 5$ & & viga $\mathrm{C} 7$ & & viga $\mathrm{J} 1$ \\
\hline & 6,4 & $\begin{array}{r}34,99 \\
\text { viga P6 }\end{array}$ & $\begin{array}{l}23,20 \\
\text { viga P6 }\end{array}$ & $\begin{array}{r}52,09 \\
\text { viga C6 }\end{array}$ & $\begin{array}{r}45,10 \\
\text { viga C6 }\end{array}$ & & $\begin{array}{r}40,80 \\
\text { viga } C 7\end{array}$ & & $\begin{array}{l}85,30 \\
\text { viga J1 }\end{array}$ \\
\hline
\end{tabular}

Observa-se que apenas para os parafusos de diâmetro 10, 12,5 e 16 mm, na primeira série de ensaios da espécie Cupiúba, os valores da resistência ao embutimento foram maiores do que aqueles encontrados para a resistência à compressão. Nos ensaios de embutimento utilizando parafusos de mesmo diâmetro, para a espécie Pinus Elliottii 
e as espécies Jatobá e Cupiúba (segunda série de ensaios), chegou-se a valores inferiores àqueles obtidos para a resistência à compressão da madeira. Esta última superou a resistência ao embutimento, em média, de 5\% a 12\%. Nos demais casos, referidos para pregos de 4,4, 5,4 e 6,4 mm, os valores da resistência à compressão paralela foram superiores aos da resistência de embutimento paralelo, variando de $6 \%$ a $51 \%$.

Atualmente, utiliza-se, no dimensionamento de ligações, a resistência à compressão paralela às fibras no lugar da resistência ao embutimento na direção paralela às fibras. Tendo em vista as relações obtidas para essas resistências nos ensaios efetuados, pode-se intuir que a substituição da resistência à compressão paralela pela resistência ao embutimento conduzirá, em boa parte das situações, a uma redução da resistência do pino.

As figuras 41 e 42 apresentam a comparação entre os resultados experimentais e teóricos, utilizando para cálculo destes últimos os valores da resistência à compressão paralela às fibras da madeira e não a resistência ao embutimento paralelo às fibras, como nos casos anteriores.

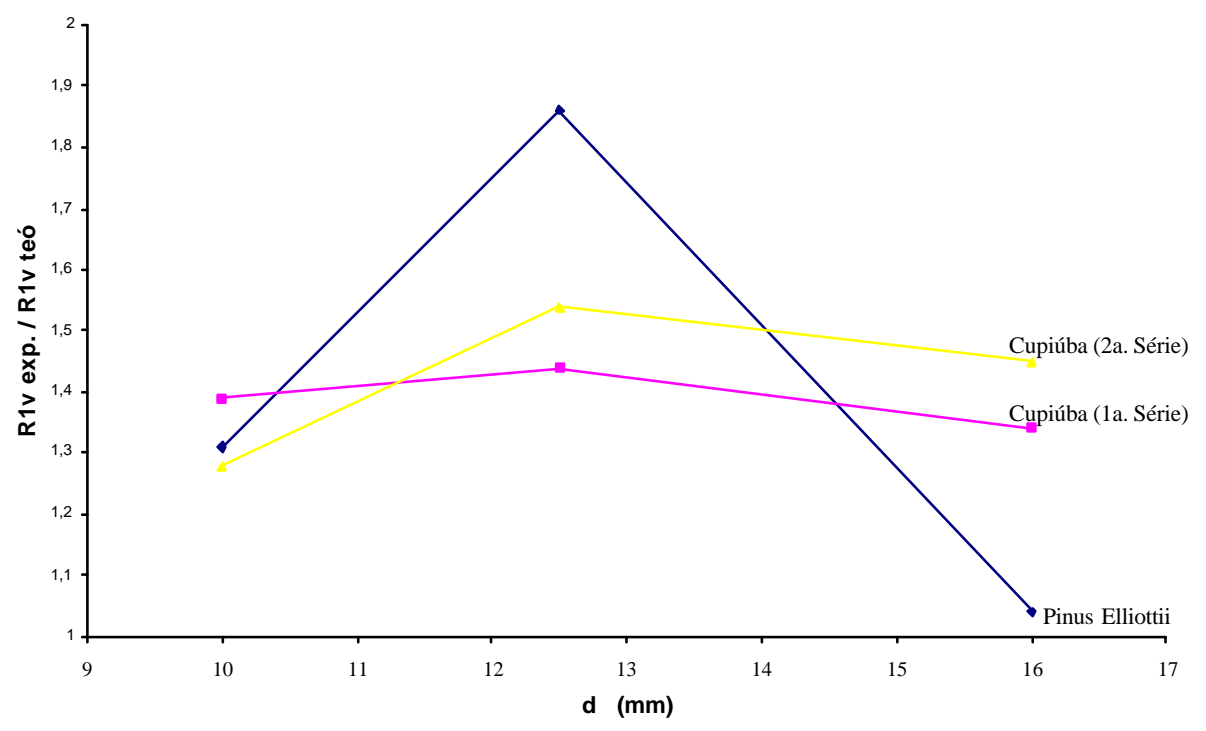

FIGURA 41 - Comparação entre os resultados experimentais e teóricos das resistências das ligações, utilizando o $\mathrm{f}_{\mathrm{c} 0}$ - ensaios complementares - parafusos 


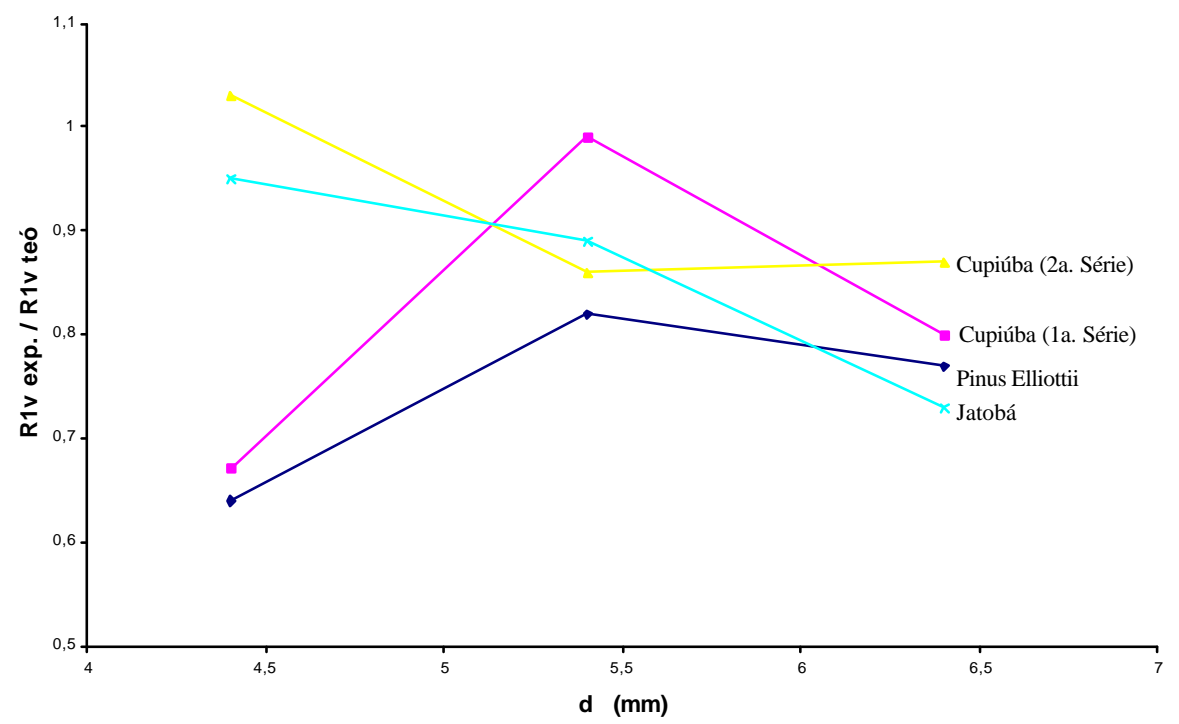

FIGURA 42 - Comparação entre os resultados experimentais e teóricos das resistências das ligações, utilizando o $\mathrm{f}_{\mathrm{c} 0}$ - ensaios complementares - pregos 


\section{6 - CONCLUSÕES}

Alguns comentários e conclusões já foram relacionados ao longo do texto deste trabalho. São apresentadas, a seguir, as principais conclusões obtidas no estudo. Como o objetivo do estudo experimental foram as ligações com dois planos de corte, estas conclusões devem ser entendidas como referentes a este caso.

No caso de parafuso, em que o efeito mais salientado é o embutimento do pino na madeira, observa-se uma tendência a obter resultados experimentais da resistência das ligações com valores superiores aos obtidos pelo critério teórico da norma NBR 7190 (a partir da resistência ao embutimento), sendo esses dois valores calculados com base em uma deformação residual de $2 \%$. Esse efeito é maior, principalmente, para o caso de madeiras com menores densidades. Outro aspecto a salientar é o valor convencionado pela NBR 7190/97 para definir a resistência ao embutimento e a resistência das ligações, em função da deformação residual de $2 \%$. Isto não é comum às outras normas consultadas, nas quais é permitida maior deformação. Pode-se depreender do texto da NBR 7190/97 que o seu intuito foi o de trabalhar somente com ligações consideradas rígidas. A consequiência imediata disto é a obtenção de valores menores para a resistência das ligações.

Ao utilizar os valores da resistência da madeira à compressão paralela às fibras na determinação da resistência teórica de um pino, nota-se que, em boa parte das situações, esse procedimento leva ao aumento desses resultados. Portanto, a utilização da resistência ao embutimento $\left(f_{\mathrm{e}}\right)$ em lugar da resistência à compressão $\left(\mathrm{f}_{\mathrm{c}}\right)$ levará à uma diminuição da resistência da ligação $\mathrm{R}_{1 \mathrm{v}, \mathrm{d}}$. 
Para a obtenção da resistência da ligação pelo método do anexo C da NBR 7190/97, é necessário realizar mais leituras de deformações do que até os $0,7 \quad F_{\text {lim }}$ estabelecidos. Observa-se, nos ensaios realizados e no tratamento dos dados, a necessidade de prolongar a leitura das deformações em todos os casos.

No caso de prego, os valores da resistência dessas ligações, obtidos experimentalmente, praticamente se equivalem aos obtidos pelo critério teórico da NBR 7190/97, em espécies de maior densidade. Para espécies de menor densidade, os resultados experimentais tendem a fornecer valores superiores aos obtidos pelo critério teórico da mesma norma.

Verifica-se também, nas ligações pregadas, que a resistência convencional da ligação (deformação específica residual de $2 \%$ ) fornece valores muito inferiores aos da carga de ruptura da ligação $\left(0,39 \mathrm{~F}_{\text {rup }}\right.$ a $\left.0,55 \mathrm{~F}_{\text {rup }}\right)$. Nas ligações parafusadas, esses valores também são inferiores, porém com ordem de grandeza menor, estando próximo do valor de $0,7 \mathrm{~F}_{\text {rup }}$

Observa-se que, nos resultados experimentais obtidos nos ensaios de ligações da equipe do LaMEM, estes são sensivelmente superiores aos obtidos pelo critério teórico da NBR 7190/97. Há que considerar que a metodologia adotada pelo LaMEM, anterior à revisão da norma, conduz à determinação da reta secante com menor inclinação e à ocorrência sistemática de deformações residuais superiores a 2\%o. Mediante a relação $\mathrm{R}_{1 \mathrm{v}}$ exp./ $\mathrm{R}_{1 \mathrm{v}}$ teór., verifica-se, nas ligações na direção normal às fibras, que tais valores são muito mais expressivos do aqueles obtidos para as ligações na direção paralela às fibras. Essa relação indica a diferença entre a resistência da ligação obtida experimentalmente e a resistência obtida pelo critério teórico.

Outro aspecto inusitado no método de ensaio da NBR 7190/97 é a utilização de uma base de medida, obtendo uma deformação residual específica, quando o efeito visualizado é o de deslocamento relativo entre os elementos unidos. As outras normas consultadas permitem deslocamentos maiores do que a NBR. 
Tendo em vista os comentários e conclusões apresentados ao longo deste trabalho, sugere-se a revisão do método de ensaio referente à ligação, bem como do critério de dimensionamento da NBR 7190/97. 


\section{REFERÊNCIAS BIBLIOGRÁFICAS}

ALMEIDA, P. A. O. e FUSCO, P. B. e CALIL JR, Carlito. Determinação das ligações mecânicas das estruturas de madeira. São Paulo: EPUSP, Depto. De Engenharia de Estruturas e Fundações, 1996. Boletim Técnico da Escola Politécnica da USP.

. Uniões pregadas de madeira. São Paulo, 1987. Dissertação (mestrado)

- Escola Politécnica, Universidade de São Paulo. 174 p.

Estruturas de grande porte de madeira composta. São Paulo, 1990,

Tese (doutorado) - Escola Politécnica, Universidade de São Paulo. 280 p.

ASSOCIAÇÃO BRASILEIRA DE NORMAS TÉCNICAS. NBR 7190/97 - Projeto

de Estruturas de Madeira. Rio de Janeiro: ABNT. 1997.

NBR 6627 - Pregos Comuns e Arestas de Aço para Madeiras . Rio de

Janeiro: ABNT. 1981.

. NBR 8800. Projeto e execução de estruturas de aço de edifícios. Rio de Janeiro: ABNT. 1986.

AMERICAN SOCIETY FOR TESTING AND MATERIALS. ASTM D 1761 - 77 -

Standard Methods of Testing Mechanical Fasteners in Wood. Philadelphia: ASTM, 1977.

BARALDI, L. T. Método de ensaio de ligações de estruturas de madeira por chapas com dentes estampados. São Carlos, 1996. Dissertação (mestrado) Escola de Engenharia de São Carlos, Universidade de São Paulo. 105 p.

BRITISH STANDARDS INSTITUTION. Part 2. The structural use of timber. Metric units. London: BSI, 1971.

DEUTSCHES INSTITUT FÜR NORMUNG. DIN 1052 - Part 2. Structural use of timber - Mechanically faste ned joints. Berlin: DIN, 1988. 
EUROPEAN COMMITTEE FOR STANDARDIZATION. CEN TC 124 WG1 N 243. Timber structures - Test methods - Load bearing nailed joints. EN TC 124.112: 1990.

CEN TC 124 WG1 N 243. Timber structures - Test methods Determination of embedding strength and foundation values for dowel type fasteners. Draft, prEN 383. Bruxelas: CEN, 1993. 12 p.

Design of timber structures - Part 1-1: general rules and rules for buildings - Draft, EUROCODE 5 - EN 1995-1-1. Bruxelas: CEN, 1999.

. Timber structures - Joints made with mechanical fasteners - General principles for the determination of strength and deformation characteristics. EN 29891. Bruxelas: CEN, 1991.

FUSCO, P. B, CALLIL JUNIOR, C., ALMEIDA, P.A.O. Projeto da nova norma brasileira NBR 7190 'Projeto de Estruturas de Madeira'. In: Instituto Brasileiro da Madeira e das Estruturas de Madeira. São Paulo, 1995.

HILSON, B. O. Nailed joints II. Timber Engineering. STEP 1. C5/1-C5/6. 1995.

JOHANSEN, K. W. Theory of timber connections. Internatinal association for Bridge and Structural Engeneering. Zurick. vol. 9. p. 249-262. 1949.

NOGUEIRA, Marta Cristina de Jesus Albuquerque. Proposta de método de ensaio e parâmetros para o dimensionamento de ligações entre peças de madeira por anéis metálicos fechados. São Carlos, 1996. Tese (doutorado) - Escola de Engenharia de São Carlos, Universidade de São Paulo. 131 p.

SMITH, I. Short term load tests on whitewood embedment specimens with a single plain circular section steel connector in a hole of the same diameter. Research Report 1/82. Inglaterra: Timber Research and Development Association (TRADA). 123p. 1982.

STAMATO, G. C. Resistência ao embutimento da madeira compensada. São Carlos, 1998. Dissertação (mestrado) - Escola de Engenharia de São Carlos, Universidade de São Paulo. 135 p.

Ligações em Estruturas de madeira compostas por chapas de madeira compensada. São Carlos: 2000. Monografia (qualificação para doutorado) Escola de Engenharia de São Carlos, Universidade de São Paulo. 
VALlE, Angela, KÖHLER, A. D., SZÚCS, C. A., FUSCO, P. B. Determinação experimental da resistência e da rigidez de embutimento da madeira com orientação das fibras variável. In: ENCONTRO BRASILEIRO EM MADEIRAS E EM ESTRUTURAS DE MADEIRA, 7. São Carlos, 2000. Anais. São Carlos, IBRAMEM. 